GIULIANO GIOVA

PROPOSTA PARA INTEGRAÇÃO DE LABORATÓRIOS FORENSES DIGITAIS VIA REDE DE WEBLABS 
GIULIANO GIOVA

\section{PROPOSTA PARA INTEGRAÇÃO DE LABORATÓRIOS FORENSES DIGITAIS VIA REDE DE WEBLABS}

Tese apresentada ao Departamento de Engenharia de Sistemas Eletrônicos, da Escola Politécnica da Universidade de São Paulo, para obtenção do título de Doutor em Ciências. 
GIULIANO GIOVA

PROPOSTA PARA INTEGRAÇÃO DE LABORATÓRIOS

FORENSES VIA REDE DE WEBLABS

Tese apresentada ao Departamento de Engenharia de Sistemas Eletrônicos, da Escola Politécnica da Universidade de São Paulo, para obtenção do título de Doutor em Ciências.

Área de Concentração: Sistemas Eletrônicos

Orientador: Prof. Dr. Pedro Luis Próspero

Sanchez

São Paulo

2016 
Este exemplar foi revisado e corrigido em relação à versão original, sob responsabilidade única do autor e com a anuência de seu orientador.

São Paulo, de de

Assinatura do autor:

Assinatura do orientador:

Catalogação-na-publicação

Giova, Giuliano

Proposta para integração de laboratórios forenses via rede de weblabs / G.

Giova -- versão corr. -- São Paulo, 2016.

$149 \mathrm{p}$.

Tese (Doutorado) - Escola Politécnica da Universidade de São Paulo. Departamento de Engenharia de Sistemas Eletrônicos.

1.WebLabs 2.Internet 3.Perito judicial I.Universidade de São Paulo. Escola Politécnica. Departamento de Engenharia de Sistemas Eletrônicos II.t. 


\section{DEDICATÓRIA}

À minha esposa Sandra. 


\section{AGRADECIMENTOS}

Ao Professor Doutor Pedro Luis Próspero Sanchez, por me ter acolhido, doutrinado e orientado quanto à importância das Ciências Forenses.

Aos dirigentes e professores Escola Politécnica pelos ensinamentos e pela honra de poder participar de um dos principais centros de ensino e pesquisa.

À Universidade de São Paulo, por viabilizar tudo isso.

Aos pesquisadores e autores referenciados neste documento, pelos importantes subsídios que proporcionaram. 


\section{EPÍGRAFE}

"A informação está substituindo a autoridade"

(Peter Drucker) 


\section{RESUMO}

Giova. G, Proposta para integração de laboratórios forenses via rede de weblabs [tese]. São Paulo: Universidade de São Paulo, Escola Politécnica, 2016. 147 f.

A intensa adoção dos sistemas eletrônicos em praticamente todas as atividades humanas gera grande quantidade de evidências digitais que devem ser utilizadas pelos juízes para entender os fatos ocorridos e assim se sentirem mais seguros ao julgar os processos judiciais conforme o seu convencimento íntimo. Em contrapartida, a coleta e análise dessas evidências são tarefas cada vez mais caras e demoradas porque essas evidências se tornam rapidamente mais complexas, sem fronteiras e escondidas por recursos protetores de privacidade. São típicos os embates que ocorrem entre autoridades policiais, juízes, fabricantes e consumidores quando são frustradas as determinações judiciais para quebra do sigilo telemático em função de criptografia das comunicações e dos dados armazenados, situação que tende a se agravar em função de novas tecnologias como serviços em nuvem, Internet das Coisas, inteligência artificial, robôs e drones. Nesse contexto, os investigadores forenses precisam de laboratórios cada vez mais sofisticados, capazes de realizar a quebra judicial da criptografia por mecanismos como força-bruta ou chip-off, entre muitas outras técnicas de forense computacional. Ocorre que os laboratórios atuais não têm sido suficientes para atender a crescente demanda e, adicionalmente, eles estão concentrados nos principais centros econômicos, portanto distantes dos milhares de comarcas onde tramitam os processos judiciais. A volatilidade dos dados e a complexidade dos exames exigem a participação dos representantes dos autores e réus no processo judicial, para que possa ocorrer o imprescindível contraditório técnico e debate entre os especialistas das partes, evitando o cerceamento de defesa. Porém, esse acompanhamento é prejudicado e até impossibilitado pela produtividade insuficiente dos laboratórios frente à demanda e pela distância entre a comarca, os peritos aceitos pelo juiz e os laboratórios forenses. A velocidade dessa revolução e a escassez de laboratórios habilitados sobrecarregam os serviços periciais, provocam erros e confundem processos judicias que com isso correm o risco de absolver culpados ou, pior, condenar inocentes. Para enfrentar esse problema, propõe-se que os laboratórios forenses passem a adotar a tecnologia de laboratórios utilizáveis 
remotamente, denominada WebLab, e que esses laboratórios passem se integrar em federações de WebLabs Forenses, de modo a proporcionar ao delegado, juiz, promotor, advogados, perito nomeado pelo juiz e representantes das partes realizar ou acompanhar remotamente via Web os exames periciais forenses, maximizando a utilização dos laboratórios mais equipados nacionalmente e internacionalmente e proporcionando a concomitante e imprescindível fiscalização pelo Poder Judiciário e pelas partes nos processos judiciais. Em síntese, esta pesquisa propõe um modelo de referência que possibilita a utilização dos laboratórios forenses via Web.

Palavras-chave: WebLabs. Internet. Perito judicial 


\begin{abstract}
Giova. G, Proposal to integrate forensic laboratories via weblabs network [thesis]. São Paulo: Universidade de São Paulo, Escola Politécnica, 2016. 147 f.
\end{abstract}

The massive adoption of electronic systems in virtually every human activity generates a great amount of digital evidence, which must be used by judges to understand facts that took place and feel more confident when judging legal processes as per one's inner belief. In contrast, evidence collection and analysis are increasingly expensive and time-consuming activities, as said evidence quickly become more complex, borderless and safeguarded by privacy protection features. Conflicts between police authorities, judges, manufacturers and consumers are common when legal provisions for breaking telematics secrecy are thwarted due to encryption of communication and stored data, a situation that tends to escalate due to new technologies such as cloud services, Internet of Things, artificial intelligence, robots and drones. In this context, forensic investigators require increasingly sophisticated laboratories capable of carrying out the legal encryption breach through mechanisms such as brute force or chip-off, among many other computing forensics techniques. It happens that current laboratories are not sufficient to supply the increasing demand and, in addition, said laboratories are concentrated on the main economic centers, therefore, away from thousands of districts in which legal processes are treated. Data volatility and test complexity require participation from authors and defendants in the legal process, so that invaluable technical adversarial proceedings and debates between specialists from the parties may take place, avoiding curtailment of defense. However, this monitoring is hampered, and even prevented, by poor productivity of the laboratories in face of the demand and distance between the district, expert approved by the judge and forensic laboratories. The speed of this revolution and scarcity of qualified laboratories overburden expert services, cause mistakes and confusion among legal processes, leading to the risk of acquitting guilty parties or, even worse, convicting innocent parties. In order to address this issue, it is proposed that forensic laboratories adopt a technology for remotely usable laboratories, called WebLab, and that these laboratories are therefore integrated in federations of Forensic WebLabs, as to provide the police chief, judge, prosecutor, attorneys, expert assigned by the judge and 
representatives of the parties to perform or remotely follow expert forensic tests, maximizing national and international utilization of better equipped laboratories and providing simultaneous and crucial supervision by the Judiciary and the parties of legal processes. In summary, this study proposes a reference model that enables use of forensic laboratories via the Web.

Keywords: WebLabs. Internet. Forensic Expert. 


\section{LISTA DE FIGURAS}

Figura 1 - Fluxo de trabalho com o Remote Laboratory Control Protocol. .29

Figura 2 - Grade sobre virtualidade e distância dos laboratórios. .33

Figura 3 - Balanceamento distribuído de carga com federação transitiva VISIR .38

Figura 4 - Diagrama de sequência de eventos para federações WebLabs Deusto..39

Figura 5 - Publicações sobre computação forense .58

Figura 6 - Publicações sobre produtividade. .58

Figura 7 - Publicações o paradoxo da produtividade .59

Figura 8 - Grade proposta para virtualidade e presencialidade pericial forense 64

Figura 9 - Sandbox no WebLab Forense. .65

Figura 10 - Visão geral do WebLab Forense .67

Figura 11 - Modelo genérico do WebLab proposto 68

Figura 12 - Mensagens GOLC .78

Figura 13 - Requisições e respostas GOLC .79

Figura 14 - Arquitetura do "gateway4labs" 84

Figura 15 - Federação de WebLabs Forenses com framework 87

Figura 16 - Federação de WebLabs Forenses com middleware 87

Figura 17 - Diagrama de sequência de eventos para federações .88

Figura 18 - Confederação de WebLabs Forenses. 89

Figura 19 - Processos judiciais eletrônicos e federações de WebLabs. .93

Figura 20 - WebLabs Forenses para encontro entre autoridades e provedores .95

Figura 21 - Diagrama de bloco simplificado. 106

Figura 22 - Visão geral da autenticação para a cadeia de custódia 106

Figura 23 - Cadeia de custódia: processo simplificado 109

Figura 24 - Mapa do ambiente alvo (Target Map) 
Figura 25 - Mapa da cadeia de custódia (Custody Map) ….................................112

Figura 26 - Mapeamento comparativo (Overlap Map) ........................................113 


\section{LISTA DE QUADROS}

Quadro 1 - Departamentos jurídicos em um laboratório virtual remoto .31

Quadro 2- Principais funções em um WebLab Forense .66

Quadro 3 - Diferenças de terminologia entre os sistemas Shara e iLabs. .75

Quadro 4 - Principais termos utilizados no GOLC ....................................... 76

Quadro 5 - Princípios GOLC norma sobre interoperabilidade ............................. 76

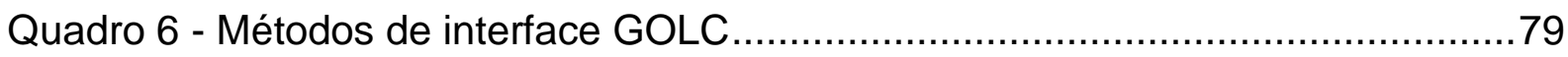

Quadro 7 - Métodos adicionais de interface GOLC ..................................... 82

Quadro 8 - Integração entre Processo Judicial Eletrônico e federações de WebLabs Forenses .91 


\section{LISTA DE SIGLAS}

$\begin{array}{ll}\text { ABNT } & \text { Associação Brasileira de Normas Técnicas } \\ \text { AFF } & \text { Advanced Forensic Format } \\ \text { ANATEL } & \text { Agência Nacional de Telecomunicações } \\ \text { CAD } & \text { Computer Aided Design } \\ \text { CD } & \text { Compact disk } \\ \text { CETIC.BR } & \text { Centro de Estudos sobre as Tecnologias da } \\ \text { CGI } & \text { Informação e da Comunicação - NIC.BR } \\ \text { ESI } & \text { Comitê Gestor da Internet no Brasil } \\ \text { HD } & \text { Electronic Stored Information } \\ \text { IBGE } & \text { Hard disk } \\ \text { ISO } & \text { Instituto Brasileiro de Geografia e Estatística } \\ \text { JSON } & \text { International Standardization Organization } \\ \text { ITU } & \text { JavaScript Object Notation } \\ \text { LaaS } & \text { International Telecommunication Union } \\ \text { LaaFS } & \text { Laboratory as a Service } \\ \text { MDGs } & \text { Laboratory as a Forensic Service } \\ \text { NIC.BR } & \text { Millennium Development Goals } \\ \text { P2P } & \text { Núcleo de Informação e Coordenação do Ponto } \\ \text { RAM } & \text { BR } \\ \text { REST } & \text { Peer to peer } \\ \text { ROM } & \text { Random Access Memory } \\ \text { SOAP } & \text { Representational State Transfer } \\ \text { T.I. } & \text { Read Only Memory } \\ \text { TIC } & \text { Simple Object Assess Protocol } \\ \text { URL } & \text { Tecnologia da Informação } \\ \text { USP } & \text { Comunicações da informação } \\ \text { VoIP } & \text { Universidade de São Paulo } \\ \text { XML } & \end{array}$




\section{SUMÁRIO}

Resumo

i

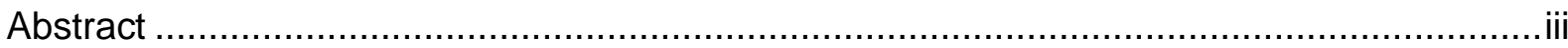

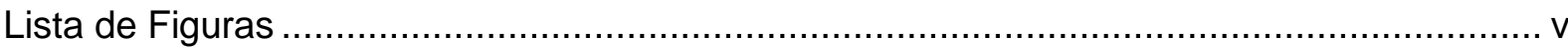

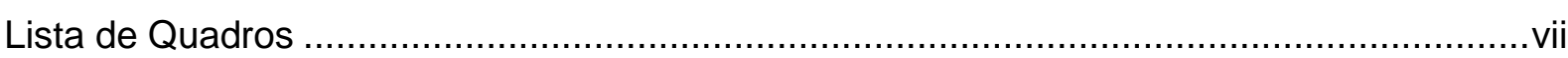

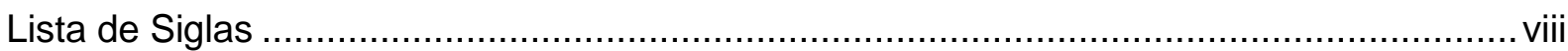

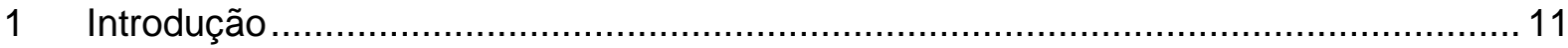

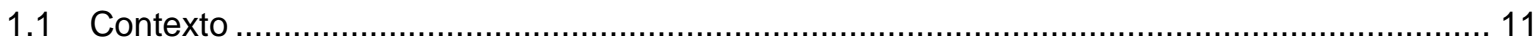

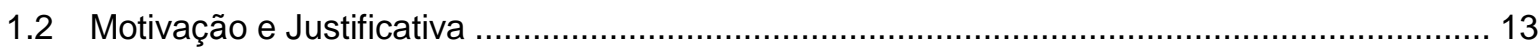

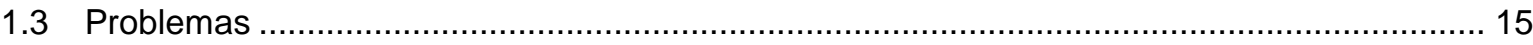

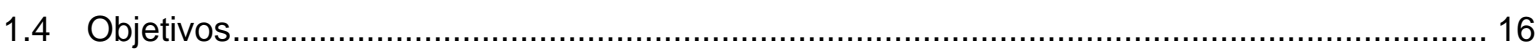

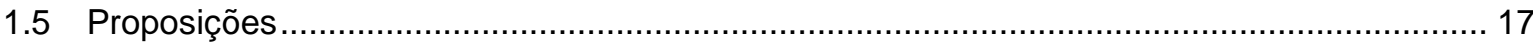

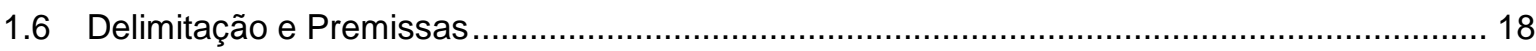

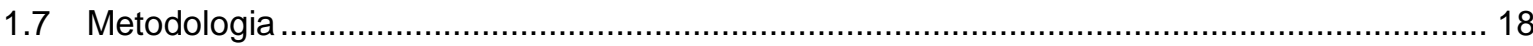

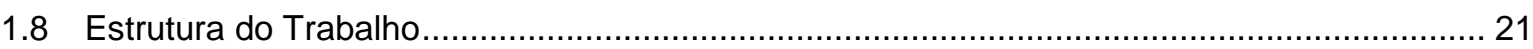

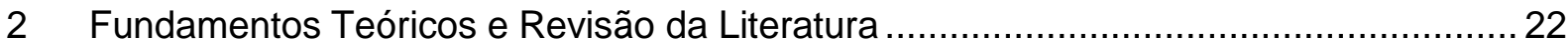

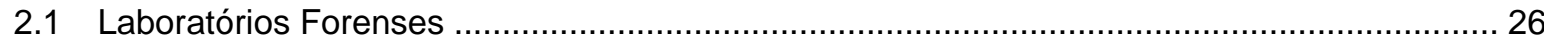

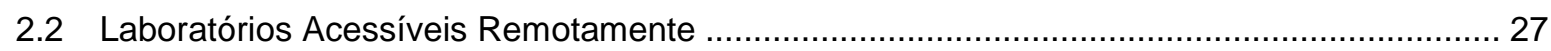

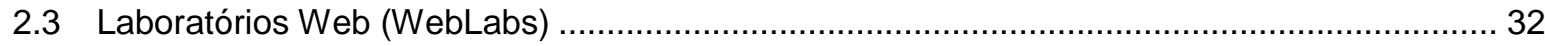

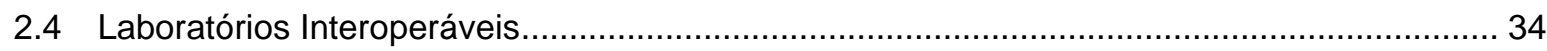

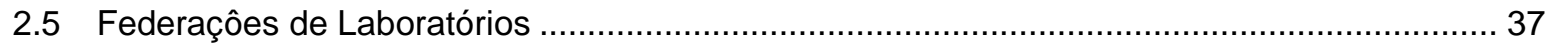

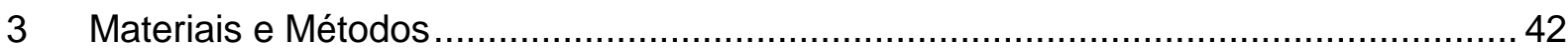

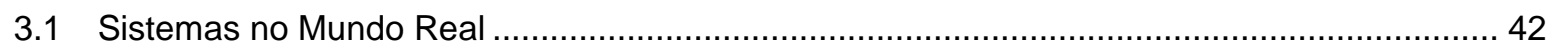

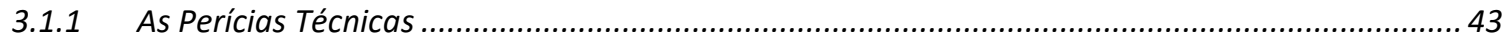

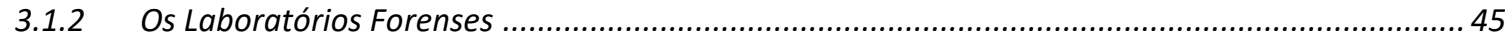

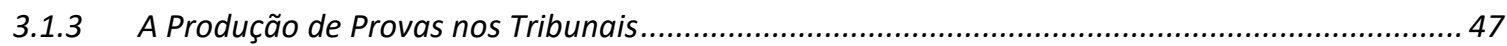

3.1.4 A Tecnologia da Informação e a Produtividade Pericial ...............................................................56

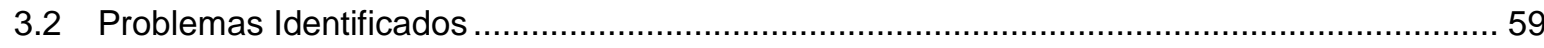

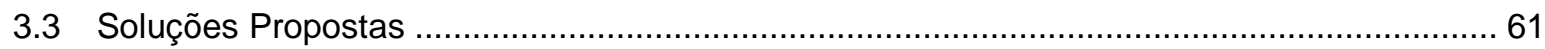


3.3.1 Adotar Tecnologia WebLabs nos Laboratórios Forenses .................................................63

3.3.2 Integrar Laboratórios Forenses em Federações de WebLabs ................................................. 70

3.3.3 Integrar Federações de WebLabs aos Sistemas de Processo Judicial Eletrônico ...........................89

3.3.4 Integração de Provedores de Serviços às Federações de WebLabs ..............................................94

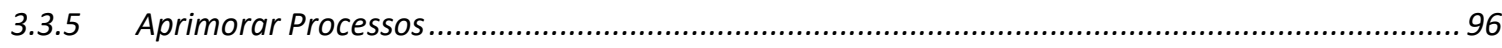

3.4 Confronto entre as Propostas e o Mundo Real ..................................................... 116

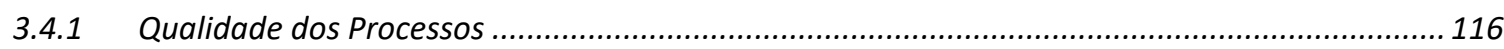

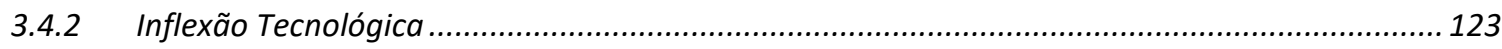

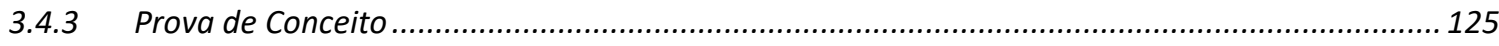

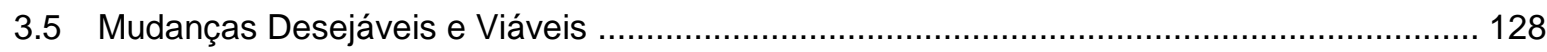

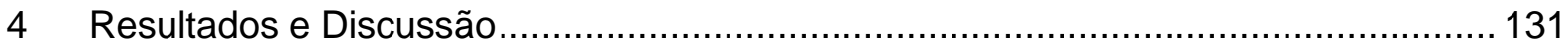

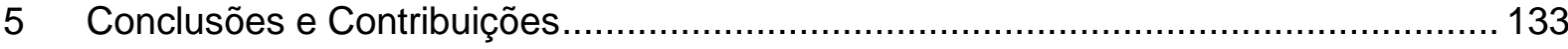

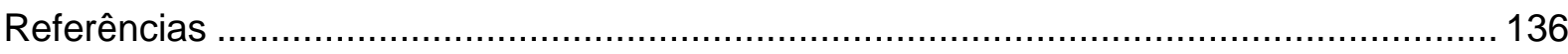




\section{INTRODUÇÃO}

O presente trabalho estuda os procedimentos utilizados pelos tribunais para produzir provas periciais relacionadas aos sistemas eletrônicos, identifica seus principais problemas e propõe alternativas de solução. Esse escopo o situa em uma região interdisciplinar comum às áreas de Engenharia, Administração e Direito, especialidades que ao longo dos últimos anos têm proporcionado transformações sociais antes nunca vistas.

\subsection{CONTEXTO}

$\mathrm{Na}$ antiguidade acreditava-se que algumas pessoas eram representantes do divino e que tal superioridade lhes concedia o poder de decidir de forma imparcial os conflitos entre humanos. Essa figura de um terceiro neutro dotado de habilidades especiais persistiu ao longo da história até que no Império Romano a função judicial se afasta do divino quando senadores foram considerados magistrados e receberam a missão de julgar as questões sociais. Nas idades média e moderna, a figura do julgador continuou a ser atribuída a pessoas privilegiadas da sociedade, mas agora elas passaram a ser remuneradas para exercer uma função estável nas disputas entre acusados e acusadores, podiam assumir papeis tanto passivos quanto tão inquisidores ao ponto de ordenar a tortura dos interrogados para arrancar a sua confissão, considerada à época como "a rainha das provas". (GUIMARÃES, 1958)

Com a evolução social, o juiz passou ser uma pessoa letrada e de comportamento exemplar que conquistou a posição de membro do poder judiciário. Uma vez que a sua atuação passou a se sujeitar às leis e normas que definiam sua competência e a conduta a ser seguida ao julgar os conflitos, ficou configurada a sua profissionalização.

Os juízes profissionais foram ganhando maior independência e autonomia no exercício da sua função jurisdicional, o que acirrou os debates a respeito de quais seriam os modelos mais adequados para se apurar a verdade sobre os fatos e valorar a sua influência nas decisões judiciais. (FACCHINI, 2006)

Surge então o regime das provas legais, modelo que subordinava o juiz a uma tabela que pré-definia tipos e pesos das provas que podiam ser aceitas, mas logo muitos 
países evoluíram para o princípio do livre convencimento do juiz sobre fatos levados a julgamento. Do ambiente de provas legais onde o juiz não tinha liberdade passouse para o extremo oposto, onde qualquer meio lícito destinado a convencer o juiz a respeito da verdade de um fato passa a ser denominado prova, como o depoimento pessoal, a exibição de documento ou coisa, a inspeção judicial e a prova pericial. Em contraposição à idade média que considerava a confissão como "rainha das provas", os tempos modernos fortaleceram o papel da prova técnica e deram liberdade de convencimento ao juiz. (MEDINA, 2015)

O Brasil adota os princípios da livre motivação das decisões judiciais e da persuasão racional do juiz. O primeiro concede liberdade ao magistrado para julgar, porém ele é obrigado a apresentar os motivos das suas decisões, dando às partes a oportunidade de entender os seus fundamentos. O segundo determina que o juiz não pode ser arbitrário mesmo diante do livre convencimento, ele permanece condicionado à racionalidade das alegações das partes e das provas dos autos. (PACHECO, 1976) O jurista (MALATESTA, 1927) ensina que a eficácia da prova será maior se ela fizer surgir de forma clara, ampla e firme no espírito do juiz a crença de posse da verdade:

É sempre a reflexão intelectual que nos conduz do conhecido ao desconhecido; e aí nos conduz por meio do raciocínio. $O$ raciocínio, instrumento universal da reflexão, é a primeira e mais importante fonte da certeza em matéria criminal.

A verdadeira certeza resulta da combinação entre a certeza física que provém dos sentidos e a certeza lógica resultante do trabalho intelectual, logo capaz de produzir em qualquer outra pessoa racional convicção similar àquela produzida no juiz (MALATESTA, 1927):

Este princípio da sociabilidade do convencimento judicial, ainda não exposto anteriormente, que eu saiba, por pessoa alguma, é da maior importância [...] nesta sociabilidade, que é uma espécie de objetivação da certeza, esta a melhor determinação do convencimento judicial, determinação que impede que ele se resolva, mais ou menos hipocritamente, em um arbítrio do juiz.

Dessa forma, o livre convencimento do juiz não deve estar inteiramente desvinculado das provas e dos elementos existentes nos autos, cabe-lhe decidir com base nos 
elementos existentes no processo judicial e avaliá-los segundo critérios críticos e racionais (CINTRA; GRINOVER; DINAMARCO, 2009).

A esse respeito, cabe notar que na esfera cível o Artigo 464 do recente Código de Processo Civil (CPC/2015) 1 inovou ao introduzir a "prova técnica simplificada". Mesmo se não apresenta definições explícitas, ao autorizar a "produção de prova técnica simplificada, quando o ponto controvertido for de menor complexidade" sugere haver gradação de provas segundo a qual, por exemplo, um exame pericial de DNA seria um prova científica que depende de profissional altamente qualificado quanto ao conhecimento acumulado de uma ciência, enquanto que a apuração do valor de um imóvel seria uma "prova técnica simplificada", tarefa que o juiz pode atribuir a um profissional com menor abrangência de conhecimentos por depender principalmente da habilidade e da experiência com as quais faz algo (MEDINA, 2015), salientando a esse respeito o mesmo autor:

Cremos que para o perito que venha trazer conhecimentos científicos a exigência de formação de escolaridade e respectivo grau, via de regra universitário, é praticamente absoluta, somente podendo haver transigência, pelo juiz, tendo em vista localidades onde seja virtualmente impossível obter-se um perito, nessas condições, seja na própria comarca, seja fora da mesma.

Dessa maneira, a crescente complexidade dos sistemas eletrônicos impõe que seu exame pericial não pode ser considerado uma prova técnica simplificada e, por isso, somente pode ser atribuído pelo juiz a profissional com formação e conhecimentos científicos adequados, escolhido na própria comarca ou fora dela.

\subsection{MOTIVAÇÃO E JUSTIFICATIVA}

O compromisso com a racionalidade e a complexidade tecnológica da sociedade moderna obrigam o juiz a recorrer ao auxílio de peritos em áreas como Engenharia, Medicina ou Contabilidade para que possa se sentir seguro ao avaliar evidências apresentadas em processos judiciais que envolvem questões tão diversas quanto

${ }^{1}$ CPC/2015 - Lei 13.105/2015 
atentados à segurança do estado, assassinatos, fraudes, roubos, acidentes de trânsito, erros médicos, colapsos em edificações, deficiências em serviços, violações de patentes, sonegações de impostos, difamações ou questões familiares, entre muitas outras disputas típicas dos países democráticos.

Cada vez mais essas evidências assumem formatos digitais em decorrência do intenso aumento da participação dos sistemas eletrônicos em praticamente todas as atividades humanas. As pesquisas sobre tendências tecnológicas indicam que até 2020 haverá algo como 5 bilhões de dispositivos eletrônicos conectados em rede, que as máquinas inteligentes rapidamente adquirirão capacidades para realizar praticamente todas as atividades diárias e que, pela primeira vez na história, mais de um milhão de trabalhadores humanos serão supervisionados por robôs (GARTNER, 2015).

Esse cenário é desafiador tanto para os juízes quanto para os peritos que os auxiliam. Os juízes precisam decidir questões inéditas que não eram conhecidas pelos legisladores e para as quais raramente há decisões ou interpretações anteriores que possam guiá-los. Os peritos enfrentam dificuldades crescentes para coletar e analisar evidências digitais, especialmente em função do grande volume de dados, da sua dispersão em nuvens, da diversidade de estruturas, da integração de sistemas em escala mundial, da mobilidade e onipresença de minúsculos dispositivos eletrônicos e da utilização de criptografia e outras técnicas de ofuscação pelo usuário malintencionado.

As próprias ferramentas utilizadas pelos peritos são afetadas pela intensa evolução tecnológica. Se por um lado a inovação tecnológica traz ferramentas periciais com melhores desempenho e nível de automação, por outro lado a rapidez ainda maior com que produtos inovadores se tornam alvo de investigação faz com que as caras ferramentas periciais logo se tornem obsoletas, elevando seu custo de propriedade e dificultando a atualização dos laboratórios periciais.

Laboratórios com envergadura e qualidade suficientes são raros até mesmo nos grandes centros onde há importantes universidades e ricos parques tecnológicos, logo tais laboratórios periciais não estão disponíveis nas médias e pequenas comarcas do interior onde ocorre a prestação dos serviços judiciais. Restam duas alternativas, ambas inadequadas: ou se pretere a produção das provas técnicas com evidentes 
prejuízos para a cidadania e para as partes $^{2}$, ou se despacha os dispositivos a examinar, desde a distante comarca do interior até o laboratório pericial na grande cidade, impossibilitando com isso que as partes no processo judicial acompanhem e fiscalizem os trabalhos periciais por questões econômicas ${ }^{3}$, contexto que poderia até mesmo configurar o cerceamento de defesa.

Cabe considerar que todos os laboratórios periciais já estão sobrecarregados, possuem grandes backlogs e que o aumento na quantidade de delegados, promotores, advogados e juízes, contratados pelo poder público para atender à crescente demanda da população amplia a quantidade de pedidos de perícia técnica e, consequentemente, sobrecarrega ainda mais os poucos laboratórios existentes.

Os fatores sociais e tecnológicos descritos nesta introdução ilustram um cenário onde o desbalanceamento entre a grande demanda por exames periciais e a pequena capacidade de realizá-los com qualidade e presteza necessárias coloca em risco os usuários dos serviços jurídicos, a população como um todo e o própria qualidade do estado democrático, pois a justiça deixa de cumprir seu papel ao produzir decisões alienadas da verdade por ausência ou mesmo pelo indevido comprometimento das provas.

Diante desse cenário, cabe circunscrever os problemas a enfrentar, lançar hipóteses, avaliar as possíveis soluções e apresentar as conclusões.

\subsection{PROBLEMAS}

A sociedade moderna depende cada vez mais da prova técnica digital na medida em ela proporciona ao julgador e às partes uma compreensão melhor sobre os fatos ocorridos em todas as áreas do conhecimento. Por outro lado, a observação do diaa-dia dos tribunais mostra severos problemas, como laudos mal-avaliados pelos juízes, distanciamento entre as comarcas e os melhores laboratórios forenses, e pedidos de perícia que ficam anos em fila de espera. Essa situação se agrava e pode chegar ao colapso: o exame da literatura científica sobre o assunto revela apenas

\footnotetext{
2 Veja-se a esse respeito comentário do autor ao final do capítulo anterior, sobre a "prova técnica simplificada" estabelecida pelo novo Código de Processo Civil (CPC/2015).

${ }^{3}$ Despesas de viagem e estadia dos representantes das partes em uma grande cidade, pelo tempo em que perdurarem os trabalhos periciais, além do custo da ausência no trabalho e na família.
} 
esforços pontuais para aumentar a produtividade das ferramentas periciais, não enfrentam diretamente o impactante desequilíbrio entre a grande adoção de inovadores sistemas eletrônicos pela população e a crônica carência de laboratórios periciais.

Em milhares de comarcas do interior, a população adota vertiginosamente novos e sofisticados dispositivos eletrônicos, impondo aos juízes encontrar localmente peritos e laboratórios aptos a realizar os exames, todavia, tais recursos geralmente estão disponíveis apenas nos grandes centros econômicos. Essa distribuição geoeconômica produz um grande distanciamento entre os principais laboratórios forenses e a comarca onde estão juiz, promotor, advogados, peritos, assistentes técnicos e as próprias partes, fenômeno que dificulta ou até mesmo impede a participação de todos na produção de provas, conforme lhes faculta a legislação. Além disso, são cada vez mais frequentes ocorrências onde nem mesmo nos grandes centros estão disponíveis soluções que possibilitam o exame de sistemas mais intensamente protegidos por criptografia ou disseminados em nuvem, tornando necessário buscar recursos laboratoriais ainda mais sofisticados, até mesmo em outros países.

Dessa maneira o problema central a resolver é, em síntese, que a rápida adoção pela sociedade de novos tipos de sistemas eletrônicos impacta o equilíbrio entre demanda por exames periciais e a capacidade dos laboratórios de atender essa demanda, fenômeno mais grave nos milhares de comarcas situadas à distância dos grandes centros econômicos. Esse contexto prejudica diretamente os serviços periciais e indiretamente a presteza e a qualidade das decisões judiciais, portanto a sociedade como um todo.

\subsection{OBJETIVOS}

O presente trabalho tem como principal objetivo propor soluções para o descompasso existente entre a elevada demanda por perícias técnicas em sistema eletrônicos complexos e a reduzida capacidade dos laboratórios forenses para realizá-las com métodos, qualidade e prazos adequados ao rito judicial.

Para alcançar esse objetivo principal, foram estabelecidos os seguintes objetivos secundários: 
- Estudar na literatura científica registros sobre contexto, problemas, causas e soluções já tentadas;

- Mapear os problemas identificados;

- Formular modelos de novas soluções;

- Avaliar sua aplicabilidade.

Os próximos capítulos sumarizam aspectos relevantes do trabalho proposto.

\subsection{PROPOSIÇÕES}

Para nortear a pesquisa, se considera razoável estabelecer a priori a proposição a seguir, cuja validade é avaliada no decorrer do trabalho.

- Laboratórios especializados em sistemas eletrônicos podem ser integrados para formar uma rede de laboratórios forenses remotos que aumente a disponibilidade, a produtividade e a qualidade desses serviços.

É razoável também estabelecer as seguintes proposições secundárias, igualmente avaliadas ao longo do trabalho:

- A integração dessa rede de laboratórios torna possível que juízes, promotores, delegados, advogados, oficiais de justiça, peritos, assistentes técnicos e as partes em processos judiciais possam comandar, executar, acompanhar e fiscalizar remotamente os procedimentos periciais;

- Uma rede de laboratórios forenses pode ser integrada também por laboratórios de outras áreas do conhecimento, desde que eles também utilizem equipamentos digitais para realizar seus exames;

- Uma rede de laboratórios forense pode ser utilizada para mediar conflitos entre as autoridades policiais e os provedores de serviços ou produtos, nos casos em que a investigação de crimes requerer judicialmente o acesso a ambientes resguardados pelo provedor por meio de criptografia ou outros métodos técnicos de proteção da privacidade do usuário;

- Uma rede de laboratórios forenses pode ter amplitude internacional e com isso pode ser utilizada para mediar a execução e a fiscalização dos procedimentos técnicos que envolvam a produção de provas simultaneamente em mais de um país; 
- Uma rede de laboratórios se presta ao treinamento e aperfeiçoamento de peritos, assistentes técnicos e operadores do Direito nas questões pertinentes à prática na produção de provas forenses;

As proposições estabelecidas são analisadas nos próximos capítulos deste documento.

\subsection{DELIMITAÇÃO E PREMISSAS}

Esta pesquisa se posiciona principalmente em uma região comum às áreas de Engenharia, Direito e Administração

- Engenharia - nas questões relacionadas ao conhecimento científico e tecnológico e sua utilização no exame pericial dos sistemas eletrônicos;

- Direito - nas questões relacionadas à produção de provas forenses;

- Administração - nas questões relacionadas à prestação de serviços forenses e à gestão de laboratórios.

Seu foco está nos procedimentos periciais realizados em sistemas eletrônicos com qualquer finalidade forense, portanto abrange os exames que têm por fim o próprio dispositivo eletrônico (por exemplo, para investigar uma invasão cibernética), assim como aqueles onde o exame do dispositivo eletrônico é apenas o meio que obter evidências de interesse de outras áreas do conhecimento (por exemplo, na coleta de evidências digitais sobre um erro médico ou uma fraude contábil).

Com relação às delimitações, cabe registrar que especialmente em função grande da amplitude do assunto tratado, não são parte do escopo deste trabalho a indicação de políticas, normas, métodos ou detalhes construtivos e operacionais dos laboratórios forenses ou da produção de provas de qualquer tipo.

\subsection{METODOLOGIA}

Quanto à sua natureza, esta pesquisa tem interesse prático no aperfeiçoamento dos processos pertinentes aos serviços de perícia judicial. Espera que seus resultados sejam imediatamente aplicados para resolver problemas na prestação de serviços pericias aos tribunais e, por consequência, à sociedade como um todo. Quanto aos 
seus objetivos, esta pesquisa tem características exploratórias na medida em que proporciona maior familiaridade com os problemas e possibilita a construção de proposições a partir de estudos diversos, tais como levantamentos bibliográficos, entrevistas com pessoas conhecedoras desses problemas, e da análise de exemplos que estimulem a sua compreensão. Quanto à forma de abordar os problemas, se trata de pesquisa qualitativa que interpreta fenômenos e Ihes atribui significados sem lançar mão de métodos quantitativos. Logo, considera como seus focos os processos identificados e a percepção do seu significado. Do ponto de vista dos métodos, este projeto utiliza uma adaptação simplificadora elaborada por este autor a partir da Soft System Methodology (SSM), um método desenvolvido especificamente para analisar agilmente situações complexas onde há visões divergentes a respeito da definição de algum problema, para isso prioriza a compreensão rápida dos sistemas do mundo real (MOBACH, 2000). Em sua origem, a SSM foi desenvolvida porque a metodologia tradicional de Engenharia de Sistemas, baseada na definição estrita dos objetivos e métodos, sofria limitações de tempo e recursos ou até era impraticável quando aplicada a problemas confusos e mal estruturados do mundo real (SIMONETTE, 2010).

A SSM auxilia a formulação e estruturação rápidas do pensamento sobre os problemas em situações intrincadas e visa a construção ágil de modelos conceituais baseados no entendimento das atividades humanas e na comparação desses modelos com o mundo real (TURRIONI; MELLO, 2012), considerando que tais problemas complexos surgem de fenômenos sociais do mundo real e, portanto, são diferentes daqueles que usualmente são estudados em laboratório (SIMONETTE, 2010).

Assim, os métodos adotados na SSM foram concebidos para a investigação de problemas e para busca de soluções em sistemas que são difíceis de se entender. Para utilizar a SSM, o pesquisador incialmente coleta informações sobre os problemas e os representa de maneira simples, até mesmo graficamente, e então os participantes do sistema e o pesquisador tentam encontrar caminhos que possibilitem melhorias no sistema (TURRIONI; MELLO, 2012), basicamente através das seguintes etapas interativas (SIMONETTE, 2010): 
1) Identificar a situação problemática (mundo real) - O pesquisador procura entender a situação mantendo contatos com pessoas envolvidas, buscando livremente informações em documentos e realizando observações;

2) Expressar a situação problemática (mundo real) - $O$ pesquisador representa os problemas identificados e os discute com pessoas envolvidas com o sistema, construindo a descrição do dia-a-dia dos problemas;

3) Imaginar (mundo sistêmico) - O pesquisador busca novas maneiras de enxergar a questão através de uma etapa imaginativa absolutamente crítica para o sucesso da pesquisa;

4) Construir modelos conceituais (mundo sistêmico) - O pesquisador desenvolve modelos conceituais de possíveis soluções;

5) Comparar modelo conceitual com o mundo real (mundos sistêmico e real) - $O$ pesquisador compara o modelo conceitual com o mundo real. Busca identificar atividades que fazem parte do modelo conceitual, mas que não acontecem no mundo real, e também atividades do mundo real que não estão presentes no modelo conceitual

6) Definir mudanças desejáveis e viáveis (mundo real) - A lista das possíveis mudanças é debatida entre os participantes do sistema com o propósito de identificar as mudanças desejáveis e culturalmente viáveis.

7) Adotar mudanças para melhorar a situação do mundo real - Implementação das mudanças.

Esse método de pesquisa adota nomenclatura que é internacionalmente conhecida como "CATOWE" (SIMONETTE, 2010)::

C - Customer, são as pessoas beneficiadas pelo sistema;

A - Actor, são as pessoas que realizam as atividades do sistema;

$T$ - Transformation, mostra as transformações ocorridas nas entradas que resultam nas saídas do sistema;

W - World View, a imagem do mundo que torna esse sistema significativo;

O - Owner, a pessoa que pode abolir o sistema;

E - Environment, as restrições do ambiente (environmental constrains) que o sistema sofre. 
Ainda segundo (SIMONETTE, 2010), as visões do pesquisador devem focalizar:

- Pergunta 1: O que é necessário?

- Pergunta 2: Por que é necessário?

- Pergunta 3: Quem irá fazer isso?

- Pergunta 4: Quem será beneficiado?

- Pergunta 5: Quem será prejudicado?

- Pergunta 6: Quais fatores externos restringem as atividades?

Dessa maneira, a presente pesquisa busca compreender pragmaticamente as dificuldades que a evolução tecnológica inflige como efeito colateral à produção de provas no âmbito do poder judiciário e propor possíveis soluções para os problemas identificados. A coleta de dados é realizada mediante pesquisas diversas, inclusive na Internet, em reuniões e nos documentos que integram os autos de ações judiciais, entre outras fontes informais. A análise dos dados é realizada por interpretação qualitativa, lógica indutiva e reflexões com base em anotações do diário de pesquisa. A qualidade e validade da pesquisa é aferida por apresentações públicas dos resultados das pesquisas e submissão de artigos e capítulos de livros.

\subsection{ESTRUTURA DO TRABALHO}

Este trabalho possui os capítulos descritos a seguir.

- CAPÍTULO 1 - Apresenta o contexto da pesquisa, estabelece objetivos, motivação e justificativa e posteriormente detalha problemas e proposições;

- CAPÍTULO 2 - Registra fundamentos teóricos e a revisão da literatura;

- CAPÍTULO 3 - Detalha os procedimentos realizados segundo o método SSM, adaptado pelo autor, expondo os problemas encontrados e as soluções propostas.

- CAPÍTULO 4 - Debate os resultados obtidos e discute sua aplicação. Descreve os trabalhos realizados para comprovar ou rejeitar as hipóteses formuladas;

- CAPÍTULO 5 - Apresenta conclusões e contribuições.

O próximo capítulo detalha os principais fundamentos teóricos. 


\section{Fundamentos Teóricos e Revisão da Literatura}

O presente estudo se refere aos laboratórios forenses que tem o exame de sistemas eletrônicos como um fim ou apenas como um meio para produzir provas em outras áreas de conhecimento. Por exemplo, a primeira situação ocorre na investigação de um computador para constatar danos sofridos em uma invasão, enquanto a segunda ocorre no exame de uma "caixa preta" para investigar as causas de um acidente aeronáutico. Ambas essas situações podem ocorrer também no hipotético exame de um laboratório espacial pousado em outro planeta, a verificação à distância dos seus sistemas eletrônicos pode ter como objetivo apurar as causas de alguma pane para fins de indenização ou então apurar o valor probante das evidências ali coletadas e armazenadas sobre a existência de vida extraterrestre.

Essa abrangência sinaliza um contexto marcantemente multidisciplinar (MARTINS, 2015). Sob a óptica do Direito são relevantes questões relacionadas à admissibilidade e valoração das provas digitais, foco que remete a subdivisões dos ramos tradicionais que recebem denominações como Direito Informático, Direito Eletrônico, Direito Digital, Direito das Telecomunicações, Direito à Privacidade e Direito ao Esquecimento, entre outras. Nas Engenharias, são relevantes os conhecimentos científicos e os métodos necessários para identificar, coletar, analisar e submeter aos tribunais evidências digitais que se tornaram onipresentes na sociedade moderna. $\mathrm{Na}$ Administração, destacam-se as questões pertinentes à gestão dos recursos e dos procedimentos realizados no âmbito dos institutos oficiais de criminalística e nos laboratórios independentes, além das tarefas executadas por milhares de peritos nomeados ad hoc. Nas outras áreas de conhecimento, são relevantes os conhecimentos próprios dessas, necessários para analisar evidências produzidas ou armazenadas em sistemas eletrônicos. De uma maneira geral, pode-se dizer que o domínio está nas chamadas Ciências Forenses que remetem ao conjunto de conhecimentos científicos e procedimentos técnicos utilizados com finalidade legal e que em sua maioria são de fato emprestados de outras áreas científicas.

Cumpre ainda notar que a área de interesse deste trabalho ultrapassa os limites da Criminalística porque além de estudar laboratórios destinados a desvendar crimes, também avalia aqueles destinados a esclarecer questões técnicas em processos cíveis, da família, da infância e juventude, da mulher, militares, do trabalho, da 
fazenda, empresariais e eleitorais, entre outros, além das instâncias arbitrais. Dessa forma, estão abrangidas todas as situações nas quais seja necessária a produção de provas com finalidade forense.

O juiz tem a responsabilidade de ser o maestro da produção de provas, pois é ele quem de fato determina a realização de exames periciais e também é o destinatário final das evidências encontradas. Em síntese, quando uma disputa judicial envolve conhecimento especializado sobre qualquer assunto técnico, o juiz determina a produção de prova científica ou técnica. Para isso, o juiz primeiramente busca nomear um perito que tenha conhecimento científico e experiência prática sobre os pontos em debate, depois enfrenta a difícil tarefa de entender o conteúdo do laudo pericial que esse especialista produzir e finalmente partir da leitura desse documento e de outros meios terá que formar racionalmente seu convencimento judicial com intensidade suficiente para julgar a causa. A prática indica que raramente o juiz realiza pessoalmente oitivas ou diligências conjuntas com o perito judicial e com os assistentes técnicos das partes para debater de maneira aberta e detalhada as evidências apresentadas pelas partes, providência que seria relevante porque a mera leitura do laudo raramente se mostra meio de comunicação eficaz entre um pensar jurídico que valoriza a dialética abordando as questões de modo relativo e um pensar fortemente cartesiano dos peritos e assistentes técnicos que aceitam apenas o que é irrefutável e desprezam tudo que lhe parece relativo. A comunicação entre peritos e magistrados foi estudada por (ZOCHIO, 2010) ao levantar a opinião que os juízes de vara cíveis da Comarca de São Paulo têm a respeito da qualidade dos laudos periciais que receberam dos seus peritos judiciais. Os resultados foram marcantes: os juízes consideraram os laudos prolixos, excessivamente técnicos, com sentido vago ou dúbio e, paradoxalmente, úteis para a elucidação da lide. Cumpre notar que os resultados obtidos por (ZOCHIO, 2010) se mostram ainda mais relevantes porque nos processos cíveis os autores e os réus usualmente indicam assistentes técnicos que atuam de fato como "peritos das partes" ao acompanhar os trabalhos realizados pelo perito nomeado pelo juiz, modelo de trabalho que naturalmente tende a melhorar a qualidade do laudo final. A percepção dos juízes sobre os laudos pode ser ainda pior nos processos criminais porque nesse âmbito é praticamente inócua a figura dos assistentes técnicos, eles raramente têm acesso ao material digital ou colaboram efetivamente com a investigação técnica, geralmente somente podem se manifestar 
depois de que o perito oficial concluiu isoladamente os exames e entregou um hermético laudo pericial. Nessas condições, os assistentes técnicos na esfera penal podem se defrontar com situações quase irreversíveis de convencimento já formado tanto pelo perito quanto pelo juiz, difícil de ser alterado quando posteriormente são encontrados erros ou omissões no trabalho pericial, o que aliás é uma tarefa árdua de realizar sem ter participado pari passu dos exames e sem ter tido acesso aos dados detalhados anteriormente examinados em algum instituto de criminalística com o emprego de ferramentas sofisticadas e longo tempo disponível, ambos indisponíveis ao assistente técnico. As razões geralmente lembradas pelos órgãos pericias oficiais para não receber assistentes técnicas são a interpretação legal de que o assistente começa a autuar após o laudo, a falta de infraestrutura adequada nesses órgãos para receber assistentes técnicos e, ainda, que cada perito atua simultaneamente em mais de um caso e por isso ele não teria como assegurar o sigilo dos demais casos se receber o assistente técnico em seu local de trabalho.

Em síntese, esse ambiente técnico-jurídico fomenta contatos apenas formais e escritos entre observadores que possuem culturas, informações e pontos de vista bastante distintos: o perito não conhece a interpretação e a aplicação da lei, o juiz não conhece a tecnologia e ambos podem estar distantes das questões técnicas essenciais que as partes precisam esclarecer no processo, mesmo sem as conhecerem de fato. Existe uma lacuna onde deveria haver um ponto de encontro entre os interlocutores.

O novo Código do Processo Civil lança alguma luz sobre a questão ao reiterar que o juiz, de ofício ou a requerimento da parte, pode inspecionar pessoas ou coisas, sendo assistido por um ou mais peritos, a fim de esclarecer fato de interesse à decisão da causa. Tal diretriz procura fomentar uma ponte entre o tribunal e o local dos fatos ou do crime, para que ali o juiz veja pessoalmente os vestígios e a partir deles possa formar com mais segurança o seu convencimento. Nessa tarefa, o juiz poderia contar não apenas com peritos de sua confiança, mas também com os assistentes técnicos das partes, se lhes forem asseguradas as condições para exercer plenamente 0 contraditório técnico durante a realização dos exames periciais.

Todavia, o exame dos complexos sistemas eletrônicos, inclusive daqueles embutidos em um simples telefone celular, demanda laboratórios cada vez mais sofisticados que não estão disponíveis nas comarcas do interior onde tramitam muitos dos processos 
judiciais e, portanto, onde residem e trabalham os seus juízes, delegados, promotores, advogados, peritos e assistentes técnicos. Esse modelo impõe o transporte das evidências digitais desde a comarca do interior até o laboratório de algum grande centro, onde elas serão examinadas provavelmente sem qualquer participação dos operadores do Direito ou dos representantes das partes, impedindo ou dificultando o efetivo contraditório técnico e a própria fiscalização sobre a manipulação de evidências digitais altamente voláteis.

Esses cenários indesejáveis requerem o estudo de alternativas. Em vez de transportar fisicamente os operadores do Direito até as grandes cidades onde são realizados os exames ou então ter que transigir em questões essenciais como a qualidade dos trabalhos periciais, cabe avaliar outras possibilidades sobre um ponto de encontro comum e de fácil acesso que ofereça aos operadores do Direito e aos laboratórios a possibilidade de custodiar e manipular evidências digitais em um ambiente de colaboração, transparência e fiscalização mútua.

Esse ponto comum entre operadores do Direito e os laboratórios naturalmente precisa se submeter aos princípios que regem a atividade jurídica. Tendo presidido o Tribunal de Justiça de São Paulo, (NALINI, 2001) lembra que todas as profissões reclamam proceder ético, mas que na atividade jurídica tornam-se imperativos atributos como a correção profissional, a diligência, a fidelidade, a discricionariedade, a lealdade e a verdade. Deve também implementar os procedimentos determinados pelos Códigos de Processo e as condições específicas determinadas pelos magistrados em cada processo.

Deve também implementar os requisitos estabelecidos pela comunidade técnicocientífica para o exame forense de sistemas eletrônicos, aplicando-se questões tão amplas e diversas quanto à titulação profissional em Engenharia ou áreas afins, as regras definidas pelos conselhos profissionais, as normas técnicas estabelecidas por organismos normativos nacionais e internacionais, os estudos científicos, os procedimentos operacionais padrões determinados pelas autoridades (SECRETARIA NACIONAL DE SEGURANÇA PÚBLICA, 2013) e as práticas recomendadas pelos fabricantes das ferramentas para perícia forense.

Finalmente, cumpre considerar as questões relacionadas à atuação dos peritos, principais operadores dos modelos ora em avaliação, uma vez que as diferenças existentes na formação e na alocação dos peritos aos trabalhos periciais forenses se 
reflete na qualidade dos trabalhos realizados. Peritos oficiais usualmente são funcionários públicos aprovados em processos seletivos, nas contratações feitas pelas polícias federal e de alguns estados há grande concorrência que naturalmente redunda na seleção de profissionais mais qualificados. Por outro lado, na esfera cível os peritos são simplesmente cadastrados em cartório do tribunal, praticamente sem qualquer seleção técnica, cenário que faz com que exista elevada heterogeneidade quanto à competência profissional.

Essa heterogeneidade na competência profissional pode ter relação com as duras críticas aos atuais procedimentos periciais. Os autores (NEUFELD; SCHECK, 2010) alertam para a necessidade de tornar mais científica a Ciência Forense, inclusive mediante a criação de círculos de estudo, o estabelecimento de padrões técnicos e a imposição da necessidade de certificações tanto para os peritos quanto para as técnicas que eles utilizam. Consideram que medidas como essas são urgentes especialmente porque a National Academy of Sciences (NAS) reconheceu que as Ciências Forenses não estão realmente embasadas em ciência sólida, muitas disciplinas forenses foram desenvolvidas apenas com o objetivo prático de solucionar crimes específicos, consideraram apenas casos individuais sujeitos a variações significativas de recursos e de conhecimentos e, salvo raras exceções como a análise de DNA, não foram submetidas a escrutínios experimentais rigorosos.

\subsection{LABORATÓRIOS FORENSES}

Laboratórios forenses são laboratórios de análise operados com finalidade forense, portanto são ambientes dotados de instrumentos e métodos apropriados a produzir exames técnicos que sejam aderentes aos princípios científicos.

Os principais laboratórios forenses brasileiros que atuam em perícias digitais na esfera criminal são o Instituto Nacional de Criminalística (INC), com sede em Brasília e unidade regionais nas principais cidades, e os institutos de criminalística subordinados às secretarias estaduais de segurança pública. Há ainda laboratórios periciais em órgãos como ministérios públicos e delegacias especializadas de polícia. Esses órgãos são apoiados financeiramente e tecnicamente pela Secretaria Nacional de Segurança Pública (SENASP), todavia, a despeito desses esforços são notórios o 
desaparelhamento e o atraso de anos na produção de laudos em diversos laboratórios governamentais estaduais.

Há ainda laboratórios de porte mantidos por empresas privadas e pequenos laboratórios mantidos por milhares de peritos judiciais na maior parte das vezes em sua própria residência, quase sempre muito limitados.

Mais recentemente, surgem laboratórios corporativos, destinados a atender às necessidades internas da empresa e que são operados por suas áreas como segurança da informação, prevenção a perdas, inspetoria, auditoria ou compliance. Essa tendência ampliou-se com a aquisição de empresas nacionais por grupos estrangeiros e com a participação de empresas brasileiras nos negócios realizados em outros países, submetendo-as a controles obrigatórios como aqueles impostos pelo Sarbanes-Oxley Act e pela Securities Exchange Commission (PATZAKIS, 2003). Tais laboratórios adotam tanto ferramentas e métodos usuais nos exames forenses quanto aqueles adotados pelas empresas norte-americanas sujeitas à E-Discovery Law4.

\subsection{LABORATÓRIOS ACESSÍVEIS REMOTAMENTE}

Tradicionalmente, os laboratórios precisam ser frequentados presencialmente pelos seus usuários, porém a crescente disponibilidade de equipamentos laboratoriais digitais que podem ser acoplados a recursos de telecomunicações propiciou sua utilização à distância. Assim, um laboratório acessível remotamente é composto por um ou mais equipamentos digitais que podem ser utilizadas remotamente pelos usuários.

Cabe notar a distinção entre laboratório remoto e laboratório virtual. O laboratório remoto contém equipamentos físicos, enquanto que o laboratório virtual contém apenas equipamentos simulados por meio de software, portanto sem a presença de equipamentos laboratoriais físicos.

Os laboratórios remotos tomaram impulso a partir da década 1970, os pesquisadores (ROSEKIND; COATES; THORESEN, 1978) investigavam doenças do sono

\footnotetext{
${ }^{4}$ Electronic Discovery Law - método para localização e apresentação de informações eletrônicas como evidências em processos judiciais nos Estados Unidos.
} 
monitorando remotamente os pacientes que dormiam em suas casas, para isso utilizavam eletroencefalógrafos de múltiplos canais conectados a transmissores que encaminhavam via linha telefônica os sinais elétricos captados no paciente diretamente para polígrafos instalados no consultório dos médicos. Posteriormente, (FELDER et al., 1995) criaram laboratórios clínicos controlados remotamente que possibilitavam a coleta e análise de sangue ao lado do paciente. Na Oregon State University, (AKTAN et al., 1996) desenvolveram um laboratório remoto com finalidade educacional que podia ser acessado via Internet para realizar experimentos.

Ao longo do tempo, as universidades foram pioneiras no desenvolvimento de laboratórios remotos educacionais (ORDUÑA, 2013), provendo ambientes que possibilitam aos estudantes conduzir os mais variados tipos de experimentos, cabendo destacar que dez universidades australianas se interligaram para proporcionar experimentos com laboratórios remotos a milhares de seus alunos (YEUNG; LOWE; MURRAY, 2010) e na Europa foi criado o Global Online Laboratory Consortium (GOLC, 2011).

Se por um lado avançam rapidamente as aplicações educacionais, a mesma agilidade não ocorreu nas aplicações reais com objetivos científicos ou empresariais. Há grandes diferenças entre as aplicações educacionais e aquelas reais, pois no ambiente educacional muitas vezes são preteridas questões como eficiência, usabilidade, fluxo de trabalho, segurança, escalabilidade e estrutura e tecnologia mais adequada (ORDUÑA, 2013). Na medida em que as aplicações educacionais evoluem, vão recebendo procedimentos de segurança, gestão de qualidade e controle de níveis de serviço que utilizaram frameworks ou componentes profissionais baseados em padrões de mercado. Os laboratórios educacionais ainda mais robustos se baseiam em um Remote Laboratory Management System (RLMS), um pacote de software empregado na criação do laboratório remoto e na geração das diversas funções que serão ofertadas aos administradores e usuários, tais como identificação e autenticação de usuários mediante técnicas como LDAP ou OpenID, auditoria, agendamento para uso dos recursos, ferramentas para administração do laboratório, recursos para integração do laboratório com sistemas administrativos (Moodle etc.) e assim por diante (ORDUÑA, 2013).

As diferenças entre os diversos RLMS e respectivas arquiteturas impõem aos pesquisadores buscar padrões para uniformizar interfaces e formas de comunicação. 
Os autores (LYAMIN; EFIMCHIK, 2012) propuseram um protocolo específico para controlar laboratórios remotos, denominado Remote Laboratory Control Protocol (RLPC), cujo modelo básico chegou a inspirar o draft de norma específica do Internet Engineering Task Force (EFIMCHICK; LYAMIN, 2013), sendo que o projeto original dos autores engloba a proposta de arquiteturas para o laboratório, ambiente servidor e ambientes cliente. O servidor gera tarefas de aprendizagem e meios de acesso para o usuário. O ambiente cliente proporciona interação com o servidor e a planta do laboratório e armazena os resultados dos testes. O fluxo de trabalho proposto pelos autores é reproduzido na Figura 1.

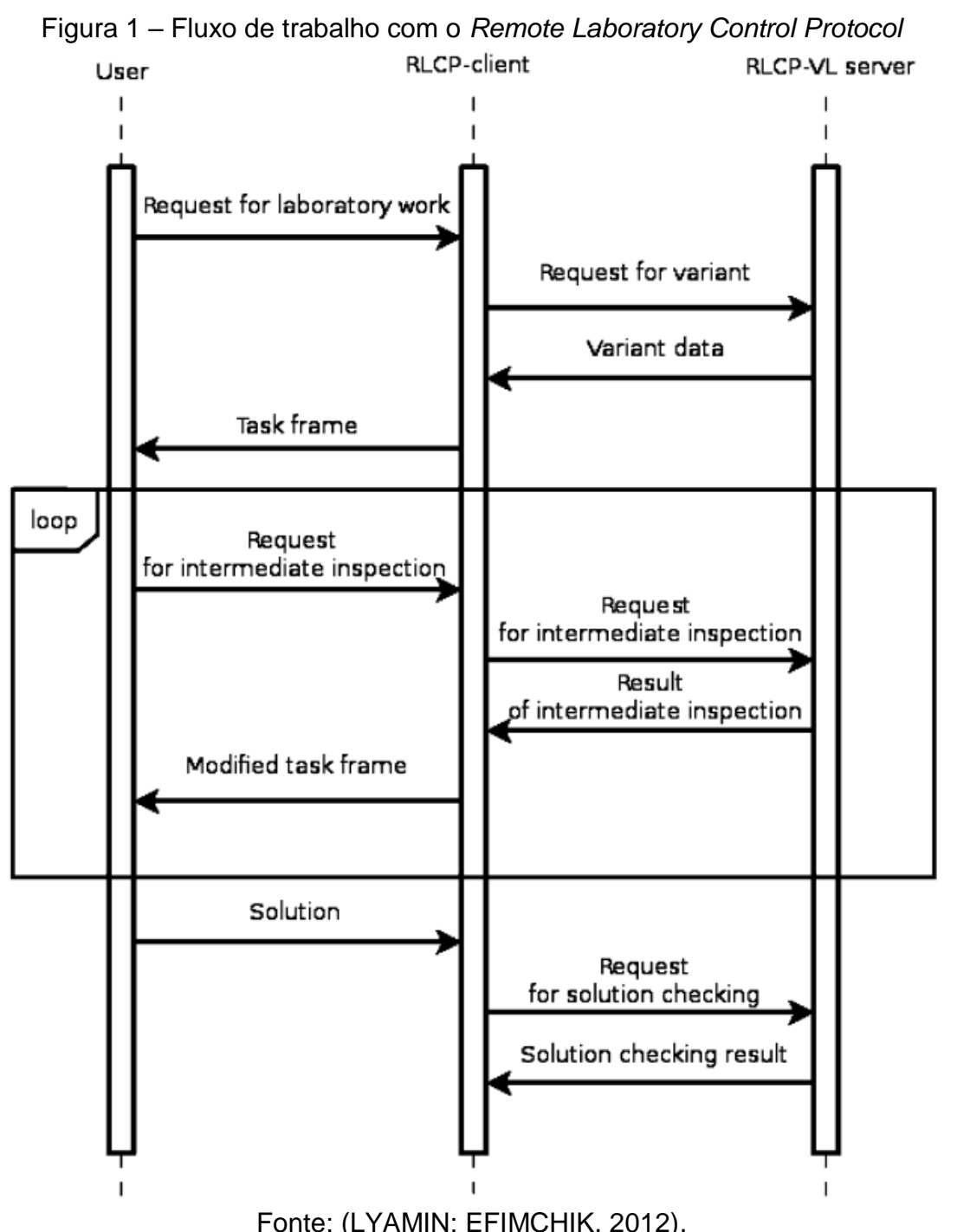

Assim, a comunicação entre o servidor e o ambiente cliente fica a cargo do protocolo RLPC propriamente dito, o qual define formatos das requisições e respostas para cada tipo de tarefa possível no laboratório remoto. Por exemplo, adota métodos como GENERATE para transmitir dados utilizados na construção da estrutura da tarefa, 
CALCULATE que transfere os resultados intermediários, e CHECK para transmitir a verificação dos dados de entrada e saída dos testes. Todas as requisições e respostas contém cabeçalho com o nome do método e respectivos dados, o corpo é apresentado como um documento XML e a sua estrutura é dependente do método. Há, ainda, um conjunto de operações para laboratórios remotos que possibilita construir dinamicamente as variáveis das tarefas do laboratório, criadas para cada usuário. Laboratórios remotos muito frequentemente utilizam o recurso de plug-ins para proporcionar independência de funções e facilidades na integração com outros ambientes.

Os laboratórios remotos devem possuir também função para identificação e autorização de usuários. Essa tarefa é realizada por sistemas que tratam e armazenam em bancos de dados os atributos dos usuários, para isso verifica-se quais mecanismos de autenticação estão disponíveis e então confirmam-se as credenciais do usuário em cada mecanismo. Os diversos sistemas de autenticação são consultados segundo hierarquias, podendo ser consultado apenas um ou então diversos mecanismo de autenticação, locais ou remotos, em função das políticas e configurações implementadas. São usuais mecanismos como bancos de dados para armazenamento de senha, lista endereços IPs e MACs confiáveis, LDAP, OpenID, OAuth, login do Facebook, biometria e outros (ORDUÑA, 2013).

A próxima função se destina ao agendamento do acesso dos usuários aos recursos do laboratório, basicamente por meio de consultas ou de reservas em calendário. Nesse procedimento é crítico o controle da disponibilidade de recursos, equipamentos físicos, suas instâncias acessíveis remotamente e experimentos realizáveis. Assim, ao agendar determinado exame, o sistema deve prever a disponibilidade e reserva dos recursos necessários. Deve prever, também, as providências para configuração inicial preparatória para o experimento e a restauração do ambiente após a sua conclusão, cuidando da preservação e limpeza dos dados por questões de segurança e deixando o ambiente pronto para novos usuários e experimentos. Entre as diversas políticas e regras de negócio, o sistema de agendamento pode prever questões relacionadas a possíveis prioridades de usuários, inclusive em função de urgência ou necessidade de alguma sincronia entre diferentes experimentos. Finalmente, 0 sistema deve prever as necessidades de manutenção preventiva ou corretiva e o provimento de suprimentos (ORDUÑA, 2013). 
Laboratórios remotos melhores estruturados possuem funções para tratar o fluxo de trabalho junto ao laboratório e, ainda, dar apoio à colaboração entre os usuários, atendendo requisitos de usabilidade, com interfaces simples e fáceis de usar. As normas técnicas definem usabilidade como uma medida da interação entre o usuário e um produto ou sistema enquanto executa tarefa específica, analisando eficácia e eficiência resultantes. Assim, a usabilidade em termos de qualidade de um sistema de trabalho deve considerar todas as influências do mundo real, incluindo fatores organizacionais como práticas de trabalho, localização e diferenças entre usuários. Assim, as questões de usabilidade abrangem os usuários, os equipamentos, as tarefas e os ambientes envolvidos (ABNT, 2002).

Os autores (LU; WANG, 2009) propuseram o desenvolvimento de um software de fluxo de trabalho virtual para a educação de operadores do Direito. Acessando remotamente um sistema de laboratório virtual, o estudante inicialmente toma contato e avalia o caso judicial e entra no departamento jurídico virtual. Em seguida, sempre virtualmente, seleciona o departamento de polícia, procurador, advogado, etc., analisa detalhes e vídeos sobre o caso e passa a responder questões, sob acompanhamento remoto do professor. O sistema remoto contempla diferentes fluxos de trabalho usuais no ambiente forense, adaptado no Quadro 1.

\begin{tabular}{|c|c|c|}
\hline \multirow{16}{*}{ judicial department } & \multirow{6}{*}{ procuratorate } & pertaining to crime trial court \\
\hline & & civil case trial court \\
\hline & & administration trial court \\
\hline & & execution court \\
\hline & & trial oversee court \\
\hline & & registered court \\
\hline & \multirow{2}{*}{ forensic } & pertaining to crime \\
\hline & & peace security \\
\hline & \multirow{7}{*}{ police department } & indictment explain examination section \\
\hline & & dereliction of duty and invade power \\
\hline & & against corruption and bribe administration \\
\hline & & scout oversee section \\
\hline & & take charge of examination section \\
\hline & & civil administration trial \\
\hline & & public prosecution section \\
\hline & lawyer business & pertaining to crime \\
\hline
\end{tabular}




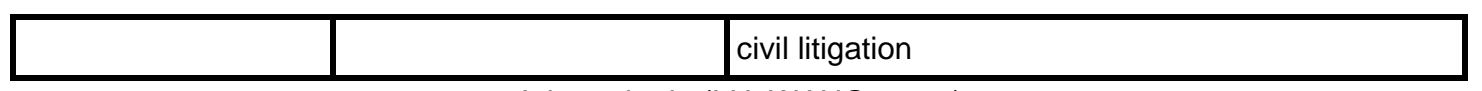

Adaptado de (LU; WANG, 2009)

Esse laboratório remoto de (LU; WANG, 2009) foi testado em duas universidades e segundo os autores atingiu o objetivo de treinar os estudantes a respeito das rotinas de um departamento jurídico. Os autores (LOSAVIO; KEELING; ELMAGHRABY, 2009) propuseram um modelo de triagem a ser adotado para atribuir mais adequadamente os casos aos peritos, propondo uma classificação simples como "básico", "intermediário" e "avançado" para classificar tanto o conhecimento dos investigadores forenses quanto o nível dos serviços e o nível de experiência requeridos nos serviços pericias forenses. Defendem que a adoção de método racional para alocação dos serviços de coleta das evidências digitais aos profissionais que tenham nível adequado pode ser uma maneira de aumentar a eficiência dos serviços forenses, do tempo empenhado pelos policiais e dos esforços dos promotores.

Como se viu, laboratórios remotos possuem facilidades para criar, implementar e realizar experimentos. Em linhas gerais, tais experimentos podem ser gerenciados ou não gerenciados, os primeiros são experimentos criados e executados sob a supervisão de administradores ou técnicos dos laboratórios, já naqueles não gerenciados o usuário pode criar e executar experimentos sem essa supervisão. Usualmente, os laboratório possuem frameworks com conjuntos de métodos à disposição do usuário para criar e realizar experimentos (ORDUÑA, 2013).

Mesmo se é menos relatado na literatura técnica, existe também o modelo segundo o qual um provedor adota um laboratório de terceiro em vez de montar seu próprio laboratório. Esse modelo ganha espaço com a existência de um mercado de distribuição de appliances de laboratórios remotos conhecidos comercialmente como FPGA, CPLD eMicrochip PICs e CoNeT Mobile Labs (ORDUÑA, 2013).

\subsection{LABORATÓRIOS WEB (WEBLABS)}

Laboratórios tradicionais são locais físicos destinados a análises, experiências, pesquisas, aplicações práticas e ensino dos conhecimentos científicos, tipicamente organizados como salas frequentadas por pesquisadores e estudantes e dotados de 
recursos materiais para tais atividades. As novas tecnologias da informação e das telecomunicações estão modificando a forma como se usam laboratórios, pois passam ser possíveis tanto o acesso à distância aos laboratórios físicos, quanto a simulação de laboratórios em ambientes totalmente virtuais. Nesse cenário, (CASINI; PRATTICHIZZO; VICINO, 2003) classificam os laboratórios em presenciais ou remotos e também em reais ou virtuais, conforme grade mostrada na Figura 2.

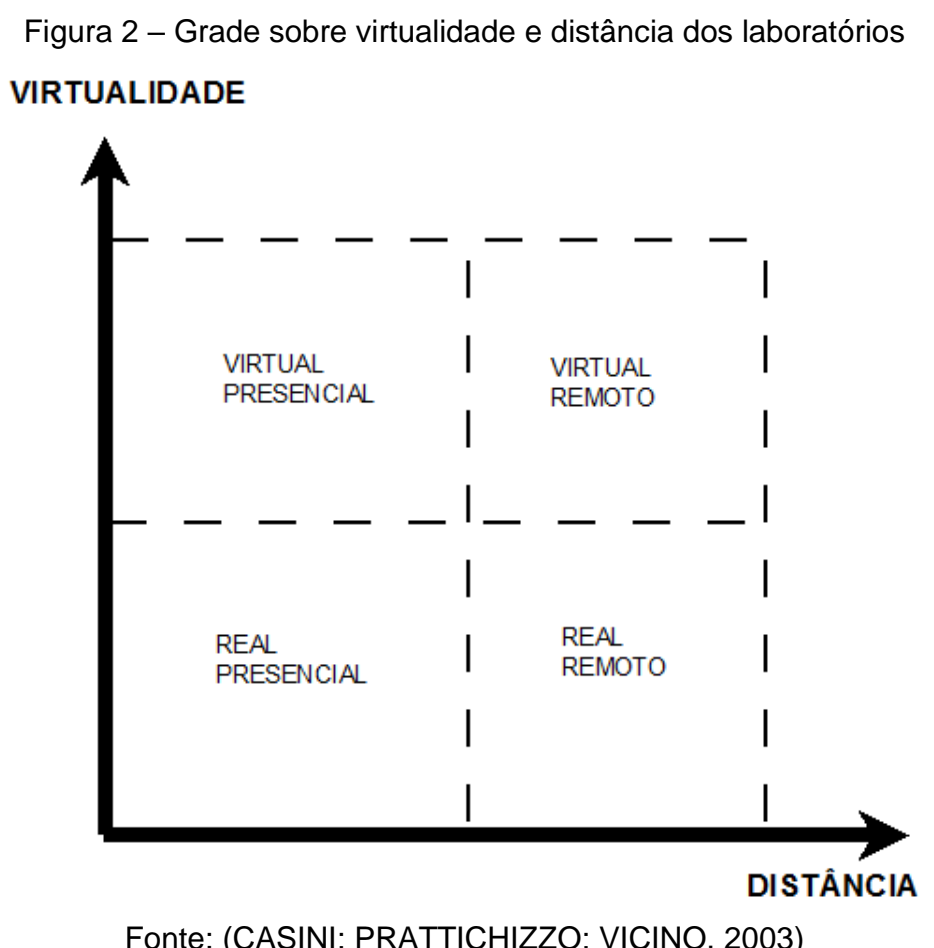

Fonte: (CASINI; PRATTICHIZZO; VICINO, 2003)

O autor do presente trabalho concorda com a classificação geral apresentada por (CASINI; PRATTICHIZZO; VICINO, 2003), mas discorda da expressão "laboratório real" em contraposição a "laboratório virtual", pois os laboratórios "virtuais" também são "reais", uma vez que recebem os mesmos dados, executam as mesmas funções e produzem os mesmos resultados, além do que objetos do mundo virtual, como uma conta corrente bancária, não podem ser considerados "irreais". Ao contrário, cada vez mais avatares, objetos e atividades virtuais se configuram como agentes reais de uma sociedade moderna. Por esse motivo, este autor prefere a denominação "laboratório físico" para indicar o local geográfico onde há equipamentos eletromecânicos físicos e, em contraposição, a expressão "laboratório virtual" para indicar um laboratório onde não há equipamentos físicos e seus equipamentos e experimentos existem apenas de maneira lógica via processamento por software. 
Mas além dos laboratórios físicos ou virtuais, a tecnologia proporcionou importante evolução que consiste na utilização remota via Web dos laboratórios físicos, modelo conhecido pela denominação WebLab. Assim, um laboratório físico contendo por exemplo osciloscópios, geradores de sinais e circuitos elétricos pode ser manipulado remotamente, de maneira individual ou colaborativa, por pesquisadores localizados em qualquer lugar do mundo. A literatura científica apresenta grande quantidade de experimentos com esse ambiente, mas até o momento as aplicações apresentadas são eminentemente fins educacionais e de treinamento.

\subsection{LABORATÓRIOS INTEROPERÁVEIS}

O aumento tanto da oferta quanto da demanda de laboratórios acessíveis remotamente faz crescer o interesse pelo compartilhamento desses laboratórios como meio para maximizar o aproveitamento dos seus recursos (KOSTULSKI; MURRAY, 2010), porém esse movimento ainda enfrenta dificuldades especialmente devido às diferenças de objetivos, funções e arquiteturas entre os laboratórios.

Os pesquisadores (YEUNG; LOWE; MURRAY, 2010) estudaram as diferenças de arquitetura existentes entre diversos laboratórios e concluíram que algumas características realmente representam fraquezas para a interoperabilidade, mas mesmo assim consideram que a diversidade deve mais ser encorajada do que evitada. Em seu estudo, investigaram mais detalhadamente duas arquiteturas específicas, o produto denominado Sahara, fornecido pela empresa Labshare ${ }^{5}$, e o produto denominado iLabs, desenvolvido pelo Massachusetts Institute of Technology (MIT) ${ }^{6}$. Essas soluções foram escolhidas para o estudo tanto pela sua maturidade como solução de mercado quanto pelo fato de apresentarem notórias diferenças entre si. Com base na análise, os autores mencionados propuseram um protocolo de comunicação capaz de para prover a interoperabilidade entre as suas plataformas.

Seus detalhes são de interesse para o presente estudo. A arquitetura Sahara deriva de um sistema de laboratório embrionário desenvolvido na University of Technology de Sidney, sua evolução proporcionou a interligação em escala nacional das

\footnotetext{
5 Veja http://www.labshare.edu.au

${ }^{6}$ Veja https://wikis.mit.edu/confluence/display/ILAB2/Home
} 
universidades australianas, ação viabilizada pela adoção de um núcleo comum para as diversas instituições e laboratórios. Em termos técnicos, adota interfaces API e recursos de portabilidade para diferentes sistemas operacionais mediante a adoção de ferramentas multi-plataforma como Java, Apache, PostgressSQL e PHP. Em evolução posterior a rede aderiu ao programa Labshare, proporcionando a diferentes instituições participantes do programa o compartilhamento mais amplo e seguro de equipamentos e processos por meio de uma arquitetura cliente-servidor e interface e comunicação via SOAP e extensible markup language (XML).

Já a arquitetura iLabs, do MIT, possui características que facilitam a criação e compartilhamento de laboratórios remotos, cabendo destacar suporte para Unicode, Single Sign On (SSO), funções para criação de "lab farm" e adição de novos componentes como "experiment manager" e "experiment engine". Adotou uma arquitetura baseada em componentes tipo service brokers com componentes distribuídos administrados de forma centralizada, interface baseada em SOAP e extensible markup language (XML) como forma de comunicação.

Logo, os autores mapearam as funcionalidades de ambos os produtos e apuraram que foram projetadas para satisfazer as necessidades particulares de seus respectivos criadores, respectivamente a University of Queensland e o MIT, resultando em diferentes objetivos, arquiteturas, terminologias, padrões de uso e até mesmo de terminologia.

Para integrar esses sistemas a despeito das suas diferenças, propuseram a criação de uma API (application programming interface) denominada LabConnector para tratar a interface de funcionalidades laboratoriais batch ou interativas. O LabConnector também resguarda as condições qualitativas em ambos os sistemas, como consistência, reusabilidade e disponibilidade. Para demonstrar o conceito dessa integração, um experimento sobre radioatividade mantido em iLab na University of Queensland foi conectado ao servidor Sahara da University of Technology, em Sidney, demonstrado sucesso na proposta de integração.

Foram realizadas pesquisas sobre integração também pelo Global Online Laboratory Consortium (GOLC), o grupo direcionou esforços no sentido de desenvolver uma norma sobre laboratórios remotos que foi intitulada Remote Laboratory Systems Interoperability Standard RFC. Sua última publicação ocorreu em 2011, como um draft, não tendo sido localizada evolução posterior efetiva dessa norma (GOLC, 2011), 
mesmo assim seu estudo é de interesse para o presente trabalho. A RFC do GOLC considera que sistemas de laboratórios remotos habilitam o usuário a acessar equipamentos em laboratórios físicos ou virtuais a partir da Internet, porém considera que os benefícios serão plenamente alcançados somente se diferentes laboratórios remotos forem capazes de interoperar, assim sistemas de laboratório distintos devem poder compartilhar funções comuns de maneira tal que um cliente de um dos laboratórios deve conseguir acessar os serviços prestados pelos outros laboratórios.

Com relação aos perfis e às interações suportadas, (GOLC, 2011) sugere um conjunto representativo de casos de uso e de sequencias de interação que devem ser suportados por interfaces de laboratórios remotos, como Baseline Profile, Usage Monitoring Profile, Rig Pools e Lesson Access Profile. O Baseline Profile determina as funções necessárias para que o sistema consumidor remoto possa acessar as funções básicas, batch e interativas, ofertadas pelo provedor do sistema laboratorial remoto. O System Enquiry indica as interações necessárias para consultar as funções suportadas pelo laboratório remoto, incluindo perfis, versão da interface e níveis de serviço associados ao provedor ou a determinados equipamentos em particular. $O$ Lab Enquiry trata das interações necessárias para se consultar o estado de um conjunto específico de equipamentos ou de um experimento que foi realizado nesse conjunto de equipamentos. Para o Batch Lab, a norma define um conjunto de interações para suportar submissão, monitoramento e recuperação de resultados em lote, considerando duas principais variações, o uso de uma interface cliente fornecida pelo consumidor ou fornecida pelo provedor (GOLC, 2011). Para o Interactive Lab, a norma GOLC define um conjunto de interações que devem suportar a interação ao vivo com um laboratório, onde, de forma similar a um laboratório em lote, a interface de usuário pode ser fornecida pelo consumidor ou pelo provedor. A norma alerta para o risco de que no uso da interface fornecida pelo consumidor, a interação entre a interface de cliente e o sistema do provedor pode se tornar mais complexa e introduzir restrições de desempenho. A interação deve se dar essencialmente na forma de mensagens XML passadas desde a interface do consumidor para o sistema do provedor, com as respectivas respostas XML passadas em retorno. O formato dessas mensagens XML é específico para cada experimento e cabe a provedor de cada conjunto de equipamentos definir se deseja suportar essa forma de interação. (GOLC, 2011) 
A RFC do GOLC prevê ainda interações para negociação do acesso a equipamentos interativos específicos, ou seja, um determinado equipamento de um conjunto de equipamentos. Dois modos primários de acesso são suportados pelo provedor: por consulta onde cada usuário pode requerer um acesso que lhe será concedido quando o equipamento estiver disponível ou por agendamento para determinado momento. A norma prevê as mensagens relacionadas ao acesso aos aparelhos, verificando sua disponibilidade e realizando seu agendamento. No cenário em que há um agendamento, será averiguada a disponibilidade de um conjunto particular de equipamentos e em seguida realizado o agendamento. A norma proposta considera mecanismos de interface como REST, SOAP, JSON e outros. (GOLC, 2011)

\subsection{FEDERAÇÔES DE LABORATÓRIOS}

Em um ambiente acadêmico, os laboratórios de diversas universidades podem ser integrados entre si de maneira a formar uma federação de laboratórios, modelo que traz benefícios relevantes para a aprendizagem experiencial, pois cada aluno poderá acessar mais laboratórios de mesma natureza, terá acesso ao mesmo tempo a laboratórios que realizam exames distintos ou até mesmo complementares, e o custo total poderá ser reduzido pelo compartilhamento e pleno emprego dos recursos disponíveis em cada laboratório, entre outras vantagens (ORDUÑA, 2013).

Grande parte das universidades australianas de engenharia rumam no sentido do compartilhamento remoto de seus laboratórios e demonstram interesse em criar federações de laboratórios (YEUNG; LOWE; MURRAY, 2010) . A União Europeia alavancou há alguns anos projetos para a criação de federações de laboratórios remotos, como o projeto Global Online Science Labs for Inquiry Learning at School (Go-Lab) que interliga em uma federação grande quantidade de laboratórios remotos de ciências. Aos estudantes oferece a possibilidade de realizar experimentos científicos em laboratórios online. Aos professores oferece facilidades pedagógicas via interface web e a possibilidade de integrar os experimentos de laboratórios com o ambiente das salas de aula. Aos proprietários de laboratórios proporciona soluções de interfaces abertas para facilmente conectar seus laboratórios online, construir seus ambientes virtuais e compartilhá-los na federação Go-Lab de laboratórios online (NUCLIO, Portugal) e (GO-LAB, [s.d.]), 
Um modelo de federação pode evoluir com a adoção do modelo de transitividade, uma função que possibilita compartilhar novamente (recompartilhar) recursos já compartilhados a partir de outros laboratórios, como parte ou extensão dos contratos já existentes. A transitividade pode ser utilizada para vincular consumidores e provedores internos e externos, por exemplo, um laboratório em um país, de modo a compartilhar seu laboratório com uma universidade em outro país e esta, por sua vez, pode recompartilhar o laboratório com as escolas secundárias da sua região.

O uso em conjunto de funções como balanceamento de carga e de transitividade proporciona o desenvolvimento de arquiteturas mais amplas, com anéis de provedores que recompartilham com outras entidades os acessos de qualquer membro dos anéis, conforme Figura 3. Com a adoção da transitividade, há o natural aumento de latência no sistema, mas experimentos como o VISIR mostram que a latência não se demostrou excessiva (ORDUÑA, 2013).

Figura 3 - Balanceamento distribuído de carga com federação transitiva VISIR

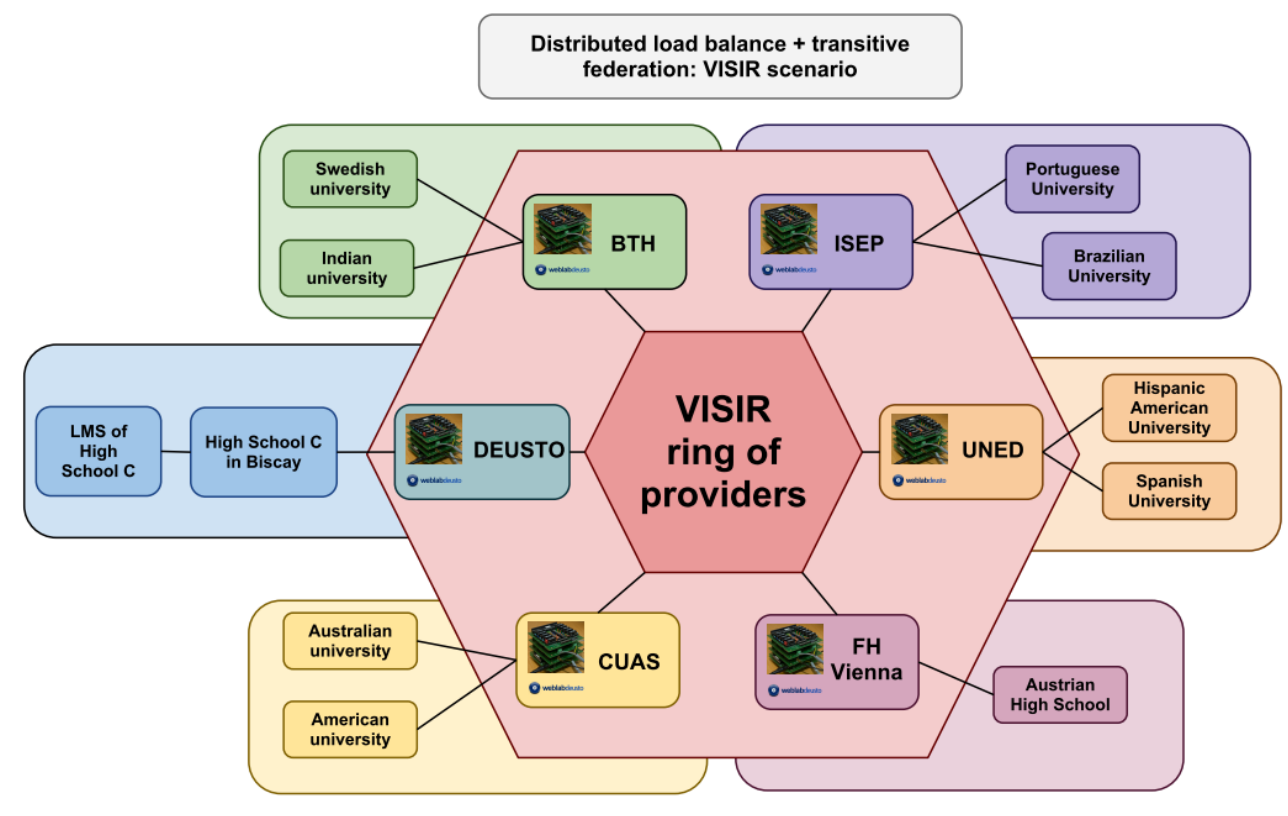

Fonte: (ORDUÑA, 2013)

Laboratórios acessíveis remotamente podem ter entre si grandes diferenças de finalidade e arquitetura, inclusive porque há uma grande possibilidade de variação em sua construção, diferenças essas que dificultam operação em conjunto de muitos laboratórios. Como consequência, o compartilhamento de laboratórios e experimentos entre instituições e países para criar federações depende tanto da definição de protocolos que possibilitem automatizar sua operação conjunta, assim como da implementação de sistemas para gerenciamento de laboratórios remotos (RLMS) 
compatíveis com o modelo de federação. O mesmo autor (ORDUÑA, 2013) propõe um modelo da federação escalável e transitivo baseado no modelo adotado no WebLab Deusto, conforme exemplo mostrado no diagrama de sequência de eventos da Figura 4.

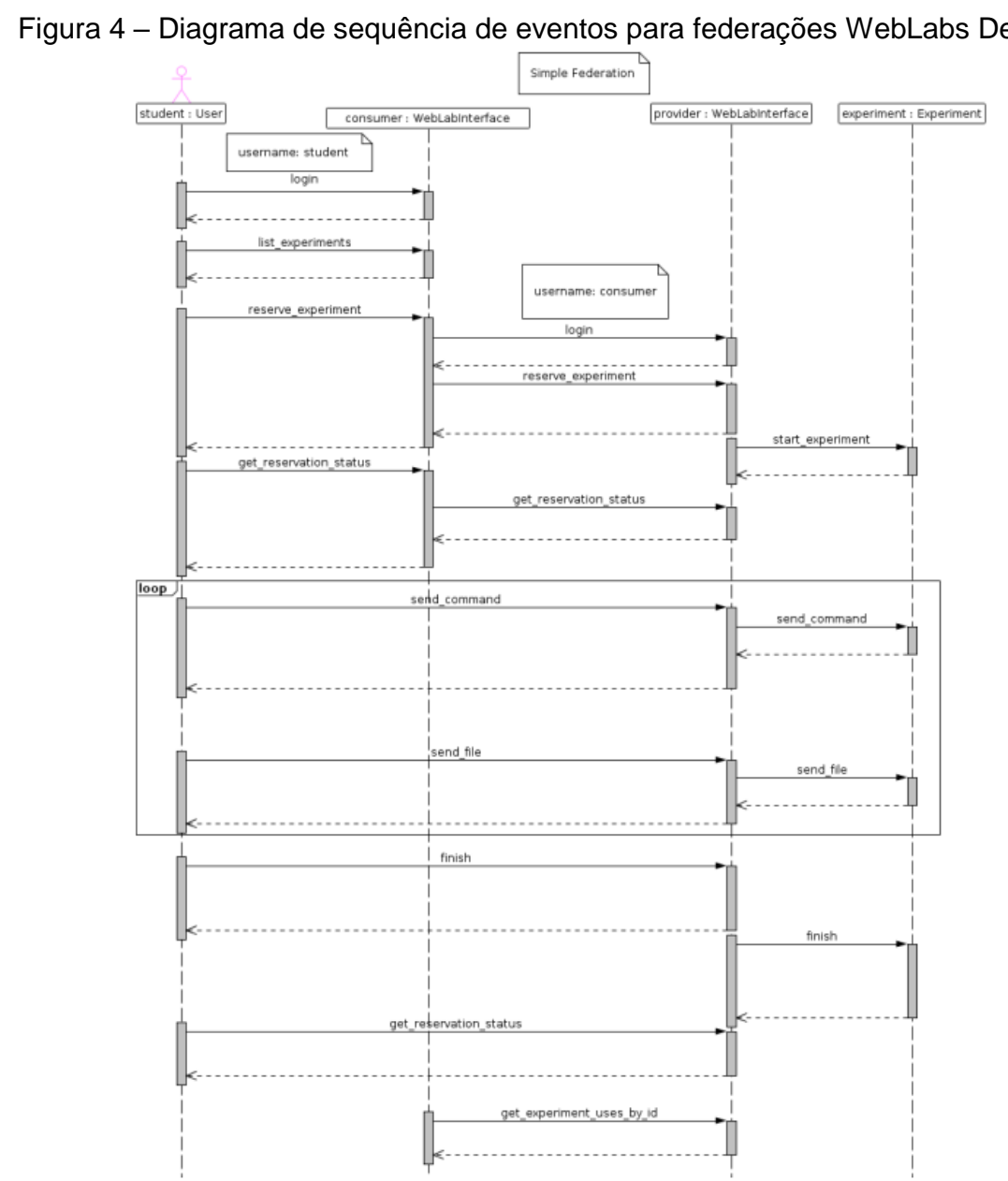

Fonte: (ORDUÑA, 2013)

Nesse modelo de federação as entidades externas são tratadas como estudantes regulares e cabe ao WebLab gerenciar internamente os recursos. As infraestruturas de federação e de agendamento são plug-ins que possibilitam a coexistência de diversas implementações, tendo sido adotadas para a federação plataformas em SQLlite/MySQL e em Linux/Redix. O sistema proposto por (ORDUÑA, 2013) prevê também a integração com seu respectivos Learning Management Systems (LMS) e Content Management Systems (CMS), sendo essa integração facilitada por haver foco em regras simples de prioridade e acesso e que buscam a reusabilidade para possibilitar a integração com sistemas de terceiros, como Moodle e Joomla. 
Uma das funções mais relevantes na federação de laboratórios é o balanceamento de carga (load balance) para redirecionar os usuários para slots disponíveis em outras instituições a partir de um controle centralizado. O balanceamento de carga na federação é relevante quando há diversos provedores de laboratórios similares, o que usualmente ocorre quando existem diversas implementações baseadas em uma mesma appliance, dentre as diversas ofertadas no mercado, como WebLab-Box, FPGA, CPLD, Microchips PICs, CoNeT Mobile Labs e VISIR (ORDUÑA, 2013).

Outro aspecto a considerar na montagem de uma federação é a utilização de recurso de plug-in. Seu uso em funções como balanceamento de carga ou agendamento, por exemplo, simplifica sua implementação entre os diversos laboratórios remotos. O sistema de agendamento é a base do modelo para federação de laboratórios remotos, os usuários passam a interagir por meio da federação com os sistemas de gestão dos diversos laboratórios remotos utilizando diferentes mecanismos de agendamento baseados em consultas sobre disponibilidade imediata ou sobre reservas com base em calendário.

A meta do sistema de agendamento nas federações é assegurar exclusividade de um conjunto de recursos para um conjunto de usuários. No contexto da federalização, o agendamento permite a reserva exclusiva de recursos em qualquer de laboratório de uma federação que abranja dois ou mais laboratórios remotos localizados em entidades distintas. Considerando que cada laboratório pode possuir sistemas próprios e diferentes para autenticação, autorização e monitoramento, a primeira missão do agendamento é verificar, criar e manter cadeias de confiança ao longo dos diversos sistemas. Mais ainda, é preciso notar que o agendamento em ambiente federado implica em alocação de recursos com exclusividade, por exemplo, o sistema provedor deverá assegurar exclusividade dos recursos àqueles usuários por um tempo determinado. O sistema consumidor, por sua vez, não deve possibilitar aos usuários o uso do laboratório fora do período que lhe foi estabelecido. Assim, sistemas provedores e consumidores deve operar com as mesmas interfaces de agendamento, dificuldade severa quando os laboratórios remotos utilizam diferentes sistemas de gestão, por isso, o modelo de federalização deve enfrentar as dificuldades de integrar diferentes sistemas de gestão (ORDUÑA, 2013).

Um modelo de federação possibilita o compartilhamento dos seus recursos e, mais ainda, um modelo de federação transitiva possibilita que entidades permitam a outras 
entidades o recompartilhamento dos seus recursos. Assim, cada entidade deve se encarregar dos recursos localizados na sua própria instituição, como também deve controlar como os seus recursos são compartilhados. Tipicamente, os contratos e acordos entre provedor e consumidor devem estabelecer os modelos de contabilização e cobrança, por exemplo por acesso ou por tempo, com ou sem limitação de acesso em função de pagamentos, e permitir a auditoria do consumo de recursos (ORDUÑA, 2013). Constata-se também a presença do conceito de consórcio, ainda em estágio inicial que visa em linhas gerais o crescimento sustentável dos laboratórios remotos (YEUNG; LOWE; MURRAY, 2010).

Nesses cenários, é visto o ecossistema de laboratórios remotos, onde surgem cada vez mais provedores e consumidores e, por isso, ganham importância os mecanismos federativos. Os novos modelos de federação tendem a reorganizar a oferta de laboratórios, gerando mercado de oferta e procura completamente novo baseado em descentralização, onde consumidores podem revender a outros os acessos a laboratórios e onde consumidores podem livremente escolher entre diferentes provedores do mesmo laboratório e mesmo consumi-los completamente, resulta tecnicamente factível suportar um volume significativo de novos consumidores. (ORDUÑA, 2013)

A federalização de laboratórios remotos impõe cuidados adicionais na avaliação e controle de riscos de compartilhamento. São considerados críticos a gestão de identidades, a gestão dos acessos permitidos a cada usuário e o controle das operações; A qualidade da gestão de identidades no sistema usualmente está baseada nas credenciais nome de usuário e senha, ambos dependentes da qualidade no provedor de identidades na entidade consumidora. Muitas vezes na prática essa gestão é atribuída à área de T.I. de cada laboratório, cabendo-lhe a responsabilidade de prover a autenticação do usuário e a geração de resposta ao provedor do compartilhamento do laboratório remoto. Assim, a federalização implica em avaliação das diversas estratégias possíveis de compartilhamento e seus respectivos riscos (ORDUÑA, 2013). 


\section{Materiais e Métodos}

Os fundamentos apresentados nos capítulos anteriores mostram ser adequado que 0 presente trabalho adote uma abordagem prática na busca de soluções para o descompasso existente entre a elevada demanda por perícias técnicas na área digital e a reduzida capacidade dos laboratórios forenses de realizá-las com prazos e qualidade adequados ou adequada

O presente capitulo detalha a pesquisa qualitativa realizada segundo a Soft System Methodology (SSM), apropriada neste contexto por envolver situações complexas com visões divergentes a respeito dos seus problemas. Dessa forma, se busca entender o funcionamento do sistema no mundo real, mapear as entidades que realizam atividades e são beneficiadas pelo sistema, conhecer as situações problemáticas, verificar como as principais transformações afetam os seus resultados frente às restrições do ambiente e, com isso, propor as mudanças necessárias frente aos problemas identificados.

\subsection{Sistemas no Mundo Real}

A interação entre o ambiente técnico-pericial e os tribunais está definida principalmente nos códigos dos processos penal, cível, do trabalho, militar e eleitoral. Quando visto em sua real dimensão, esse ambiente configura um sistema muito complexo e de grande escala, especialmente por se basear em atividades humanas onde há um elevado grau de liberdade em função da autonomia dos juízes, promotores, advogados e partes nos processos judiciais, além da sua operação ser regulada por interpretações a respeito de uma igualmente muito complexa estrutura de leis e normas. Os peritos, em particular, se submetem tanto a esse ambiente jurídico quanto às regras científicas e tecnológicas da sua área de conhecimento.

Em função dessa complexidade, para o presente trabalho foi escolhido o método SSM pelo qual nesta etapa o pesquisador procura observar o mundo real e entender o funcionamento dos sistemas que nele atuam. Para isso, presencia procedimentos, examina documentos, acompanha notícias e interage diretamente com pessoas envolvidas com os procedimentos típicos. Os principais resultados dessa etapa de observação do mundo real estão sumarizados a seguir. 


\subsubsection{As Perícias Técnicas}

Para efeito do presente trabalho, considera-se perícia técnica como a análise realizada por especialista legalmente habilitado com a finalidade de avaliar as peças submetidas a exame e esclarecer fatos de interesse do juiz e das partes em um processo judicial. $\mathrm{Na}$ esfera criminal, as peças a examinar usualmente são encaminhadas pelas autoridades policiais ou pelo juiz até um fórum ou laboratório mantido pelo estado, onde elas permanecerão custodiadas. Em algumas circunstâncias cabe à perícia deslocar-se para vistoriar e coletar vestígios em outro lugar, normalmente o local dos fatos ou local de crime, conduzindo em seguida os vestígios coletados até o laboratório pericial. Modalidade similar é a busca e apreensão, na qual a autoridade policial se desloca até um endereço determinado pelo juiz para ali localizar e coletar evidências de interesse do processo. Nessas atividades deve ser gerado um registro cronológico denominado cadeia de custódia, que descreve as características identificadoras de cada vestígio ao longo do seu ciclo de vida e registra toda e qualquer manipulação que tenha sofrido. Quando são coletados dados digitais, o principal elemento da cadeia de custódia é o seu código hash, que é o resultado do processamento desses dados por uma função homônima que os mapeia para um conjunto pequeno dados, geralmente com tamanho de 16 ou 20 bytes. Esse resumo matemático poderá então ser utilizado em qualquer momento posterior para atestar que o conjunto de dados permanece exatamente nas condições originais em que foi coletado. O mesmo método é utilizado para assegurar que uma cópia é idêntica ao material original. Assim, o material original ou sua cópia poderá ser então examinada pelos peritos utilizando ferramentas e métodos largamente aceitos e os resultados desse exame serão registrados em laudo pericial submetido ao juiz. É usual que essas peças continuem custodiadas até o final do processo judicial, mesmo depois de examinadas pelo perito.

Há diversas outras variações nos métodos utilizados para coletar e examinar evidências digitais. As interceptações telefônicas adotam procedimentos peculiares, pois os pedidos são feitos usualmente pela autoridade policial diretamente ao juiz e, caso deferidas, serão executadas pelas operadoras de telecomunicações e não por um funcionário público. Para isso, após receber e confirmar a determinação que o juiz Ihe encaminhou por ofício, a operadora de telecomunicação fará na sua rede o provisionamento dos recursos necessários para ativar a interceptação e com isso 
produzirá automaticamente uma cópia de conversas e dos dados que têm como origem ou destino o terminal interceptado. O material coletado na interceptação é então imediatamente transferido de maneira online para os sistemas da autoridade policial, onde são armazenados, analisados e reportados por meio de relatórios de investigação que depois são submetidos ao juiz. Mesmo se esse procedimento não é por si propriamente um trabalho pericial, na prática proporciona a coleta de uma grande quantidade de arquivos digitais que frequentemente são submetidos a pericias técnicas posteriores para verificar se não foram editados, para reconhecer falantes, transcrever os diálogos e identificar dados de georeferenciamento, entre outros exames.

Outro procedimento investigativo que gera dados periciáveis é realizado por meio do software policial denominado SpiaMule, ele é frequentemente utilizado pelas autoridades policiais para analisar conexões ponto-a-ponto (P2P) utilizadas pelos usuários de um aplicativo chamado Emule, com esse método a autoridade averigua se aquele usuário está compartilhando material ilícito via Internet. Assim, em um primeiro momento a autoridade policial consegue obter remotamente informações sobre quais computadores estão distribuindo fotografias ou vídeos ilícitos, mesmo se o programa de comunicação utilizado pelo infrator busca ocultar a origem dos dados. Em uma segunda etapa a autoridade realizará busca e apreensão no local, submetendo então o computador do infrator a um exame completo. Outros procedimentos são utilizados para coletar evidências de diversas origens, como tomógrafos, caixas pretas de aviões ou tornos automáticos no chão de fábrica.

Assim, em sentido mais amplo, as tarefas periciais e os laboratórios forenses são realizadas não apenas no interior dos prédios da polícia científica ou escritórios dos peritos judiciais. Em verdade, o laboratório pericial pode se estender ao exterior do prédio e para muito além, alcançando até os backbones dos sistemas de telecomunicações, transpoders de satélites artificiais em órbita e datacenters postos em qualquer lugar do mundo. Na esfera criminal, há acordos internacionais de cooperação (MALT) que visam inclusive a coleta de evidências em outros países.

Quando as perícias técnicas se destinarem a causas cíveis, como nas disputas envolvendo relações contratuais ou falhas em sistemas, os exames são realizados por universidades, por pesquisadores individuais ou por profissionais de mercado nomeados como peritos diretamente pelos juízes. Estes trabalham em casa ou em 
pequenos escritórios, e muitas vezes não possuem sequer um laboratório forense propriamente dito, dispõem apenas de alguns computadores e softwares básicos para trabalhos forenses. Além dos peritos judiciais deveriam participar desses trabalhos também os assistentes técnicos representantes das partes, com os objetivos de colaborar com os trabalhos e exerce o contraditório técnico, ou seja, fiscalizar a qualidade do trabalho realizado pelo perito para o juiz

\subsubsection{Os Laboratórios Forenses}

O termo laboratório vem do latim laboratorium com o significado original de local de trabalho, mas mais modernamente passou a indicar sala ou espaço físico destinado à realização de experimentos e pesquisas científicas, equipado com instrumentos de medida e recursos para a realização de ensaios.

A função de laboratório forense foi se introduzindo paulatinamente a partir dos trabalhos de patologia e depois evoluiu para as outras ciências. A prestação de serviços periciais forenses passou a demandar cada vez mais a utilização de ferramentas mais potentes e especializadas para coletar e analisar os mais diversos tipos de evidências, razão pela qual modernamente se considera que há estreita vinculação entre a prestação de serviços forenses e a existência de laboratórios destinados exclusivamente à realização de exames forenses.

Os principais laboratórios forenses são mantidos pelos órgãos de segurança e estão organizados sob denominações como polícia científica, institutos médico-legais e institutos de criminalística, entre outras. Atuam em áreas como medicina, engenharia, biologia, química, tecnologia da informação, contabilidade e documentoscopia. Usualmente são laboratórios de grande porte e estão equipados com ferramentas avançadas de análise.

Alguns ministérios públicos mantêm laboratórios mais reduzidos, usualmente focados em tecnologia da informação, telecomunicações e contabilidade visando atender as demandas das investigações que realizam.

Os países mantêm também organismos especializados em segurança nacional, mesmo se pouco divulgados, mantém estruturas mais sofisticadas para monitoramento, filtragem, coleta e análise de dados, emitindo relatórios de inteligência. 
Outros centros de pesquisa que também coletam e examinam evidências e emitem laudossão centros especializados como aqueles que tratam de pesquisas tecnológicas, metrologia, meio ambiente, saúde pública, identificação de pessoas e diversos outros. Esse grupo de laboratórios é mantido pelos estados ou por iniciativa privada, geralmente afeitos a universidades.

Os peritos que atuam como pessoa física, portanto nomeados pelos juízes, mantém pequenos laboratórios, instalados em escritórios ou até mesmo em suas residências. Coletam dados, realizam exames e emites laudos muito utilizados especialmente na esfera cível.

Há ainda muitos laboratórios mantidos por empresas privadas para prestar serviços de analise forense ou mesmo para uso interno, neste caso chamados de forense corporativa. Na medida em que cresce a utilização dos sistemas eletrônicos nas empresas, aumenta também sua exposição às vulnerabilidades internas ou externas, por isso lhes cabe adotar razoáveis sistemas de proteção para proteger tanto seus próprios interesses, como também aqueles dos seu clientes, inclusive com a contratação de profissionais ou serviços especializados e preparados para entender os crimes, coletar evidências e emitir pareceres técnicos para colaborar com as autoridades (FRANCIA; CLINTON, 2005). Ainda na área corporativa, praticamente todas as maiores empresas do mundo adotam sistemas de e-Discovery, que na prática são grandes laboratórios corporativos que monitoram o fluxo de dados em busca de padrões suspeitos, para depois colecioná-los como evidências em análise de compliance ou em processos judiciais, sendo que o sistema de e-Discovery de uma multinacional pode chegar a monitorar e coletar dados em todo o mundo.

Como se verificou, há uma grande quantidade de laboratórios que realizam exames técnicos e emitem laudos, os quais, ao final, acabam sendo utilizados em processos judiciais. Como resultado dessa análise, se verifica que grande parte desses laboratórios é de interesse para as decisões judiciais, nas esferas penal ou cível. Mais ainda, os laboratórios de fato não estão confinados pelas paredes dos prédios onde estão instalados, tendo-se em vista que a mobilidade de peritos e dos equipamentos possibilita seu deslocamento pela cidade, pelo estado ou por todo o país, adicionalmente a massiva adoção de sistemas eletrônicos faz com que de fato um laboratório forense possa estar em qualquer lugar. 


\subsubsection{A Produção de Provas nos Tribunais}

O termo "comarca" vem do latim commarca e do germânico mark, originalmente define um território limítrofe ou região fronteiriça. No Brasil, esse termo foi adotado no âmbito jurídico para designar os limites territoriais de competência de um determinado juiz de primeira instância, ou seja, a região geográfica onde cada juiz exerce sua jurisdição.

Os limites da comarca geralmente coincidem com o município, mas algumas comarcas englobam vários pequenos municípios em obediência à norma pela qual devem atender a pelo menos quinze mil habitantes ou oito mil eleitores, processar mais de duzentos feitos judiciais por ano e estar em região com receitas municipais superiores a três mil salários mínimos. Tais critérios levam à ordem de grandeza de aproximadamente três mil comarcas para cerca de seis mil municípios. (SILVA; CASTRO, 2013).

A comarca pode ter uma ou mais varas judiciais, sendo que cada vara corresponde ao posto de um juiz com atribuições determinadas pela organização judiciária. Usualmente uma comarca pode ter diversas varas, como criminais, fazenda pública, eleitorais, cíveis, do trabalho, de família, de infância e juventude e juizados especiais, entre outras. Assim, a competência da vara é aderente à especialização do juiz e ele julga os processos segundo o seu livre convencimento motivado e a persuasão racional. Porém, quando estão envolvidas questões técnicas, os juízes devem determinar a realização de perícia técnica a ser realizada por perito de sua confiança, considerado como seu auxiliar direto. Na prática o juiz adota procedimentos distintos em função da matéria jurídica. Quando se trata de um processo criminal o juiz encaminha o pedido de perícia a um instituto federal ou estadual de criminalística onde será atribuído a dois peritos oficiais, funcionários públicos de carreira; já em processos cíveis ele nomeia para cada processo específico algum especialista de sua confiança que recebe a designação de perito judicial, mais modernamente o juiz cível passou a poder atribuir a tarefa pericial também a algum órgão público ou empresa privada ${ }^{7}$.

\footnotetext{
7 A respeito das diferenças entre peritos oficiais e judiciais, cabe notar que os peritos oficiais são funcionários públicos, geralmente policiais, e por isso têm o crédito da presunção de veracidade em suas declarações, o que não se aplica aos peritos judiciais por exercerem atividades de natureza e interesse privados. Já a fé pública é um crédito ainda mais amplo atribuído a escrivães de polícia e a oficiais de justiça que faz com que as suas declarações sejam consideradas verdadeiras sem a necessidade de qualquer demonstração, motivo pelo qual são destacados para acompanhar vistorias realizadas por peritos oficiais ou judiciais.
} 
São frequentes perícias técnicas realizadas em áreas como medicina, engenharia, administração de empresas, contabilidade e muitas outras. Essa grande amplitude impõe limitar o presente estudo às perícias técnicas em engenharia eletrônica e ciência da computação, mesmo se não excluem aprioristicamente as perícias nas demais áreas porque progressivamente todas elas vão se tornando dependentes dos modernos sistemas eletrônicos, logo podem ser também objeto de perícia técnica multidisciplinar ora em estudo.

Quanto ao método, como se viu as perícias geralmente são realizadas em quatro fases principais: (i) planejamento das atividades pericias; (ii) vistoria no local para identificar, coletar e preservar vestígios; (iii) análise técnica do material coletado; e (iv) apresentação dos resultados ao juiz.

Vistorias ou diligências são descritas na legislação penal como atos pelos quais peritos inspecionam coisas ou locais para constatar situações e vestígios. Quando são encontrados equipamentos ou componentes eletrônicos de interesse, cabe ao perito decidir se fará a coleta dos dados diretamente naquele local ou se os equipamentos serão apreendidos e levados ao laboratório pericial para coleta posterior. Entre os fatores de decisão estão: (i) as ordens estabelecidas pelo juiz e as considerações do oficial de justiça que acompanha o feito; (ii) os riscos em cada alternativa de que vestígios possam ser indevidamente ou inadvertidamente inseridos, alterados ou perdidos; (iii) a janela de tempo disponível para coletar todos os dados durante a vistoria; (iv) a viabilidade técnica de coletar os dados no local da vistoria ou de apreender o equipamento e desloca-lo até o laboratório, fator crítico por exemplo quando o alvo for computadores de grande porte em um datacenter; (v) os riscos e prejuízos para as partes se o equipamento for desligado e apreendido, podendo inclusive parar as operações de toda uma empresa e seus fornecedores e clientes; e (vi) quais métodos periciais devem ser empregados nessas atividades.

Em função da grande quantidade de dados armazenados nos modernos dispositivos eletrônicos, o que torna praticamente inviáveis exames preliminares confiáveis, o método pericial forense recomenda que, por princípio, se faça a coleta integral de todos os dados existentes em dispositivos de memória que possam conter potenciais evidências. Devem ser coletados os arquivos ativos dos usuários do equipamento, assim como aqueles que foram sendo excluídos ou transformados ao longo do tempo e todos os arquivos do sistema operacional e dos sistemas aplicativos. Para isso, são 
produzidas cópias "bit-a-bit" de todo o conteúdo dos dispositivos de memória, gerando "clones", cópias "espelho" ou arquivos de "imagem forense", não sendo usualmente suficientes as cópias simples de dados como aquelas realizadas por usuários dos sistemas, porque apenas copiam arquivos ativos, perdendo-se os demais dados de interesse forense. A cópia "bit-a-bit" é realizada preferencialmente pelo método "passivo", isto é, o equipamento alvo permanece desligado e apenas seu dispositivo de memória é conectado a um computador forense, assim denominado porque protege o material original de qualquer contaminação, em atenção ao princípio de Edmond Locard8.

Em diversas circunstâncias, como na coleta de dados dos serviços em nuvem ou em smartphones, geralmente não é possível utilizar o método "passivo", porque os sistemas periféricos impedem o acesso direto à memória. Restam métodos alternativos que, de uma maneira ou de outra, contaminam a peça pericial. O mais comum é que a perícia transmita comandos ao sistema operacional ou a algum software aplicativo presente no alvo para forçar o fornecimento da maior quantidade possível de dados, esse é um método de exame ao "ao vivo" que certamente contamina a prova com rastos deixados pela perícia, sendo que posteriormente as partes no processo judicial podem tentar utilizá-los para desqualificar a prova pericial. Essa coleta "ao vivo" pode, a depender do tipo aparelho e das fermentas forenses à disposição do perito, ser realizada durante a vistoria, porém se ele se deparar com alguma proteção eficiente de privacidade, como criptografia e bloqueio ou autodestruição em caso de excesso de tentativas, precisará recorrer a métodos alternativos quase sempre inviáveis no local e prazo em que ocorre a vistoria.

No caso de smartphones, um dos métodos alternativos é o chamado chip-off, é um procedimento destrutivo no qual a memória é dessoldada da placa-mãe e inserida em um dispositivo de leitura e clonagem para gerar uma cópia forense do conteúdo mesmo que ele esteja criptografado. De posse dessa imagem o investigador pode então repetir infinitas tentativas de quebra da segurança porque quando ocorrer 0 autobloqueio ou mesmo a autodestruição, basta repor a imagem original e então conduzir nova série de tentativas de quebra da segurança até que se tenha sucesso.

\footnotetext{
${ }^{8}$ Edmon Locard, diretor do primeiro laboratório forense (França), expôs o princípio de que no contacto entre dois items ocorre uma permuta de materiais, deixando, portanto, algum um rasto.
} 
As considerações apresentadas até aqui ilustram os crescentes desafios que devem ser enfrentados e superados pelo poder judiciário em geral e pelos peritos em particular. Por exemplo, durante uma busca e apreensão realizada de surpresa com acompanhamento policial em uma empresa alvo de investigação. Frequentemente se encontra um ambiente tecnologicamente complexo, com características desconhecidas se não houver colaboração espontânea pelos investigados, e que não deve ser prejudicado em seu funcionamento por atividades periciais exploratórias. Ainda que a perícia não cause qualquer perturbação no ambiente tecnológico investigado, sempre há o risco de que por alguma coincidência ou por fraude processual se manifeste exatamente naquele momento alguma pane na empresa, logo a causa poderá ser injustamente atribuída ao perito. Mesmo sendo ele representante do juiz, são necessárias todas as cautelas técnicas e a geração de registros históricos que possam ser utilizados para comprovar os procedimentos realizados durante a vistoria.

Se por um lado o perito tem a obrigação de atender o pedido do juiz que manda identificar e preservar vestígios, por outro lado deve proteger o ambiente investigado, tal equilíbrio somente pode ser alcançado pela busca contínua dos melhores métodos e ferramentas periciais em engenharia e ciência da computação, tendo em vista a disseminação dos recursos para proteção da privacidade, o crescimento do volume de dados e o aumento na quantidade e diversidade de dispositivos utilizados por cada pessoa, família ou empresa. Nesse cenário, é necessário considerar:

a) A apreensão de um equipamento pode trazer severos danos ao usuário, pois ele ficará sem os seus computadores e possivelmente sem programas ${ }^{9}$ e dados neles contidos enquanto não for realizada a cópia forense e não for autorizada judicialmente a devolução do equipamento, situação que pode demorar apenas algumas horas ou demorar muitos anos em função de sobrecarga dos

\footnotetext{
${ }^{9}$ Por exemplo, quando a licenças de uso estiver atrelada ao equipamento, como ocorre em sistemas operacionais OEM e em alguns sistemas ERP.
} 
laboratórios forenses ${ }^{10}$ ou por questões processuais ${ }^{11}$. A apreensão desnecessária de equipamentos ou a escolha equivocada de procedimentos pode sujeitar o autor do processo ou os peritos nomeados a ter que responder por possíveis perdas e danos causados ao réu. Por exemplo, são claros os prejuízos que podem ser causados pela apreensão de computadores servidores em bancos, hospitais ou indústrias.

b) A apreensão dos equipamentos sem que seja deixada cópia forense com o réu pode dar margem a contestações das provas obtidas e a reclamações de cerceamento de defesa, pois o réu pode alegar que ficou sem saber detalhes dos dados apreendidos e, ainda, ficar impedido de confrontar o resultado da perícia com os dados que existiam na data da vistoria.

c) A coleta de potenciais evidências mediante cópia bit-a-bit no local da vistoria geralmente é o melhor procedimento técnico, porém isso é cada vez mais difícil por falta de perito habilitado a lidar com os modernos e complexos sistemas, pela falta de equipamento adequado ${ }^{12}$ e pelas crescentes dificuldades técnicas impostas pelos recursos de proteção de privacidade, chegando a inviabilizar a produção de provas em locais distantes dos grandes centros tecnológicos.

d) Os processos judiciais que tramitam nas milhares de comarcas distantes dos grandes centros universitários são os mais prejudicados, exatamente pela ausência de recursos imprescindíveis para produzir provas em sistemas de alta tecnologia, como laboratórios e profissionais qualificados. Paradoxalmente,

\footnotetext{
${ }^{10}$ A sobrecarga de muitos Institutos de Criminalística gera filas de espera de diversos anos até que os equipamentos apreendidos sejam examinados. Os delegados de polícia podem solicitar urgência em casos que envolvam crimes como sequestro e outros, como consequência casos com menor urgência permanecem na fila.

11 O Código de Processo Penal estabelece que os materiais apreendidos somente podem ser devolvidos ao réu com o fim do processo. No âmbito deste trabalho cabe comentar que alguns mandados determinam a apreensão de equipamentos, enquanto que outros a apreensão dos dados contidos nos equipamentos. Essa diferença pode ser relevante para que o juiz decida a respeito da devolução dos equipamentos aos proprietários antes do término do processo judicial, se o mandado determina a apreensão dos dados, o equipamento pode ser devolvido antecipadamente desde que exista clone ou imagem forense devidamente preservado, salvo melhor juízo.
}

12 A rapidez da evolução tecnológica provoca descompassos entre o nível de engenharia dos dispositivos eletrônicos alvo da coleta e os computadores forenses utilizados para coletar os dados. Um computador forense para coleta de dados em discos rígidos pode demorar anos para ser projetados, construído, homologado por órgãos como o NIST, nos Estados Unidos, e finalmente comercializado e utilizado por um perito para coletar os dados de um disco rígido. Ocorre que tal disco pode ter sido recém-fabricado com tecnologia inexistente quando o computador forense foi projetado e homologado, com isso os resultados do trabalho pericial podem ser imprevisíveis. 
nessas comarcas há grande utilização de dispositivos modernos e sofisticados que terminam por ser objeto de exames periciais para a produção de provas em processos judiciais.

e) A alternativa que resta é enviar os dispositivos da distante comarca até o grande centro para coleta e exames, se por um lado viabiliza-se a realização dos exames, em contrapartida esse procedimento pode violar direitos das partes e reduzir a fiscalização que obrigatoriamente deveria ser realizada sobre 0 trabalho pericial, especialmente se forem consideradas a volatilidade e 0 vertiginoso aumento na quantidade de dados que deveriam ser examinados pelo perito.

f) A realização de coletas e exames em local distante da comarca cerceia o acompanhamento e fiscalização dos trabalhos por delegado, juiz, promotor, advogados, assistentes técnicos e pelas próprias partes. Para que possam acompanhar os trabalhos ou realizar diligências conjuntas será necessário deslocamento e acesso físico de todos até o local de exame, situação agravada porque esses procedimentos podem demorar dias, meses ou mesmo anos, provocando grandes gastos com hospedagem e alimentação, além de prejuízos por distanciar as pessoas dos seus locais de trabalho. Caso não possam comparecer em comarcas distantes podem alegar cerceamento de defesa.

g) Pode haver questionamentos legais quanto ao deslocamento físico das evidências para fora da comarca de apreensão, sujeitando-as a custódia e procedimentos realizados em comarcas estranhas ao processo.

h) O deslocamento físico de peças originais apreendidas pode implicar em riscos para sua integridade física.

i) Devem ainda ser considerados os riscos relacionados a acidentes, falhas em equipamento, defeitos ou erros periciais que podem ocorrer durante a vistoria, coleta, transporte, armazenagem e exames; o que pode ocorrer no local da vistoria, no cartório da vara ou no laboratório pericial, podendo gerar imputações à perícia e aos autores do processo.

j) A intensa evolução tecnológica agrava essas questões na medida em que se disseminam os recursos para proteção da privacidade, impedindo o acesso das 
autoridades ao conteúdo das comunicações e dos sistemas que armazenam dados, aumenta a quantidade de dados a examinar, dados são transferidos para às vezes inalcançáveis serviços em nuvem e os dispositivos eletrônicos se tronam mais complexos e ubíquos.

Além das condições técnicas e jurídicas necessárias para a execução dos procedimentos, são imprescindíveis registros que assegurem o valor probante dos resultados obtidos. Vistoria e coleta somente poderão ser realizados com segurança e normalmente são considerados válidos se forem executados por profissional habilitado que tenha recebido os poderes necessários para realizar esses atos e que sejam realizados em estrita obediência às determinações judiciais. Especialmente se o perito não tiver fé pública ou créditos de presunção de verdade, será recomendável haver a supervisão por agente com os poderes necessários, como oficial de justiça, escrevente, delegado ou o próprio juiz. Mais ainda, é necessário e fortemente desejável que todos os atos periciais sejam acompanhados por testemunhas e por representantes das partes, na medida do possível e autorizado, e que sua participação, ativa ou passiva, seja devidamente registrada. Finalmente, e não menos importante, deve ser gerada a correspondente cadeia de custódia, pelo menos com o cálculo e registro formal do código hash dos dados coletados, o que a possibilitará verificações posteriores sobre a manutenção da integridade da prova.

Tais dificuldades se ampliam durante a realização dos exames técnicos e se propagam até a emissão do laudo pericial, sua apreciação pelo juízo e eventuais oitivas sobre os procedimentos e avalições periciais.

Nesse contexto, cabe averiguar se essas dificuldades técnicas têm sido adequadamente enfrentadas e superadas pelos órgãos públicos, como os Instituto de Criminalística, pelas entidades que prestam serviços periciais, como diversas universidades e laboratórios privados, e finalmente pelos especialistas que prestam serviços pessoais ao Poder Judiciário na qualidade de peritos nomeados.

Verifica-se em síntese que:

a) Os trabalhos periciais não têm sido produzidos em prazos compatíveis com o rito das demandas judiciais e com as necessidades dos autores e réus nos processos, provocando severos prejuízos às partes e à sociedade como um todo. Grande parte dos institutos oficiais de polícia científica acumulam muito 
trabalhos pendentes (backlog) que demoram anos até que possam ser atribuídos a algum funcionário para início dos exames periciais. Tal demora causa danos graves à parte que tem razão na demanda e beneficia indevidamente a parte que não tem razão. Muitas vezes tais prejuízos são irreparáveis, especialmente quando envolvem questões não financeiras ou porque a parte perdedora teve tempo para dilapidar ou ocultar patrimônio. Além disso, essa demora excessiva frequentemente inviabiliza a produção das provas devido a questões como falha ou extravio de equipamentos armazenados por longo tempo em depósitos ou perda da possibilidade de identificar o responsável por um endereço IP descoberto no exame tardio porque os provedores de conexão ou aplicação já não possuem mais os registros (logs) da época dos fatos, facilmente descoberto se a busca tivesse sido realizada mais celeremente. $O$ crescimento vertiginoso na capacidade, quantidade e complexidade de dispositivos eletrônicos tende a agravar rapidamente esses tipos de problemas, prejudicando a atuação do sistema judiciário e a sociedade como um todo porque se veem obrigados a abrir mão das essenciais provas técnicas. Verifica-se que há poucas pesquisas acadêmicas em busca de soluções mais eficazes e que aperfeiçoamentos trazidos pela indústria de ferramentas forenses não têm sido suficientes para fazer frente à demanda a despeito do seu custo bastante elevado, motivo pelo qual o tema é tratado neste trabalho visando propor novas soluções.

b) Os estudos acadêmicos mostram que se ruma para a inviabilidade de produzir provas periciais em sistemas eletrônicos em função de fatores como a ampla adoção de mecanismos para proteção da privacidade, especialmente com o uso generalizado de criptografia forte. Esse cenário gera intensas disputas entre as autoridades policiais e ministérios públicos, incumbidos de conduzir investigações prejudicadas pela impossibilidade de produzir provas, e os fabricantes de aplicativos divididos entre proteger a qualquer custo a privacidade dos seus usuários ou atender os pedidos das autoridades de deixar uma porta dos fundos, o que ao final pode redundar em vulnerabilidades. Não se constatam estudos efetivos em busca para esse problema, criando oportunidade para novas propostas como aquelas expostas neste trabalho.

c) Ainda nessa linha, constata-se importante descompasso entre métodos, ferramentas e competências periciais efetivamente disponíveis na maior parte 
das comarcas quando comparados com a elevada tecnologia aplicada nos dispositivos eletrônicos utilizado no dia-a-dia da população. Conforme já exposto, não se constata na academia e nos produtores de ferramentas forenses soluções em escala tal que efetivamente venham a reduzir ou pelo menos deter o crescimento desse descompasso tendo em vista o ritmo vertiginoso de adoção de novas tecnologias pela sociedade.

d) Grande parcela das dificuldades técnicas e falhas de procedimentos não têm sido resolvidos, como se constata nos resultados insuficientes submetidos ao poder judiciários e ao crescente backlog formado por perícias que não são realizadas em prazos compatíveis com o rito jurídico e as necessidades das partes.

e) As pesquisas indicam baixa coesão entre os resultados apresentados pelas perícias técnicas e sua utilização como fonte de decisão dos juízes. A escassez de pesquisas nessa área cria oportunidades para novas propostas.

Como se viu, esse cenário tende a se agravar rapidamente, por fatores como:

a) Aumento da quantidade e capacidade dos dispositivos digitais submetidos à perícia forense;

b) Dispositivos mais complexos e diversos entre si;

c) Aumento dos recursos de segurança e de proteção da privacidade, dificultando muito o exame pericial de sistemas eletrônicos digitais;

d) Pequena quantidade e baixa qualidade de laboratórios periciais próximos às comarcas judiciais;

e) Dificuldade em utilizar serviços nos poucos laboratórios bem equipados,

f) Escassez de profissionais preparados, deficiência em sua formação e atualização técnica;

g) Falta de padrões de qualidade e uniformidade nos procedimentos periciais, insuficientes para trazer segurança às decisões judiciais.

h) Dificuldade ou mesmo impossibilidade de que os operadores do Direito e a própria sociedade exerçam seu papel de fiscalização sobre a produção da prova pericial, questão bastante grave tendo em vista que a prova técnica é considerada uma das mais importantes; 
i) Severas consequências sociais, pois a sociedade presume que exames e as conclusões periciais são confiáveis e imparciais.

Os muitos fatores apontados neste capítulo geram a motivação e fundamentam a justificativa para a execução do presente trabalho, além dos profundos reflexos sociais uma vez que a ausência de soluções pode provocar a absolvição de culpados ou a condenação de inocentes, o que é muito pior. Em síntese, este capítulo descreveu os principais problemas identificados e relevância para a sociedade, cabendo considerar os indicadores de intenso agravamento no curto prazo. As análises apresentadas no restante deste trabalho avaliam os problemas e propõem soluções conceituais e práticas.

\subsubsection{A Tecnologia da Informação e a Produtividade Pericial}

Fatores administrativos como a escassez de laboratórios e fatores técnicos como a crescente complexidade dos dispositivos eletrônicos impõem a busca contínua por recursos laboratoriais cada vez mais eficientes.

A evolução tecnológica tem proporcionado o desenvolvimento de ferramentas forenses cada vez mais sofisticadas, todavia as estatísticas governamentais mostram que elas não têm sido suficientes para fazer frente à demanda. Os estudos sugerem que o perfil atual de evolução das ferramentas laboratoriais não conseguirá impedir o breve colapso da perícia forense em sistemas eletrônicos, fenômeno que está sendo chamado como "o fim da era de ouro da perícia forense" (GARFINKEL, 2010).

Esse cenário guarda relação com o paradoxo da produtividade dos investimentos em T.I., apontado por Robert Solow a partir dos seus estudos realizados em diversas áreas de aplicação, em apertada síntese mostram que não é possível atestar que investimentos em T. I. estejam contribuído efetivamente com a produtividade. (BRYNJOLFSSON, 1993).

Mesmo se não é escopo do presente trabalho estudar especificamente a produtividade dos laboratórios forenses ou averiguar se neles se constata o paradoxo da produtividade, cabe analisar as pesquisas existentes no mundo acadêmico sobre esses temas. Com esse objetivo, este autor buscou avaliar sob a óptica da cienciometria as publicações que relacionam a produtividade da TI com a atividade de 
computação forense ${ }^{13}$. Saravanan e Jaysekar utilizaram métodos da cienciometria para analisar as publicações globais sobre ciências forenses, produzindo um estudo mais focado na quantidade e impacto das citações. Partindo da palavra-chave "forensic science" realizaram pesquisas na base de dados SCOPUS, considerada a mais ampla base multidisciplinar do mundo, e os resultados para os autores mais produtivos foram confrontados com a base de dados do Google Scholar que demonstrou ter para a maior parte dos autores também a maior quantidade de obras. Em seguida, avaliaram o impacto dos autores (paper, citations, $h$-index, $g$-index, eindex) com base no software Publish or Perish. Concluíram que a literatura sobre ciências forenses dobrou em um período de dez anos e que o Laboratório do FBI está relacionado aos dez maiores autores acadêmicos, possivelmente devido aos elevados incentivos financeiros e status proporcionados pela agência (SARAVANAN, P; JEYASEKAR, 2014).

No presente estudo, para delimitar as áreas relacionadas à forense computacional foram utilizadas expressões "computer forensics" e "digital forensics", já para as áreas relacionadas à produtividade em T.I. foram escolhidas as expressões "productivity paradox" e "Solow paradox". A coleta de dados foi realizada na base de dados SCOPUS por ser a maior base internacional com dados multidisciplinares. Primeiramente foram realizadas buscas com as expressões "computer forensics" ou "digital forensics", obtendo-se 3.276 publicações, distribuídas ao longo do tempo conforme a Figura 5.

${ }_{13}$ Baseda nos trabalhos realizados no âmbito da disciplina PRO5805 - Planejamento e Gestão da Tecnologia da Informação, ministrada em nível de pós-graduação na Escola Politécnica da Universidade de São Paulo. 
Figura 5 - Publicações sobre computação forense

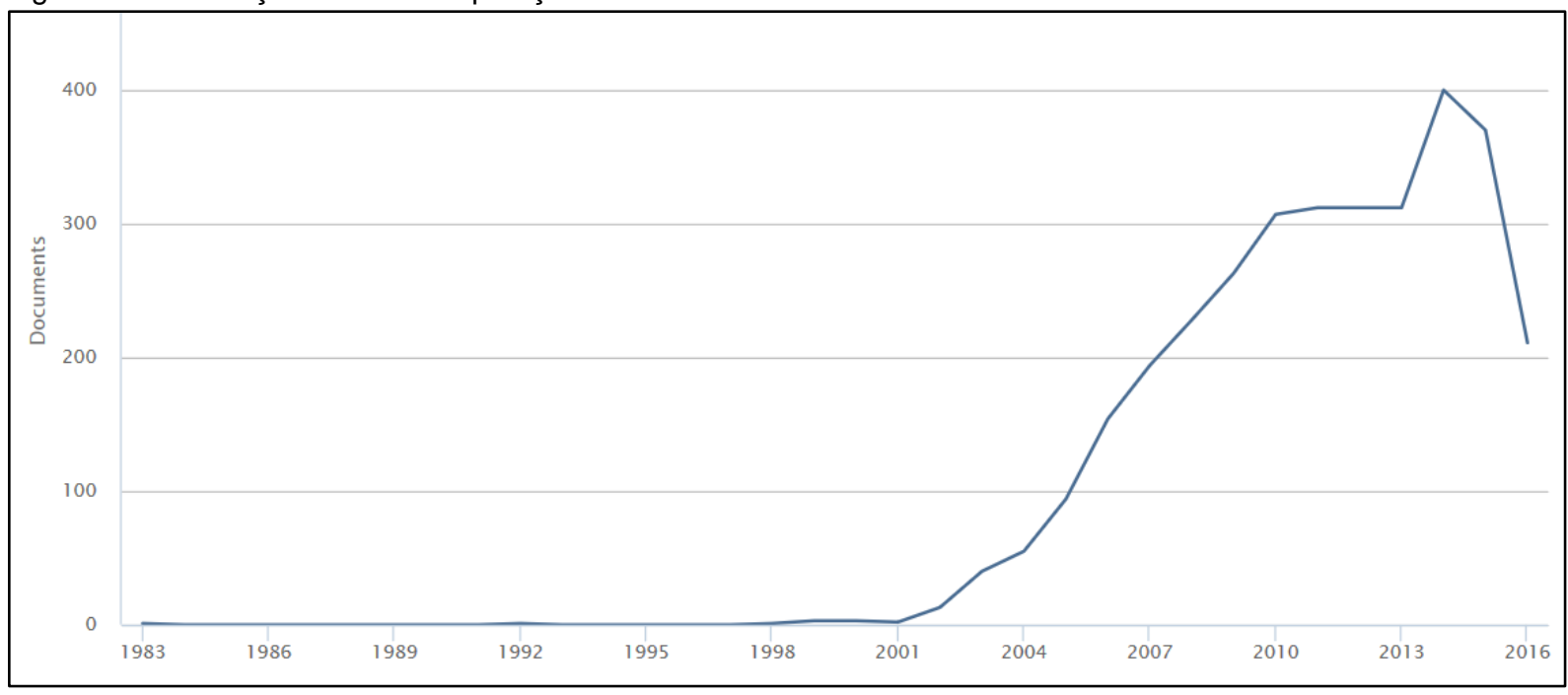

Fonte: SCOPUS

Pesquisando-se com os argumentos "(computer forensics OR digital forensics) AND productivity", são obtidos (10) resultado como mostra a Figura 6

Figura 6 - Publicações sobre produtividade

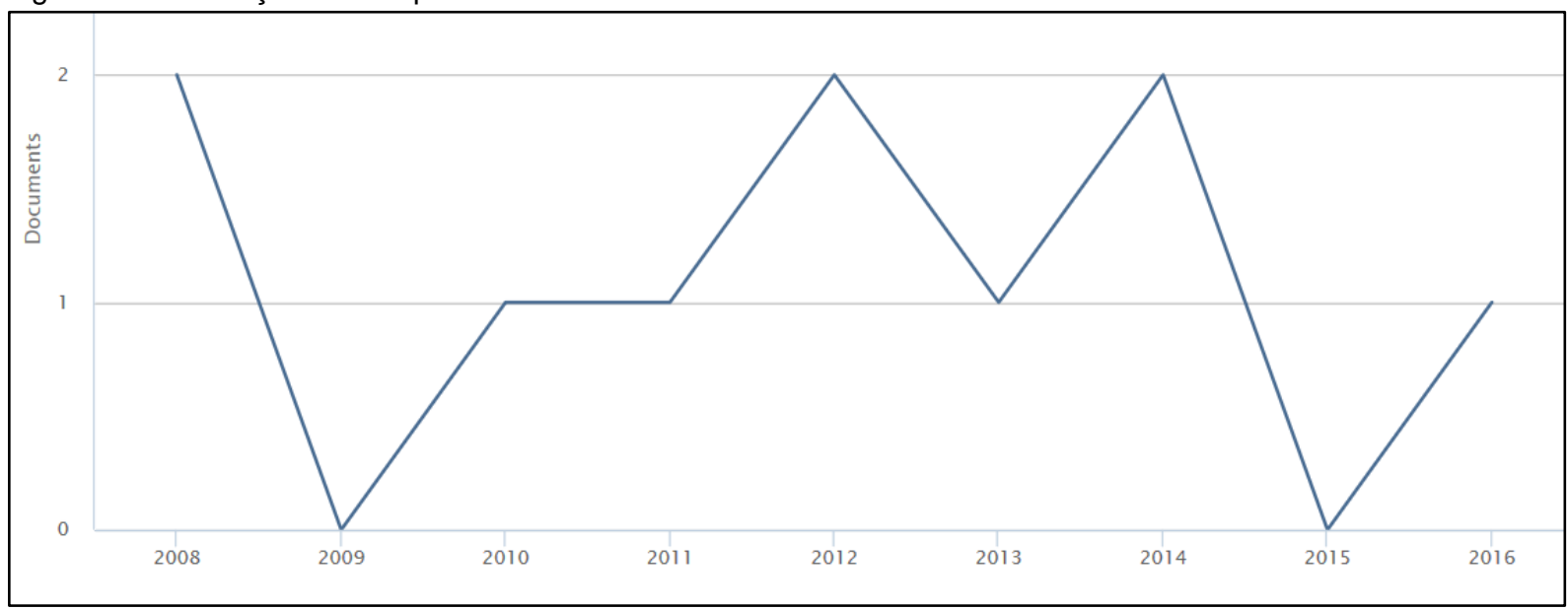

Fonte: SCOPUS

Entre as 10 publicações apontadas por Scopus como relacionadas a computação forense e produtividade, 3 delas propõem algum tipo de automação no processo forense, em síntese ferramentas para aquisição de dados em celulares, exame de sistemas operacionais e validação remota de licenças. A busca pelos mesmos argumentos no SCOPUS Patentes apresenta 30 ocorrências, sendo que aquelas relacionadas a produtividade forense se referem à utilização de clusters, adoção de RFID e detecção de código malicioso em imagens forenses.

A busca no SCOPUS pelos argumentos "(computer forensics OR digital forensics) AND (productivity paradox OR Solow paradox)" não é satisfeita por qualquer publicação. 
Figura 7 - Publicações o paradoxo da produtividade

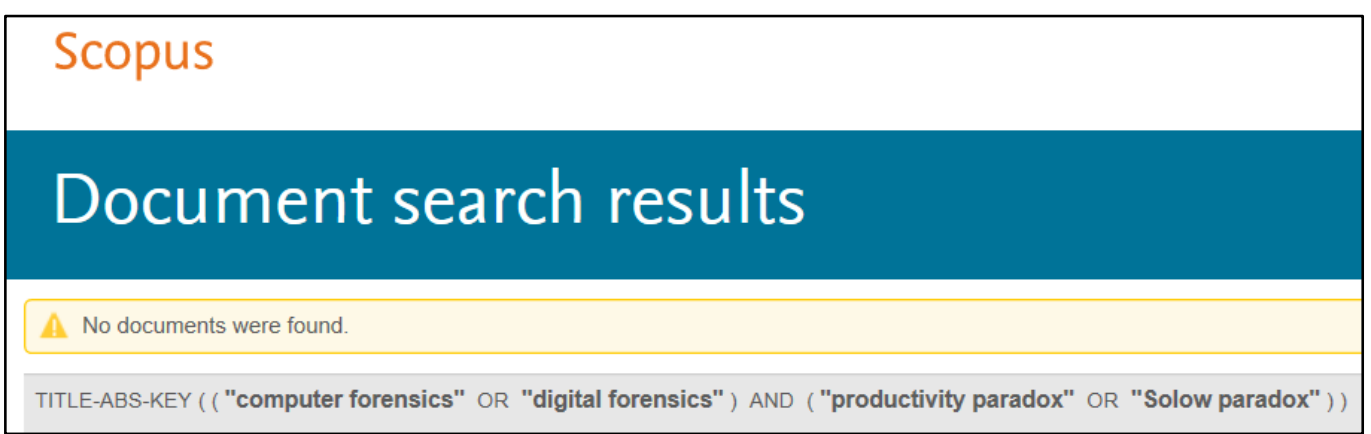

Os levantamentos realizados sugerem que não há estudos dirigidos sobre os efeitos dos investimentos em TI na produtividade dos serviços de computação forense, a despeito das pesquisas mencionadas neste capítulo indicarem que os laboratórios forenses voltados a sistemas eletrônicos não conseguirão atender à crescente demanda.

\subsection{Problemas Identificados}

A grande amplitude dos ambientes jurídico e técnico recomenda que a síntese dos problemas identificados no mundo real se baseia em uma representação gráfica bastante simplificada e complementada por descrição textual.

Assim, em síntese, o dia-a-dia dos problemas em exame pode ser demonstrado por meio dos pontos principais indicados a seguir.

- Comarcas distantes sem acesso à produção de provas técnicas

Como em todo o mundo, nas milhares de comarcas distantes dos grandes centros também cresce intensamente a disponibilidade de sofisticados dispositivos eletrônicos, por consequência, sua importância como origem de vestígios que podem esclarecer os fatos disputados nos tribunais. Em contraposição, não há nesses locais quantidade de especialistas e laboratórios equipados para examinar tais equipamentos sob o acompanhamento e vigilância das autoridades e dos representantes técnicos das partes. A alternativa seria remeter os equipamentos para vistoria em grande centro, porem esse procedimento torna impraticável o acompanhamento pelas partes, pois os exames podem demorar semanas ou meses, implicando em gastos expressivos com transporte, hotel, alimentação, ausência do trabalho, desguarnição dos filhos, fazendo com que as partes com menos posses 
abdiquem do seu direito de acompanhar os trabalhos e, por consequência, beneficiando a parte com maiores posses. Nesse cenário resta então a alternativa de manter a perícia na pequena comarca distante com isso possivelmente prejudicar sua qualidade pela falta de especialistas e laboratórios devidamente equipados.

- Demandas forenses não atendidas por carência de laboratórios pericias

Os estudos indicam estar havendo um aumento significativo na adoção de sistema eletrônicos sem o coerente aumento na sua capacidade de atendimento.

- Baixa qualidade e produtividade dos exames forenses

O descompasso entre a rápida evolução tecnológica e as limitações existentes nos laboratórios e peritos gera demora nos exames e erros periciais, com consequentes prejuízos ao poder judiciário e às partes, além de falhas nos julgamentos.

- Baixo valor probante por falhas nos exames e erros na cadeia de custódia A rápida evolução tecnológica e as limitações técnicas dos laboratórios e peritos provocam exames e laudos periciais incompletos ou até mesmo errados, anulando sua validade forense. Além disso, falhas na geração e manutenção da cadeia de custódia provoca redução do valor probante das evidências apresentadas ao juiz. Esses fatores comprometem o andamento dos processos, geram custos adicionais às partes e à sociedade e podem induzir erros nas decisões judiciais.

- Backlog incompatível com os prazos da justiça e as necessidades sociais A desorganização do processo e a inadequação dos recursos provocam filas de espera que podem durar até mais de 5 anos até que uma evidência digital seja examinada, situação que tende a se agravar devido ao aumento da complexidade dos novos dispositivos e sistema rapidamente adotados pela sociedade.

- Baixo aproveitamento das pesquisas científicas e tecnologias disponíveis

Os pesquisadores produzem estudos e soluções para enfrentar a crescente dificuldade pericial, contudo tais recursos geralmente estão disponíveis nos grandes centros, não sendo efetivos nos milhares de pequenas comarcas distantes desses centros.

- Ausência de propostas, diretrizes e ações efetivas para enfrentar o aumento e mudança de perfil da demanda por novas perícias 
O desastre já foi anunciado pelos pesquisadores ao indicar que as perícias técnicas se tornarão inviáveis frente ao aumento dos recursos para proteção da privacidade do usuário, mesmo assim neste trabalho não foram encontradas propostas que encarem o problema de frente.

- Ineficácia dos acordos de assistência legal mútua

Cada país possui suas próprias leis e estrutura judiciária, assim quando determinado país precisa que outro tome providências como quebrar sigilo de um suspeito ou providenciar alguma vistoria em seus computadores, por exemplo, é necessário recorrer a acordos internacionais. Conforme as pesquisas analisadas, conforme (CORTES, 2015), (HARFIELD, 2004) e outros, tais acordos não se mostram eficientes e muitas vezes chegam até a ser imprestáveis. Além disso, não se encontram nas pesquisas acadêmicas propostas de soluções efetivas para esse problema.

Além desses, o dia-a-dia dos procedimentos judiciais se defronta cada vez mais com disputas que envolvem complexas questões tecnológica, demandando para isso laboratórios e profissionais especializados que possam estar próximos, pois o perito é o homem de confiança do juiz para essas questões.

Dessa maneira, considera-se que os problemas apresentados têm abrangência nacional e até mesmo internacional, afetam intensamente a vida dos governos, empresas e pessoas envolvidas em disputas judiciais e para eles ainda não se têm solução efetiva e viável em prazos não excessivamente longos. Diante dessa envergadura de problemas, a presente pesquisa busca soluções mais amplas e cujos benefícios possam ser aproveitados em ritmo não muito diferente da adoção de novas tecnologias.

\subsection{Soluções Propostas}

O método adotado neste trabalho indica que, após identificar e mapear os problemas no mundo real, o pesquisador deve construir modelos que sejam inovadores no mundo sistêmico e, em seguida, identificar atividades do modelo conceitual que não acontecem no mundo real e atividades do mundo real que não estão representadas no modelo conceitual (SIMONETTE, 2010). Essas três etapas serão descritas em 
conjunto no presente capítulo, remetendo-se para capítulo subsequente a avaliação sobre a sua viabilidade no mundo real.

Nesse contexto, adotamos a perspectiva Customer, Actor, Transformation, World, Owner e Environment (CATOWE) como indicado a seguir:

- C - Customer - pessoas beneficiadas pelo sistema: a sociedade é a primeira beneficiada por ser a demandante do sistema judiciário e, portanto, do mecanismo de produção de provas técnicas que subsidia os julgamentos. Mais diretamente, são beneficiários o juiz, pelo auxílio na compreensão dos fatos, os delegados, promotores, advogados, peritos, assistentes técnicos e as próprias partes em processos judiciais.

- A - Actor - pessoas que realizam as atividades do sistema: em síntese, são os próprios beneficiários uma vez que todos eles têm ou deveriam ter participação ativa.

- T - Transformation - transformações ocorridas nas entradas que resultam nas saídas do sistema: Em síntese, o sistema transforma vestígios em provas judiciais destinadas a fomentar o livre convencimento motivado e a persuasão racional do juiz incumbido de julgar processos, além disso, o sistema também proporciona o contraditório técnico na medida em que os atores podem ser manifestar através do sistema para validar ou anular potenciais evidências que resultam da coleta e exame de vestígios.

- W - World View - imagem do mundo que torna esse sistema significativo: O sistema proporciona a substituição de métodos irracionais de julgamento pela persuasão racional e pelo convencimento fundamentado (motivado), base da atuação judicial em países democráticos.

- O - Owner - pessoa que pode abolir o sistema: O Estado, através dos seus Poderes, é a única entidade que pode abolir o sistema.

- E - Environment - restrições podem impedir o sistema de operar: a principal restrição que pode impedir ou prejudicar o funcionamento do sistema é o descompasso entre os recursos e métodos disponíveis para produzir provas periciais quando comparado aos recursos e métodos efetivamente necessários para examinar com sucesso as peças apresentadas à perícia, sendo que tal descompasso prejudica a apresentação das provas ao judiciário. 
Uma vez que a restrição apontada no indicador Environment consta entre os problemas identificados nas etapas anteriores de trabalho, cabe ao pesquisador apresentar modelos de solução e procurar responder as seguintes questões a sobre possíveis soluções (SIMONETTE, 2010):

- O que é necessário?

- Por que é necessário?

- Quem irá fazer isso?

- Quem será beneficiado?

- Quem será prejudicado?

- Que fatores externos restringem as atividades?

Essas questões estão descritas nos itens a seguir.

\subsubsection{Adotar Tecnologia WebLabs nos Laboratórios Forenses}

Como se viu nos capítulos anteriores, nos grandes centros econômicos e acadêmicos existem laboratórios dotados de recursos modernos e equipes capacitadas, porém mesmo assim não são suficientes para atender toda a demanda local, restando sempre uma parcela não atendida (backlog). Além disso, esses laboratórios maiores precisam também atender parte da demanda proveniente das comarcas do interior, o que é feito mediante deslocamento não só das peças a periciar, como também dos operadores do direito para que possam exercer o contraditório técnico e fiscalizar os trabalhos periciais cada vez mais complexos e realizados com dados altamente voláteis e manipuláveis.

Por questões como essas o backlog é muito superior ao que seria admissível diante dos prazos judiciais e da volatilidade dos sistemas eletrônicos, configurando importante desbalanceamento entre a crescente demanda por exames periciais e a insuficiente capacidade de realizá-los. Por esse motivo este autor propõe que o Poder Judiciário adote nos laboratórios públicos e recomende aos privados adotar a tecnologia WebLab, para que os peritos, assistentes técnicos e operadores do Direito em geral domiciliados nas pequenas comarcas passam utilizar remotamente os laboratórios forenses existentes nas grandes cidades (GIOVA, 2011a), atribuindo a esses órgãos a função de WebLab Forense. 
Os estudos realizados sugerem que não há um modelo único de WebLab Forense que deva ser utilizado por todos os laboratórios, bem ao contrário, cabe a cada laboratório escolher a arquitetura, funcionalidades e ferramentas que sejam mais adequadas aos seus objetivos, políticas e regras de atuação. O limite dessa liberdade está na necessidade de integração com outros laboratórios e ferramentas forenses. Em síntese, trata-se de adotar primeiramente ferramentas que propiciem a cada laboratório forense o aumento do grau de acessibilidade remota via Web, conforme indica a Figura 8, para isso se deve aumentar a acessibilidade remota tanto aos equipamentos físicos do laboratório quanto aos equipamentos virtuais, assim entendidos aqueles logicamente simulados por software.

Figura 8 - Grade proposta para virtualidade e presencialidade pericial forense

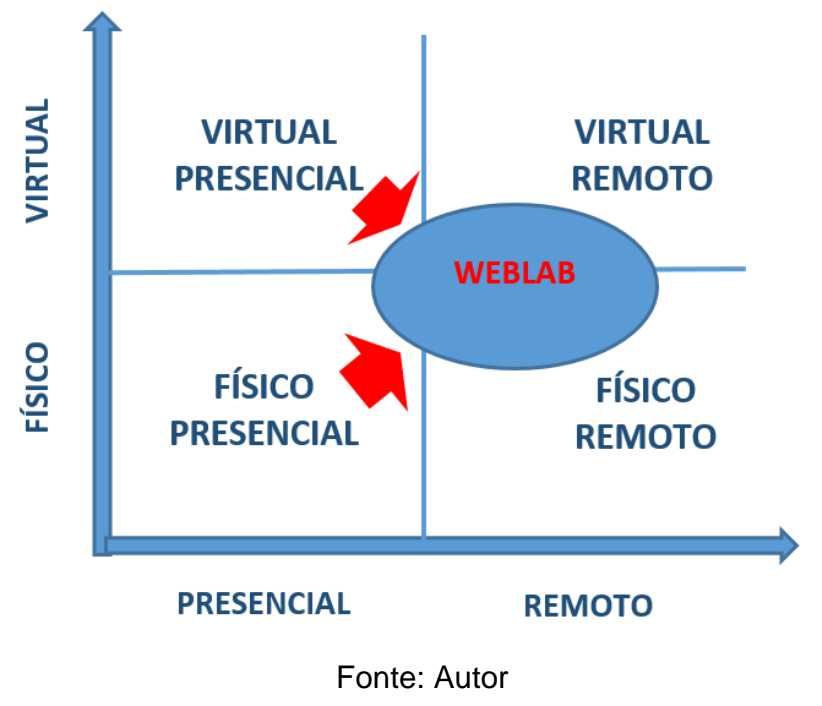

O próximo critério consiste em adotar no laboratório forense funções similares àquelas usuais em aplicações conhecidas como sandbox, termo já usual em tecnologia da informação para indicar um ambiente protegido onde são realizados exames de vírus ou testes de componentes de um sistema. Dessa maneira propõe-se que o WebLab Forense seja composto por diversos sandboxes isolados entre si, um para cada processo judicial, que possam ser manuseados remotamente e colaborativamente pelos operadores do Direito para neles realizar os exames necessários, agindo neles em conformidade com as normas legais, as determinações judiciais e os princípios periciais forenses, conforme ilustrado na Figura 9. 
Figura 9 - Sandbox no WebLab Forense

CONTROLEE CUSTÓDIA DE EVIDÊNCIAS

PROTEÇÃo TOTAL do AMBIENTE, ALARMANDO DESCONFORMIDADES

- VIGILÂNCIA, REGISTRO E AUDITORIA DETALHADAS (LOGS, VÍDEO, SENSORES): AMBIENTE, OPERAÇÖES, USUÁRIOS

- MEDIAR AÇÖES dos diVERSOS USUÁRIOSE SISTEMAS EM UM MESMO PROCESSO JUDICIAL, ASSEGURANDO ISONOMIAE TRANSPARÊNCIANO USO DO WEBLAB, RESPEITADAS AS DETERMINACŌES JUDICIAIS E CONDUÇÄO DOS TRABALHOS PELO PERITO

- REPOSITÓRIO dE MÉtODOS E FERRAMENTAS FORENSE
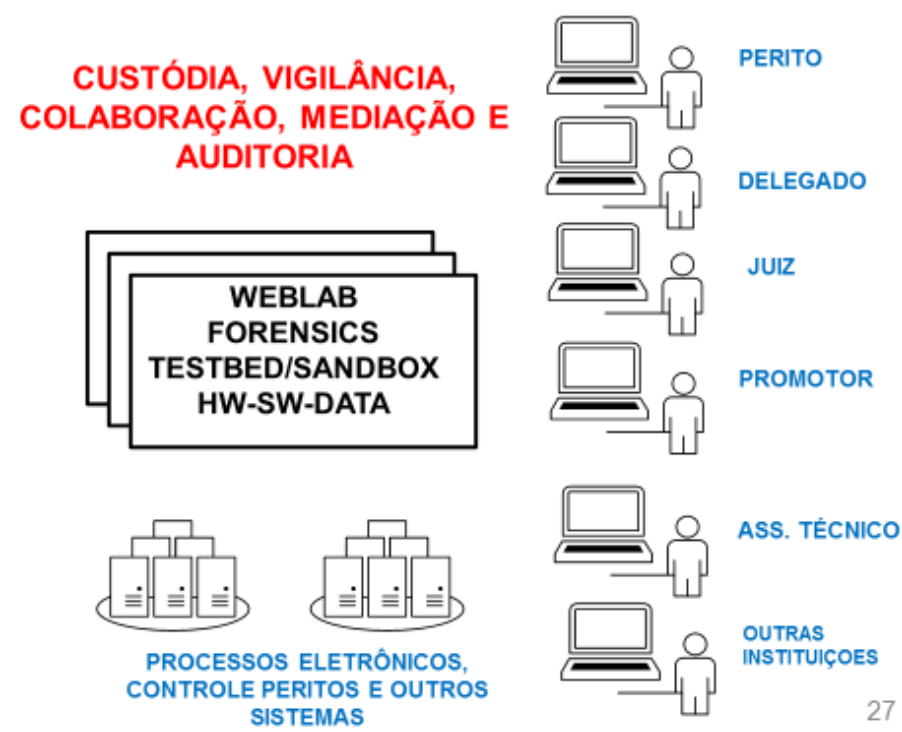

Fonte: Autor

Assim, os WebLabs Forenses conterão um leque de ferramentas à disposição para que os usuários possam com elas realizar os exames de forma mais rápida, eficiente e segura, por dispor de ambiente e ferramentas remotos já preparados e devidamente certificados. Os sandboxes deveráo prover também funções como custódia de evidências, vigilância severa sobre o ambiente e as evidências e ferramentas de auditoria e controle. Deverá prover ainda integração com os demais sistemas de interesse, como os sistemas de gestão dos processos jurídicos e os novos sistemas de cadastramento de peritos, mantidos pelo Poder Judiciário. Assim, cada sandbox deve ser um ambiente completo padrão para realizar trabalhos periciais colaborativos devidamente mediados pelo perito ou outras autoridades que participam remotatemente. Portanto, em síntese, entende-se que os WebLabs Forenses devem contemplar pelo menos as seguintes funções:

\begin{tabular}{|l|l|}
\hline Principais Funções & \multicolumn{1}{|c|}{ Descrição } \\
\hline Processos/Casos & $\begin{array}{l}\text { Gestão de processos judiciais e das tarefas periciais } \\
\text { (controles de processo, partes envolvidas, peças } \\
\text { submetidas à perícia, prazos, quesitos, etc.), na } \\
\text { dimensão que interessa aos trabalhos periciais. }\end{array}$ \\
\hline Usuários & $\begin{array}{l}\text { Gestão de usuários (direitos , permissões, } \\
\text { responsabilidades, etc.) }\end{array}$ \\
\hline Serviços & $\begin{array}{l}\text { Gestão e execução de serviços (cadeia de custódia, } \\
\text { coleta, armazenamento, exames, laudos, pareceres, } \\
\text { etc.) }\end{array}$ \\
\hline
\end{tabular}




\begin{tabular}{|l|l|}
\hline Recursos & $\begin{array}{l}\text { Gestão de recursos (alocação de recursos, controle de } \\
\text { qualidade, etc.) }\end{array}$ \\
\hline Administração & $\begin{array}{l}\text { Gestão do sistema (políticas, normas, planejamento, } \\
\text { autenticações, auditoria, segurança, manutenção etc.) }\end{array}$ \\
\hline
\end{tabular}

Quadro 2- Principais funções em um WebLab Forense

Propõe-se que os WebLabs Forenses adotem as funções e a arquitetura modular e escalável descrita nos capítulos a seguir (GIOVA, 2011a). Cumpre notar que o modelo proposto contempla a realização de procedimentos atribuídos pelas normas vigentes e por determinações judiciais diretamente aos peritos e assistentes técnicos, todavia o modelo proposto contempla também a utilização pelos demais operadores do Direito, sendo que nesse contexto podem vir a se aplicar questões pertinentes à Lei n. 11.419/2006, que dispõe sobre o processo judicial eletrônico, e em especial quanto à prática de atos sem a intervenção dos cartórios ou secretarias judiciais e à conservação dos Autos por meio eletrônico, entre outras questões relevantes no processo eletrônico (BALDAN, 2011)

\subsubsection{Arquitetura}

Um WebLab Forense se distingue dos WebLabs tradicionais especialmente pela necessidade de ser aderente aos rigorosos requisitos do ambiente forense, o que naturalmente implica na construção de uma arquitetura completa e confiável e que seja compatível com os demais sistemas que são próprios do Poder Judiciário. Deve também atender as características particulares dos seus usuários, que em síntese são: (i) administradores do sistema com responsabilidades relacionadas à integridade do ambiente, dos procedimentos e da custódia de evidências judiciais; (ii) peritos que gerenciam os trabalhos e realizam os exames; (iii) assistentes técnicos que participam ativamente dos exames; (iv) delegados e investigadores de polícia que podem participar ativamente dos exames; (v) juízes que requerem, determinam, fiscalizam e são destinatários últimos dos trabalhos; (vi) oficiais de justiça e escreventes; (vii) promotores; (viii) advogados; (ix) representantes das partes no processo. 
Figura 10 - Visão geral do WebLab Forense

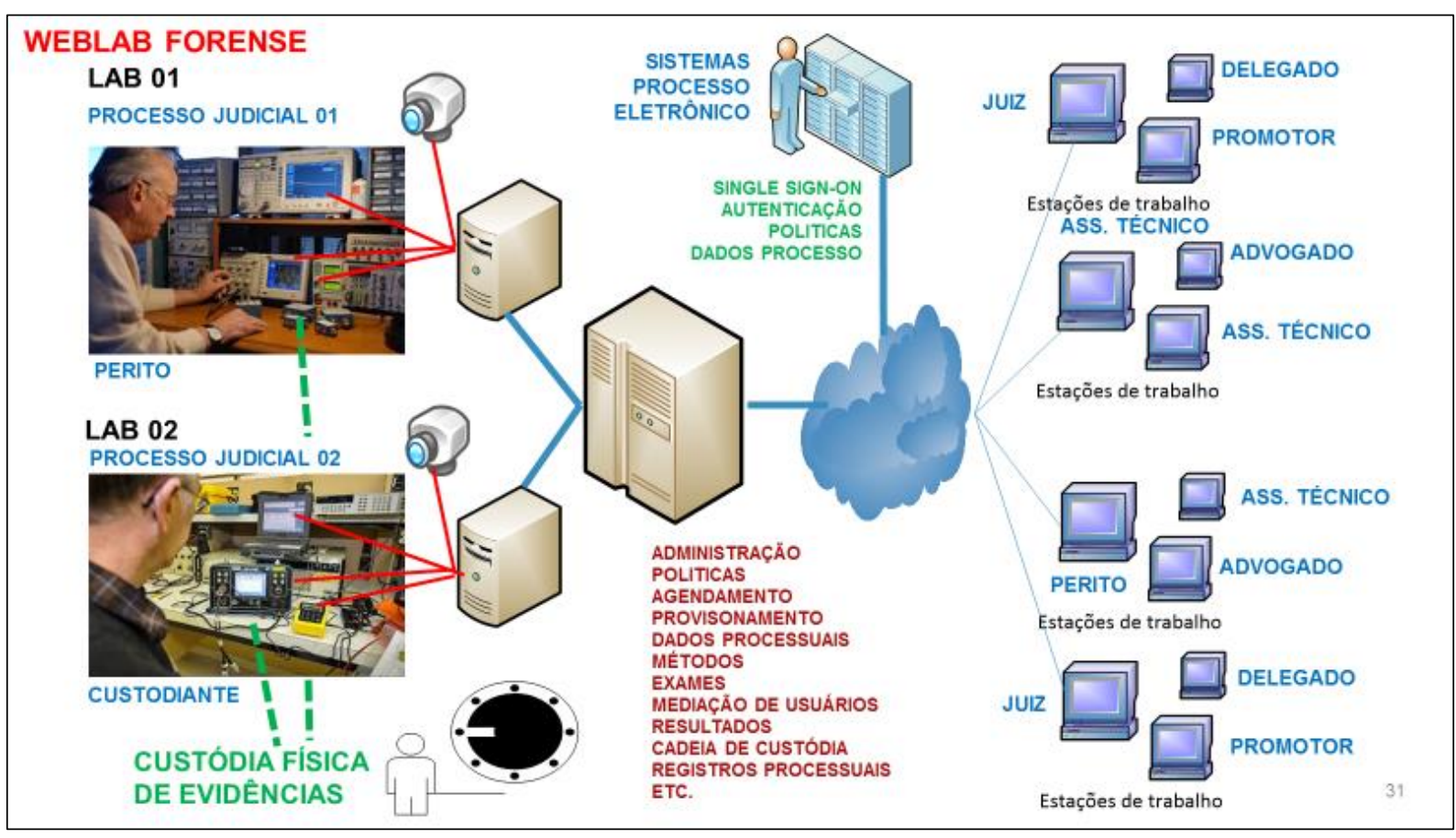

Fonte: Autor

Em especial, a função forense impõe estrita obediência às normas e determinações legais inclusive quanto à custódia física e lógica das evidências juntadas aos processos judiciais e que, por consequência, são submetidas à guarda do WebLab Forense, pelo menos em cópia. Abrange proteção contra modificações ou destruições inadvertidas ou indevidas, proteção contra violação do sigilo, proteção contra inserções indevidas ou inadvertidas de evidências, trilhas de auditoria, vistoria física ou lógica pelos interessados autorizados e certificações de qualidade para todo o ambiente. O sistema deve seguir estritamente as determinações legais gerais, as normas particulares de cada tribunal e as condições específicas definidas em cada processo judicial. Os usuários de um WebLab Forense devem poder acessar o sistema tanto localmente quanto remotamente, o que implica em adotar layouts físicos e lógicos apropriados para ambos os tipos de utilização, sendo que pode haver utilização mista e simultânea em um mesmo processo.

A grande diversidade de dispositivos eletrônicos a examinar impõe a utilização de métodos, ferramentas e meios de acesso igualmente muito diversos entre si, livremente selecionáveis pelos usuários, para cada caso, em função de variáveis como as determinações judiciais, as características de cada peça a examinar e as estratégia e métodos de análise mais apropriados em cada situação. 
Os exames que potencialmente podem ser realizados em cada laboratório devem ser classificados quanto aos seus requisitos, métodos e ferramentas, gerando casos de uso de maneira a mapear praticamente todo o seu espectro de aplicações possíveis nesse laboratório. Com base nos casos de uso devem então ser implementados frameworks padrão, pelo menos um para cada caso de uso. Assim, um determinado framework poderá ser utilizado para um ou mais WebLabs Forenses, gerando ganhos de escala, melhores condições de interoperabilidade e maior segurança para os laboratórios e seus usuários. O modelo genérico proposto é mostrado na Figura 11.

Figura 11 - Modelo genérico do WebLab proposto
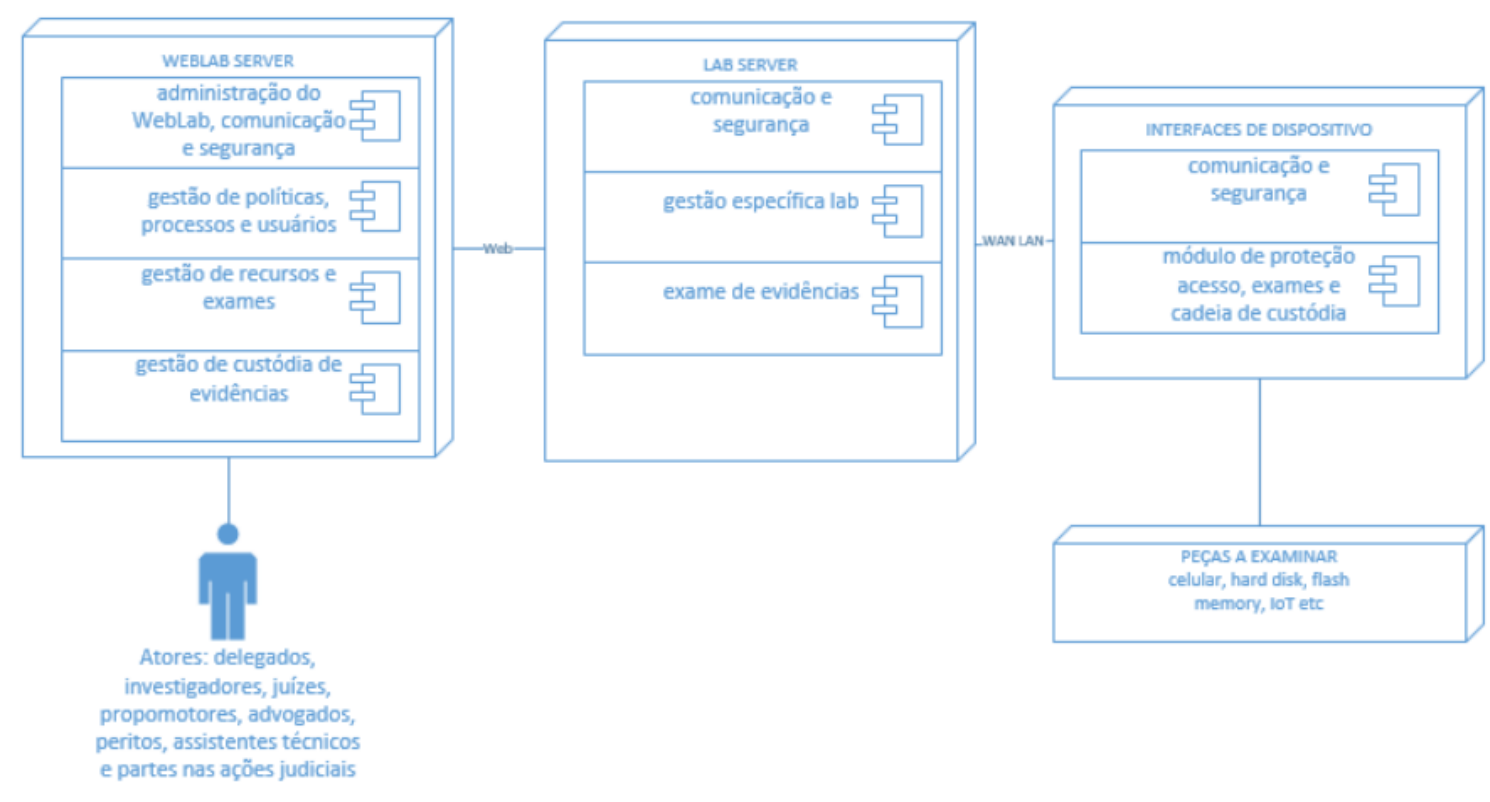

Fonte: Autor

Com a arquitetura proposta fica configurada para cada WebLab a existência de dois domínios principais: um domínio de serviços denominado WebLab Server e um domínio de gateway composto por um ou mais conjuntos de Lab Servers e Devices Controllers.

\subsubsection{WebLab Server}

O WebLab Server é o núcleo central de controle do WebLab Forense, tendo em síntese as funções:

(i) Administração geral do sistema;

(ii) Gestão de políticas, processos e usuários;

(iii) Gestão de recursos do sistema e contabilização; 
(iv) Gestão dos exames;

(v) Gestão da custódia de evidências;

(vi) Gestão dos resultados;

(vii) Auditoria; e

(viii) Gestão de qualidade, comunicações, storage, processamento, segurança etc.

Essas funções configuram em essência o Remote Laboratory Management System (RMLS) adaptado para o ambiente forense, contemplando itens em síntese como:

a) Identificação e autenticação dos usuários;

b) Autorização para utilização dos serviços disponíveis no WebLab;

c) Reserva, agendamento, provisionamento e contabilização dos recursos;

d) Fluxo de trabalho para os exames (regras de negócio, papéis dos usuários, processos etc.);

e) Coleta, custódia, proteção, devolução e destruição de evidências;

f) Preparação para exames e desinfecção pós-exames;

g) Controle de informações e apoio documental;

h) Administração do laboratório (políticas, manutenção, suprimentação, renovação, contabilização, segurança, regras de negócio do laboratório em si, controle de empréstimo e recompartilhamento, etc.)

i) Integração do laboratório com outros sistemas;

j) Planejamento, auditoria, certificação etc.

\subsubsection{Lab Server}

Para cada WebLab Server pode haver um ou mais Lab Servers, sendo esse componente responsável pelo gerenciamento local de cada conjunto de equipamentos de análise. Dessa maneira, poderá haver um Lab Server para exames em discos rígidos e outro para exames em telefones celulares, por exemplo.

\subsubsection{Device Controller}

Cada Lab Server poderá ter um ou mais Device Controller. Trata-se em síntese de uma interface especializada que possibilita a conexão e a execução de exames em um tipo específico de dispositivo digital a ser periciado. Essa solução é necessária em 
função da grande diversidade e mutabilidade dos aparelhos eletrônicos a examinar, dessa maneira, o conjunto de Devices Controllers de um WebLab Forense constitui um middleware responsável pela comunicação, acesso e interoperação com uma grande variedade de dispositivos heterogêneos. Por exemplo, deve haver um Device Controller específico para cada marca, modelo e versão de telefone celular a ser analisado, necessidade decorrente das características específicas de acesso, aproveitamento de vulnerabilidades ou de quebra de proteções para cada tipo de exemplar. Esse dispositivo pode ter um papel mais passivo enquanto apenas coletor de dados ou mais ativo quando for necessário interagir com o dispositivo em exame.

Considera-se que esse middleware deve adotar quando possível paradigmas de Internet das Coisas (IOT) exatamente em função da grande heterogeneidade dos dispositivos submetidos à perícia, atendendo requisitos como: (i) interoperabilidade; (ii) descoberta e gerenciamento de dispositivos; (iii) interfaces de alto nível; (iv) ciência de contexto; (v) escalabilidade; (vi) gerenciamento de grandes volumes de dados; (vii) segurança, e; (viii) adaptação dinâmica (PIRES et al., 2015). Além disso, deve atender as especificidades do ambiente forense, provendo: (a) isolamento necessário para não contaminar as evidências; (b) manter o registro da cadeia de custódia detalhando todas as ações realizadas (o que, quem, quando, como, onde, por que foi manipulada); (c) interação com o módulo de custódia de evidências; e (d) quando possível integrar-se com robô para manipulação automática de evidências.

\subsubsection{Integrar Laboratórios Forenses em Federações de WebLabs}

Com base no estudo realizado, propõe-se a integração dos laboratórios forenses em Federações de WebLabs Forenses. Preliminarmente, cabe considerar que a estrutura de laboratórios periciais no país é constituída basicamente pelos seguintes recursos:

a) Instituto Nacional de Criminalística, afeito ao Departamento de Polícia Federal, com sua sede central em Brasília e representações regionais nos estados;

b) Órgãos periciais estaduais ligados às secretarias de segurança pública ou diretamente às polícias civis ou militares;

c) Órgãos ligados aos Ministérios Públicos;

d) Órgãos especializados e universidades que realizam exames periciais 
e) Empresas públicas ou da iniciativa privada que prestam serviços relacionados à perícia forense

f) Peritos judiciais e assistentes técnicos que prestam serviços como pessoas físicas.

Levantamentos realizados pela Secretaria Nacional de Segurança Pública a respeito dos órgãos oficiais (JUSTIÇA, 2013) indicam em 2013 a existência de 343 unidades de criminalística, como mostra a Tabela 1.

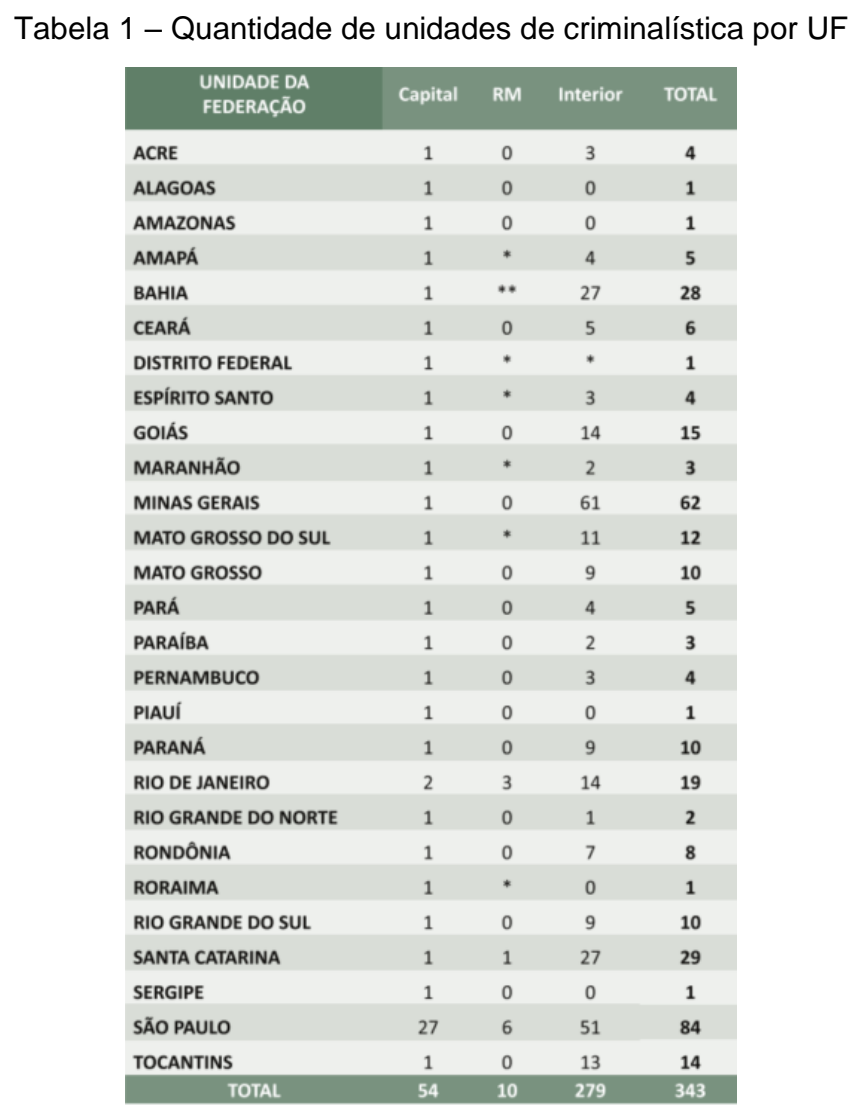

Fonte: SENASP

Uma vez que há no Brasil milhares de comarcas distantes das capitais, a reduzida quantidade de laboratórios indica que não existe atendimento pericial direto na maior parte dos fóruns brasileiros. Mais ainda, boa parte dos pontos de presença existentes em cidades de tamanho médio em verdade não produzem exames mais complexos, eles são apenas agentes que recebem e despacham as peças para as capitais e grandes centros do país, onde efetivamente elas serão periciadas. As consequências dessa distribuição heterogênea podem ser percebidas em outros indicadores negativos, por exemplo, a Associação Brasileira de Criminalística informa que a 
quantidade de assassinatos cujos culpados são descobertos e punidos nos Estados Unidos é de $65 \%$, em França $80 \%$, no Reino Unido $90 \%$, enquanto que no Brasil é de apenas $8 \%$, índice que reflete também as dificuldades na investigação e na produção de provas técnicas.

Ocorre que cada vez mais a produção de provas digitais nos tribunais requer o exame de dispositivos eletrônicos complexos e capazes de armazenar trilhões de bytes, se por um lado registram fatos relevantes para a investigação, por outro sua verificação requer muito tempo, a disponibilidade de peritos altamente qualificados e a utilização de poderosas ferramentas que localizem até mesmo vestígios digitais propositalmente escondidos (NEUFELD; SCHECK, 2010).

Os exames são realizados por peritos judicias nomeados por juízes na esfera cível, pelos institutos de criminalística em níveis federal ou estadual e por órgãos ou empresas independentes. Esses recursos estão cada vez mais sobrecarregados porque a demanda supera fortemente a capacidade de atendimento, provocando lentidão da Justiça e laudos periciais de baixa qualidade (ZOCHIO, 2010) que podem levar a falsos negativos, como a liberação de criminosos, ou, pior, falsos positivos que podem levar inocente à prisão, um cenário que tende a se agravar muito rapidamente pela intensa adoção de dispositivos digitais em praticamente todas as atividades humanas e pelo aumento da dificuldade técnica no exame desses dispositivos (GARFINKEL, 2010).

O poder público busca aumentar os investimentos na infraestrutura tecnológica dos institutos de criminalística e nas próprias universidades interessadas em questões de perícia forense, visando torná-los mais eficazes inclusive mediante o aparelhamento dos laboratórios, porém os resultados alcançados não se mostram suficientes.

Cumpre notar a respeito dessa questão os estudos de Robert Solow: analisando outras áreas do conhecimento ele observou que não é possível atestar que a Tecnologia da Informação tenha contribuído efetivamente com a produtividade nas empresas, fenômeno que denominou como paradoxo da produtividade de T.I. (BRYNJOLFSSON, 1993). Mesmo se outras pesquisa se contrapõem a esse entendimento (CARR, 2003), cabe considerar que a redução do gap existente entre a demanda e a capacidade de atendimento dos laboratórios forenses depende de dotálos de ferramentas inovadoras que possam fazer frente às inflexões tecnológicas. 
Por esse motivo, o modelo proposto neste trabalho visa inovar na forma de maximizar o aproveitamento dos recursos disponíveis e levar serviços periciais até as comarcas não atendidas ou pouco atendidas por meio da criação de redes de Rede de WebLabs Forenses.

O conceito de WebLab está sendo estudado por diversos pesquisadores no Brasil e no mundo como ferramenta para que estudantes e pesquisadores possam acessar remotamente via Web os laboratórios fisicamente instalados em outros locais e neles realizar, à distância, experimentos sobre sistemas eletrônicos, físicos, biológicos, químicos ou nucleares, entre outros. A inovação consiste em utilizar essa tecnologia no ambiente forense.

A primeira adaptação necessária no modelo padrão de WebLabs é a adição de funções de cadeia de custódia que atuem continuamente, de forma online e com elevada segurança para proteger as evidências coletadas, custodiadas, analisadas e depois devidamente descartadas. Em segundo lugar, são necessárias funções que possibilitem aos investigadores, peritos e assistentes técnicos realizar exames periciais forenses de maneira online e remota sob a fiscalização igualmente online dos operadores do Direito, ou seja, pelos juízes, delegados, promotores, representantes de ministérios públicos, advogados e pelas próprias partes no processo.

Tendo em vista que os laboratórios de referência geralmente possuem competências, especializações, localizações e perfis de demandas não idênticos, o modelo proposto contempla a integração de diferentes laboratórios para compor um serviço que sob o ponto de vista dos seus usuários se apresenta como integrado, multidisciplinar, onipresente, com maior capacidade de atendimento total e pleno emprego dos seus recursos.

Há que se considerar nesse cenário não apenas os laboratórios das polícias científicas, como também centros especializados em investigações sobre segurança nacional, laboratórios das forças armadas, laboratórios de universidades públicas ou privadas, laboratórios de empresas fabricantes de produtos, empresas prestadoras serviços técnicos especializados, centros de resposta a incidentes e demais empresas, pesquisadores e peritos que reúnem conhecimentos e técnicas relevantes para os objetivos periciais. 
A forte segmentação e a baixa integração desses recursos são fatores que geram ineficiências, trabalhos redundantes, perdas de escala, baixo aproveitamento de conhecimentos e estruturas, deficiências no compartilhamento de conhecimento e falta de recursos para treinamento e aperfeiçoamento de profissionais.

Assim, o presente trabalho propõe a adoção da tecnologia WebLab nos laboratórios forenses, a integração desses laboratórios em Federações de WebLabs Forenses e finalmente a criação de uma Confederação de WebLabs Forenses com abrangência nacional ou internacional focada no atendimento de demandas legais para exame de sistemas eletrônicos.

$\mathrm{Na}$ mesma linha, porém com um escopo mais amplo, propõe-se a ampliação do modelo de modo a abranger não apenas os laboratórios voltados ao exame pericial dos sistemas eletrônicas, mas também os laboratórios forenses de outras áreas do conhecimento que utilizem sistemas eletrônicos como ferramentas relevantes na execução de tarefas de perícia forense, em áreas como Medicina, Engenharia Civil, Engenharia Química, Engenharia Naval, Biologia, entre outras.

A implementação da solução apresentada demandará, entre outras tarefas futuras, a definição o estudo das questões legais envolvidas, o estabelecimento de padrões para o desenvolvimento e operação segura dos sistemas, o estabelecimento de padrões para coleta e custódia de evidências e a criação de mecanismos mais maduros para a utilização remota e a integração dos diversos laboratórios.

Dentro do escopo do presente trabalho, cabe a busca por modelos conceituais que possam servir de base técnica para a evolução pretendida. Tendo em vista a ausência de aplicações reais e maduras que já tivessem sido propostas e avaliadas pela comunidade acadêmica sob a óptica das Ciências Forenses, no presente trabalho foram identificadas aplicações na área educacional que, por apresentarem um grau maior de maturidade, podem servir como plataforma inicial para evolução no sentido do seu aproveitamento em aplicação com finalidade forense, após os devidos aperfeiçoamentos especialmente quanto à sua segurança e às trilhas de auditoria.

A busca por plataformas em princípio adequadas para derivação rumo a aplicações forenses apontou para os seguintes grupos de pesquisa e produtos: (i) LabConnector: Shara (Labshare) e iLabs (MIT); (ii) Global Online Laboratory Consortium; (iii) iniciativa "gateway4labs", de (ORDUNA et al., 2015), e laboratórios como serviços 
(LaaS), de (CAMINERO et al., 2014). Os próximos itens apresentam suas principais características de interesse para o escopo proposto.

\subsubsection{LabConnector: Shara (Labshare) e iLabs (MIT)}

Entre essas diversas pesquisas, (YEUNG; LOWE; MURRAY, 2010) avaliaram o produto Sahara, da Labshare ${ }^{14}$, e o produto iLabs, do MIT $^{15}$, ambas com aceitável maturidade como solução de mercado, mas com diferenças entre si, motivo que os levou à concepção de protocolo de comunicação para interoperabilidade das plataformas.

Quadro 3 - Diferenças de terminologia entre os sistemas Shara e iLabs

\begin{tabular}{|l|l|}
\hline \multicolumn{2}{|c|}{ Nomenclature Mapping } \\
\hline Sahara & \\
\hline Rig & LabEquipament \\
\hline RigClient & LabServer \\
\hline Capability & Annotation \\
\hline Lesson & Experiment Specification \\
\hline Queued & Experiment (Queue) \\
\hline Session & Experiment (Running) \\
\hline Scheduling Server & LSS+ESS \\
\hline Distributed File System & Experiment Storage Server \\
\hline (no equivalent) & Service Broker \\
\hline
\end{tabular}

Fonte: (YEUNG; LOWE; MURRAY, 2010)

Visando integrar ambos os sistemas, aqueles autores desenvolveram uma API (Application Programming Interface) denominada LabConnector para tratar a interface de funcionalidades laboratoriais batch ou interativas e resguardar consistência, reusabilidade e disponibilidade em cada sistema, recurso que contribui com a evolução de um protótipo de aplicação forense.

\footnotetext{
14 Veja http://www.labshare.edu.au

${ }^{15}$ Veja https://wikis.mit.edu/confluence/display/ILAB2/Home
} 


\subsubsection{Global Online Laboratory Consortium}

Ainda visando a integração de laboratórios forenses, cabe considerar a contribuição do Global Online Laboratory Consortium (GOLC, 2011) que estabeleceu os seguintes termos e conceitos principais para laboratórios remotos:

Quadro 4 - Principais termos utilizados no GOLC

\begin{tabular}{|c|c|}
\hline Interface & $\begin{array}{l}\text { Uma interface de comunicação comum através da qual dois sistemas de } \\
\text { laboratórios remotos, um considerado sistema do consumidor e outro } \\
\text { sistema do provedor, possam se comunicar. }\end{array}$ \\
\hline Consumidor & $\begin{array}{l}\text { Uma organização que negociou acesso ao laboratório remoto do provedor } \\
\text { em nome dos usuários que pertencem à organização consumidora. }\end{array}$ \\
\hline Grupo do Consumidor & $\begin{array}{l}\text { Grupo de usuários de um consumidor que corresponde a um acordo uso } \\
\text { particular }\end{array}$ \\
\hline Usuário & $\begin{array}{l}\text { Um usuário identificável de um laboratório remoto aprovisionado, sendo que } \\
\text { o provedor faz a autenticação no nível de consumidor, não no nível de } \\
\text { usuário, assim pode o Consumidor autenticar apropriadamente seu usuário e } \\
\text { determinar a qual grupo de consumidor pertence. O provedor faz seu } \\
\text { controle de acesso baseado no grupo de consumidor, não em usuário } \\
\text { individual, e somente requer identificação de usuário com a finalidade de } \\
\text { monitorar seu uso. }\end{array}$ \\
\hline Provedor & $\begin{array}{l}\text { Uma organização que torna disponível seu laboratório remoto para uso pelos } \\
\text { consumidores. }\end{array}$ \\
\hline $\begin{array}{l}\text { Equipamento e Conjunto de } \\
\text { Equipamentos }\end{array}$ & $\begin{array}{l}\text { Um equipamento é uma única instância de um aparato experimental sobre o } \\
\text { qual um experimento pode ser executado. A entrega de múltiplas cópias de } \\
\text { equipamentos similares pode ser tratada de diferentes maneiras por } \\
\text { diferentes sistemas de laboratórios remotos. Para um determinado } \\
\text { experimento a quantidade de diferentes equipamentos pode ser } \\
\text { intercambiável, enquanto que para um experimento diferente somente um } \\
\text { subconjunto equipamentos pode ser utilizado ou um estudante pode querer } \\
\text { selecionar um equipamento específico, por exemplo para assegurar } \\
\text { consistência na calibração. Além de adotar conceitos limitados de tipo de } \\
\text { equipamento e instância de equipamento, a norma adota o conceito de } \\
\text { conjunto de equipamentos com sendo uma coleção de equipamento que } \\
\text { podem ser intercambiados em um determinado experimento. Um conjunto } \\
\text { de equipamentos pode ser composto por outros conjuntos de equipamentos. }\end{array}$ \\
\hline
\end{tabular}

Fonte: (GOLC, 2011)

Os princípios relevantes para um padrão de interoperação de laboratórios remotos segundo a estrutura proposta por GOLC são:

Quadro 5 - Princípios GOLC norma sobre interoperabilidade

\begin{tabular}{|c|c|}
\hline Perfil Base & $\begin{array}{l}\text { O padrão deve determinar um perfil base obrigatório e suporte para } \\
\text { perfis adicionais que definem conjuntos de capacidades funcionais } \\
\text { além das capacidades básicas (p.ex., suporte a planos de aula } \\
\text { podem ser adicionados em um perfil com suporte opcional). A } \\
\text { interface deve incluir um mecanismo para consulta de perfis } \\
\text { suportados por um determinado sistema. }\end{array}$ \\
\hline Interoperabilidade & $\begin{array}{l}\text { O padrão deve acomodar a interoperabilidade entre os sistemas que } \\
\text { estão de acordo com as diferentes versões deste padrão. Isto deve } \\
\text { incluir um processo de negociação entre os sistemas que identifica o } \\
\text { maior conjunto de capacidades comuns }\end{array}$ \\
\hline
\end{tabular}




\begin{tabular}{|c|c|}
\hline Compatibilidade & $\begin{array}{l}\text { As versões deste padrão devem, sempre que possível, ser } \\
\text { verticalmente compatíveis. Em outras palavras, uma versão mais } \\
\text { recente não deve invalidar a funcionalidade especificada em uma } \\
\text { versão anterior. Quando isto for inevitável, a funcionalidade obsoleta } \\
\text { deve ser claramente identificada. }\end{array}$ \\
\hline Nível de Serviço & $\begin{array}{l}\text { 4. O padrão deve acomodar escolhas variadas por provedores } \\
\text { laboratoriais a respeito do nível de serviço que desejam fornecer em } \\
\text { relação aos sistemas laboratoriais - interna externamente, em todos } \\
\text { os sistemas. O padrão deve também fornecer suporte para } \\
\text { determinação automática do nível de serviço fornecido por um } \\
\text { provedor laboratorial. Exemplos podem incluir (mas não se limitam a): } \\
\text { a. Níveis variados de garantia de serviço e laboratórios disponíveis; } \\
\text { b. Níveis variados de segurança da informação, tais como } \\
\text { informações sobre quem tem acesso aos resultados de laboratório } \\
\text { (p.ex., Acesso por terceiros/faculdade/etc.) e se os resultados } \\
\text { acessados são tornados anónimos antes do acesso; } \\
\text { c. Níveis variados de qualidade de dados, resolução e retenção além } \\
\text { da vida útil de um experimento, incluindo quantidade de vezes que os } \\
\text { resultados podem ser recuperados antes da remoção; } \\
\text { d. A extensão da informação disponível a respeito do rastreio da } \\
\text { procedência (em outras palavras, que hardware foi usado para } \\
\text { realização da sessão de experimento, qual software foi empregado } \\
\text { em qualquer processamento de dados, quais dados foram } \\
\text { intercambiados durante a sessão, etc.) }\end{array}$ \\
\hline Autenticação e autorização & $\begin{array}{l}\text { 5. O padrão deve fornecer suporte à autenticação de } \\
\text { cliente/grupo/usuário e autorização com base nos mecanismos de } \\
\text { autenticação padrão da indústria. O padrão deve suportar, pelo } \\
\text { menos: } \\
\text { a. Autenticação no nível do cliente (em outras palavras, identificação } \\
\text { de instituição que solicita acesso - p.ex., UTS - a partir de um } \\
\text { determinado provedor - p.ex., MIT); } \\
\text { b. Associação obrigatória de um consumidor de uma solicitação com } \\
\text { um grupo de consumidores identificado (ou coorte de usuários) de } \\
\text { modo que a solicitação possa ser ligada pelo provedor laboratorial a } \\
\text { um acordo específico de nível de serviço entre o provedor e o } \\
\text { consumidor (considerando que pode haver múltiplos acordos com o } \\
\text { mesmo consumidor. p.ex., diferentes provedores de cursos UTS } \\
\text { podem receber diferentes níveis de acesso como parte do acordo de } \\
\text { acesso da UTS com o MIT - Steve Murray pode ter } 50 \text { testes de lote } \\
\text { para seus alunos no Laboratório } 1 \text { e David Lowe pode ter } 100 \text { testes } \\
\text { no mesmo Lab 1). } \\
\text { Nota: Embora um consumidor possa optar ou não por rastrear a } \\
\text { utilização por parte de seus usuários (de modo que, entre outras } \\
\text { razões, a utilização relatada pelo Provedor possa ser validada), isto } \\
\text { está além do escopo de definição da interface. }\end{array}$ \\
\hline
\end{tabular}

Fonte: (GOLC, 2011)

Com relação aos perfis e às interações, cabe tomar em consideração os casos de uso e as sequências de interação que devem ser suportados por interfaces de laboratórios remotos segundo GOLC:

a) Perfil base (versão 1) - Os perfis atualmente planejados para versões subsequentes do padrão incluem: 
b) Perfil de Monitoramento de Uso - Um perfil com suporte para que um consumidor possa consultar o nível atual de utilização do equipamento pelos usuários associados a um Grupo de Consumidores ou Consumidor em particular.

c) Perfil de Agrupamento de Equipamentos / Balanceamento de Carga - Suporte para balanceamento do uso compartilhado de conjuntos de equipamentos similares em todos os diferentes provedores.

d) Perfil de Acesso a Aulas - Suporte à funcionalidade de acesso a materiais de estudo associados.

Para cada perfil, a norma GOLC apresenta diferentes cenários e mensagens, conforme exemplo a seguir.

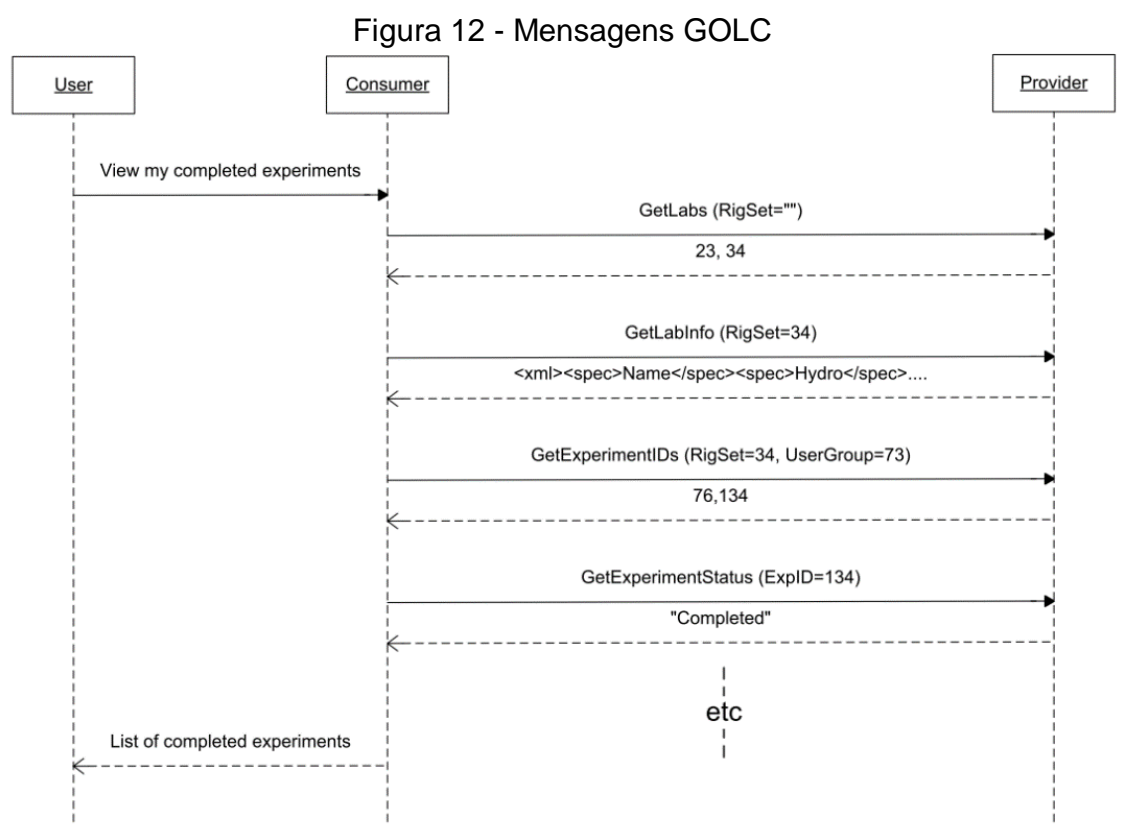

Fonte: (GOLC, 2011)

A norma GOLC propõe interações para suportar submissão, monitoramento e recuperação de resultados em lote e o uso de uma interface cliente fornecida pelo consumidor ou pelo provedor. 
Figura 13 - Requisições e respostas GOLC
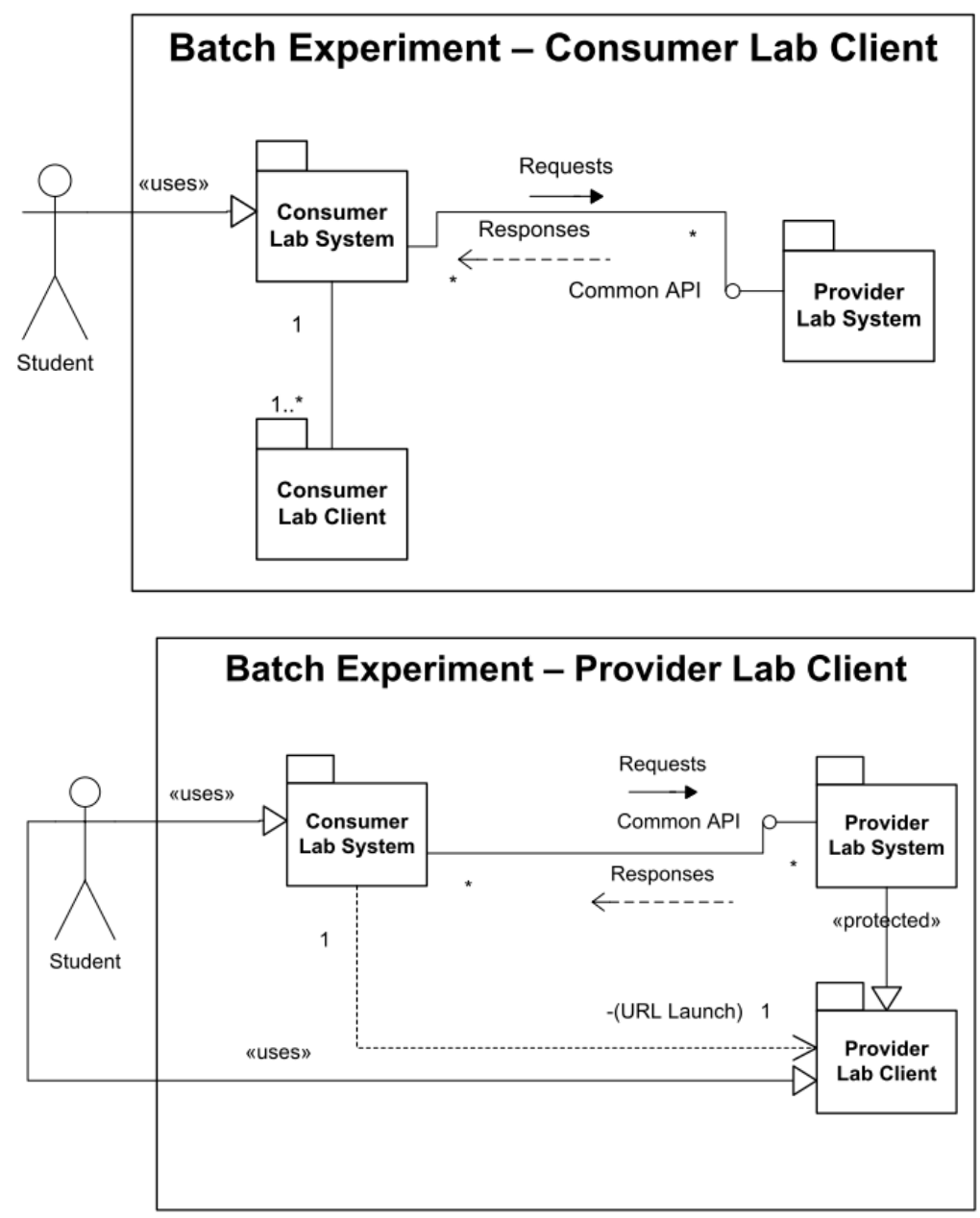

Fonte: (GOLC, 2011)

A respeito dos métodos de interface, a norma considera:

Quadro 6 - Métodos de interface GOLC

\begin{tabular}{|c|c|c|c|c|}
\hline PARÂMETROS & DESCRIÇÃOO & $\begin{array}{l}\text { TIPO DE } \\
\text { DADOS }\end{array}$ & $\begin{array}{l}\text { ESCOLHA DE } \\
\text { SEQUÉNCIA }\end{array}$ & $\begin{array}{l}\text { CARDINAL } \\
\text { IDADE }\end{array}$ \\
\hline \multicolumn{5}{|c|}{ queryprofiles(): usado para obter uma lista de perfis suportados pelo provedor } \\
\hline \multicolumn{5}{|l|}{ Consulta: } \\
\hline- & - & - & - & - \\
\hline \multicolumn{5}{|l|}{ Resposta: } \\
\hline profileNames & $\begin{array}{l}\text { Conjunto dos nomes dos perfis suportados pelo } \\
\text { Provedor. }\end{array}$ & série & sequência & {$\left[0 . .^{*}\right]$} \\
\hline error & Código de erro para determinada chamada de API. & integral & sequência & {$[0 . .1]$} \\
\hline errorMessage & Mensagem de erro visualizável pelo usuário & série & sequência & {$[0 . .1]$} \\
\hline \multicolumn{5}{|c|}{ QUERYPROFILEVER(): FORNECE A VERSÃO ESPECÍFICA DE UM PERFIL SUPORTADO. } \\
\hline \multicolumn{5}{|l|}{ Consulta: } \\
\hline profileName & Nome do perfil consultado & série & sequência & [1..1] \\
\hline Resposta: & & & & \\
\hline
\end{tabular}




\begin{tabular}{|l|l|l|l|l|}
\hline PARÂMETROS & \multicolumn{1}{|c|}{ DESCRIÇÃO } & \multicolumn{1}{|c|}{$\begin{array}{c}\text { TIPO DE } \\
\text { DADOS }\end{array}$} & \multicolumn{1}{|c|}{$\begin{array}{c}\text { ESCOLHA DE } \\
\text { SEQUÊNCIA }\end{array}$} & $\begin{array}{c}\text { CARDINAL } \\
\text { IDADE }\end{array}$ \\
\hline profileVer & Versão do perfil suportado especificado & série & sequência & {$\left[0 .{ }^{*}\right]$} \\
\hline error & Código de erro para determinada chamada de API. & integral & sequência & {$[0 . .1]$} \\
\hline errorMessage & Mensagem de erro visualizável pelo usuário & série & sequência & sequência \\
\hline
\end{tabular}

QUERYSERVICELEVEL(): FORNECE INFORMAÇÕES ESPECÍFICAS DO PROVEDOR PARA O NÍVEL DE SERVIÇO SUPORTADO PELO PROVEDOR.

\begin{tabular}{|l|l|l|l|l|}
\hline Consulta: & & & \\
\hline serviceAttribute & Nome do atributo de serviço consultado & série & sequência \\
\hline rigSetID & $\begin{array}{l}\text { RigSet [conjuntos de equipamentos] de Provedor } \\
\text { específico ao qual esta consulta se aplica. }\end{array}$ & integral & sequência & [1..1] \\
\hline Resposta: & & & & [0..1] \\
\hline ServiceAttribute & $\begin{array}{l}\text { Valor visualizável pelo usuário do atributo específico } \\
\text { de serviço par o RigSet relevante. }\end{array}$ & série & sequência \\
\hline error & Código de erro para determinada chamada de API. & integral & sequência \\
\hline errorMessage & Mensagem de erro visualizável pelo usuário & série & sequência & [0..1] \\
\hline
\end{tabular}

GETLABS(): FORNECE UMA LISTA DE RIGSETS ACESSIVEIS AO CONSUMIDOR. CASO SEJA ESPECIFICADA UM GROUPID, A LISTA SERÁ LIMITADA AOS RIGSETS ACESSÍVEIS A ESTE GRUPO DE CONSUMIDOR. CASO UM RIGSET NÃO SEJA ESPECIFICADO, O SISTEMA FORNECERÁ UMA LISTA DOS RIGSETS DE NÍVEL MÁXIMO ÚNICOS ACESSÍVEIS; DO CONTRÁRIO, SERÁ FORNECIDA A LISTA DOS RIGSETS INFANTIS DO RIGSET ESPECÍFICO ACESSÍVEL. EM OUTRAS PALAVRAS, CHAMADAS REPETIDAS PARA ESTE MÉTODO PERMITIRÃO QUE O CONSUMIDOR CONSTRUA UMA ÁRVORE HIERÁRQUICA DE RIGSETS ACESSÍVEIS.

\begin{tabular}{|l|l|l|l|l|}
\hline Consulta: & & & & \\
\hline groupID & $\begin{array}{l}\text { Identificação do grupo ao qual esta consulta se } \\
\text { aplica. }\end{array}$ & integral & sequência & {$[0 . .1]$} \\
\hline rigSetID & $\begin{array}{l}\text { RigSet de Provedor específico ao qual esta consulta } \\
\text { se aplica. }\end{array}$ & integral & sequência & {$[0 . .1]$} \\
\hline Resposta: & & & & \\
\hline rigSets & Identificação dos RigSets acessíveis & integral & sequência & {$\left[0 . *^{*}\right]$} \\
\hline error & Código de erro para determinada chamada de API. & integral & sequência & {$[0 . .1]$} \\
\hline errorMessage & Mensagem de erro visualizável pelo usuário & série & sequência & {$[0 . .1]$} \\
\hline
\end{tabular}

GETLABSTATUS(): FORNECE O STATUS ATUAL DO RIGSET (CONFORME RELEVANTE PARA O GRUPO DE CONSUMIDORES FORNECIDO, DESDE QUE O PROVEDOR DISPONIBILIZE UM RIGSET APENAS PARA ALGUNS GRUPOS E NÃO PARA OUTROS).

\begin{tabular}{|l|l|l|l|l|}
\hline Consulta: & \multicolumn{1}{|l|}{} & & \\
\hline groupID & $\begin{array}{l}\text { Identificação do grupo ao qual esta consulta se } \\
\text { aplica. }\end{array}$ & integral & sequência & {$[0 . .1]$} \\
\hline rigSetID & $\begin{array}{l}\text { RigSet de Provedor específico ao qual esta consulta } \\
\text { se aplica. }\end{array}$ & integral & sequência & {$[0 . .1]$} \\
\hline Resposta: & & & & \\
\hline online & Este RigSet está online? & booleano & sequência & {$[1 . .1]$} \\
\hline available & $\begin{array}{l}\text { Um ou mais equipamentos dentro deste RigSet está } \\
\text { disponível para uso imediato? }\end{array}$ & booleano & sequência & {$[1 . .1]$} \\
\hline status & Mensagem de status específica do Provedor & série & sequência & {$[1 . .1]$} \\
\hline error & Código de erro para determinada chamada de API. & integral & sequência & {$[0 . .1]$} \\
\hline errorMessage & Mensagem de erro visualizável pelo usuário & série & sequência & [0..1] \\
\hline $\begin{array}{l}\text { GETLABINFO(): } \\
\text { QUAL ESTÁ DISPONÍVEL PARA O GRUPO DE CONSUMIDOR ESPECIFICADO (SE ESPECIFICADO). }\end{array}$ \\
\hline Consulta: & & & & \\
\hline
\end{tabular}




\begin{tabular}{|c|c|c|c|c|}
\hline PARÂMETROS & DESCRIÇÃO & $\begin{array}{l}\text { TIPO DE } \\
\text { DADOS }\end{array}$ & $\begin{array}{l}\text { ESCOLHA DE } \\
\text { SEQUENNCIA }\end{array}$ & $\begin{array}{l}\text { CARDINAL } \\
\text { IDADE }\end{array}$ \\
\hline grouplD & $\begin{array}{l}\text { Identificação do grupo ao qual esta consulta se } \\
\text { aplica. }\end{array}$ & integral & sequência & {$[0 . .1]$} \\
\hline rigSetID & $\begin{array}{l}\text { RigSet de Provedor específico ao qual esta consulta } \\
\text { se aplica. }\end{array}$ & integral & sequência & {$[1 . .1]$} \\
\hline \multicolumn{5}{|l|}{ Resposta: } \\
\hline rigSetProperties & $\begin{array}{l}\text { Um arquivo XML contendo uma lista de propriedades } \\
\text { específicas do Provedor para este RigSet. }\end{array}$ & série-xml & sequência & {$[1 . .1]$} \\
\hline \multirow[t]{2}{*}{ Error } & Código de erro para determinada chamada de API. & integral & sequência & {$[0 . .1]$} \\
\hline & \multicolumn{4}{|c|}{$\begin{array}{l}\text { Note 1: As propriedades devem estar de acordo com o conjunto padrão de elementos de metadados } \\
\text { Dublin Core }{ }^{16} \text {, sendo apenas o Título (ou seja, nome do RigSet) e o Tipo ("Lote" ou “Interativo") sendo } \\
\text { obrigatórios. Todos os outros metadados são opcionais e ficam a critério do Provedor, e o Provedor pode } \\
\text { acrescentar propriedades adicionais não convencionais. }\end{array}$} \\
\hline
\end{tabular}

GETEXPERIMENTIDS(): RECUPERA UMA LISTA DE IDENTIFICAÇÕES DE EXPERIMENTOS ATIVOS ASSOCIADOS AOS EQUIPAMENTOS NESTE RIGSET, E RELACIONADOS A UM CONSUMIDOR, GRUPO DE CONSUMIDORES OU USUÁRIO EM PARTICULAR.

\begin{tabular}{|c|c|c|c|c|}
\hline \multicolumn{5}{|l|}{ Consulta: } \\
\hline grouplD & Identificação do grupo ao qual esta consulta se aplica. & integral & Sequência & {$[0 . .1]$} \\
\hline userlD & $\begin{array}{l}\text { Identificação de um usuário específico ao qual esta } \\
\text { consulta se aplica. }\end{array}$ & integral & sequência & {$[0 . .1]$} \\
\hline rigSetID & $\begin{array}{l}\text { RigSet de Provedor específico ao qual esta consulta } \\
\text { se aplica. }\end{array}$ & integral & sequência & {$[1 . .1]$} \\
\hline \multicolumn{5}{|l|}{ Resposta: } \\
\hline explDs & Uma lista de identificações de experimentos ativos & integral & sequência & {$\left[0 .{ }^{*}\right]$} \\
\hline error & Código de erro para determinada chamada de API. & integral & sequência & {$[0 . .1]$} \\
\hline errorMessage & Mensagem de erro visualizável pelo usuário & série & sequência & {$[0 . .1]$} \\
\hline & \multicolumn{4}{|c|}{$\begin{array}{l}\text { Note 1: Um experimento "ativo" é definido como aquele em que o Provedor ainda está de posse dos registros } \\
\text { atuais, em outras palavras, pode ter sido criado, mas ainda não foi apresentado para execução, } \\
\text { apresentado, mas ainda não executado, atualmente em execução, ou concluído e cujas informações ainda } \\
\text { estão disponíveis. }\end{array}$} \\
\hline
\end{tabular}

GETEXPERIMENTSTATUS(): FORNECE UMA INDICAÇÃO DO STATUS ATUAL DE UM EXPERIMENTO, SE UM EXPERIMENTO ESTÁ EM PROGRESSO (SE SIM, POR QUANTO TEMPO), OU SE FOI CONCLUÍDO OU ESTÁ EM ESTADO INATIVO.

\begin{tabular}{|l|l|l|l|l|}
\hline Consulta: & & & & \\
\hline expID & Identificação do experimento consultado & integral & sequência \\
\hline Resposta: & & & & {$[1 . .1]$} \\
\hline expStatus & Status atual do experimento & série & sequência \\
\hline expStatusDesc & $\begin{array}{l}\text { Descrição do status do experimento visualizável pelo } \\
\text { usuário }\end{array}$ & série & sequência & {$[1 . .1]$} \\
\hline Error & Código de erro para determinada chamada de API. & integral & sequência \\
\hline errorMessage & Mensagem de erro visualizável pelo usuário & série & sequência & [0..1] \\
\hline
\end{tabular}

\footnotetext{
${ }^{16}$ Dublin Core é um esquema de metadados para descrever objetos digitais (vídeos, sons, imagens, textos, sites) utilizando XML e o RDF (Resource Description Framework), definido por Dublin Core Metadata Initiative (DCMI), organização para padrões de interoperabilidade de metadados e vocabulários especializados para descrever fontes que tornem mais inteligentes sistemas de descobrimento de informações. O Dublin Core Metadata Element Set (DCMES) consiste de quinze elementos opcionais e repetíveis de metadados: 1.Title: Título, 2.Creator: Criador, 3.Subject: Assunto, 4.Description: Descrição, 5.Publisher: Editor, 6.Contributor: Contribuidor, 7.Date: Data, 8.Type: Tipo, 9.Format: Formato, 10.Identifier: Identificador, 11.Source: Origem, 12.Language: Idioma, 13.Relation: Relação, 14.Coverage: Abrangência e 15.Rights: Direitos
} 


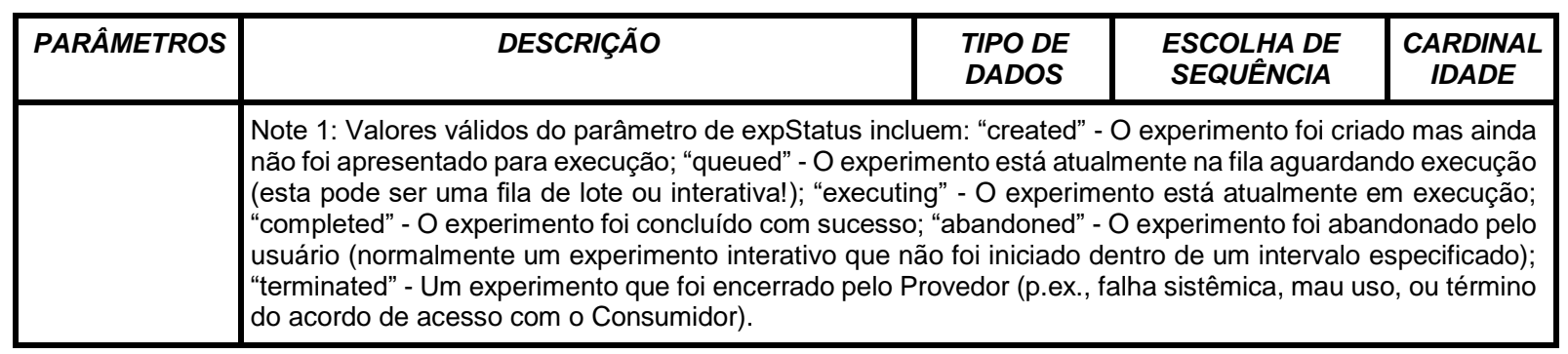

Fonte: (GOLC, 2011)

Quadro 7 - Métodos adicionais de interface GOLC

\begin{tabular}{|c|c|}
\hline MÉTODO & DESCRIÇÃO \\
\hline BatchExpCreate(): & $\begin{array}{l}\text { Cria uma definição de experimento em branco "vazia" no Provedor, a ser executada no } \\
\text { RigSet específico que pode, a partir daí ser manipulado, preenchido, executado, etc. }\end{array}$ \\
\hline BatchExpDelete (): & Apaga uma definição de experimento criada anteriormente. \\
\hline BatchExpGetSpecs(): & $\begin{array}{l}\text { Fornece uma lista da informação necessária para execução com sucesso de um } \\
\text { experimento. Tipicamente é um arquivo XML que determina o formato, informação } \\
\text { necessária e padrões para definição de um experimento válido. }\end{array}$ \\
\hline BatchExpSetDefn(): & $\begin{array}{l}\text { Fornece a informação necessária para definição de um experimento válido e salva em um } \\
\text { experimento existente. }\end{array}$ \\
\hline BatchExpGetDefn(): & Recupera a definição de experimento a partir de um experimento definido anteriormente. \\
\hline BatchExpExecute(): & $\begin{array}{l}\text { Solicita a execução de um experimento de lote definido anteriormente. O experimento } \\
\text { (caso seja aceito para execução) passará para a fila de execução. }\end{array}$ \\
\hline BatchExpLaunchProvlF(): & $\begin{array}{l}\text { Fornece uma URL para utilização no lançamento de uma interface de usuário associada } \\
\text { ao experimento específico. }\end{array}$ \\
\hline BatchExpGetResults(): & Recupera os resultados de uma execução de experimento concluída. \\
\hline InteractiveExpCreate(): & $\begin{array}{l}\text { Cria uma definição de experimento em branco "vazia" no Provedor, a ser executada no } \\
\text { RigSet específico que pode, a partir daí ser executada de forma interativa. }\end{array}$ \\
\hline InteractiveExpDelete(): & Apaga uma definição de experimento criada anteriormente. \\
\hline InteractiveExpGetSpecs(): & $\begin{array}{l}\text { Fornece uma cópia dos esquemas em XML usados para interação com o equipamento } \\
\text { interativo, utilizando uma interface do Consumidor. }\end{array}$ \\
\hline InteractiveExpLaunchConsIF(): & $\begin{array}{l}\text { Solicita início de um experimento interativo utilizando uma interface fornecida pelo } \\
\text { consumidor. }\end{array}$ \\
\hline InteractiveExpSendCommand(): & $\begin{array}{l}\text { Envia um arquivo XML contendo informações de execução e/ou consultas para um } \\
\text { experimento interativo atualmente em execução. }\end{array}$ \\
\hline InteractiveExpEndConsIF(): & Encerra um experimento interativo em execução utilizando uma interface de Consumidor. \\
\hline InteractiveExpLaunchProvIF(): & $\begin{array}{l}\text { Fornece uma URL para utilização no lançamento de uma interface de usuário associada } \\
\text { ao experimento específico. Note que, se o Consumidor não possuir um Equipamento } \\
\text { alocado, uma mensagem de erro será retornada. Da mesma forma, se o Consumidor } \\
\text { tentar lançar a interface com acesso expirado, o comportamento é indefinido. (Consulte a } \\
\text { informação abaixo sobre a gestão de acesso). }\end{array}$ \\
\hline GetExperimentResults(): & Recupera os resultados de uma execução de experimento concluída. \\
\hline RigAccessType(): & $\begin{array}{l}\text { Esta mensagem permite que o consumidor determine a possibilidade de agendamento ou } \\
\text { enfileiramento (ou ambos) de um RigSet específico por um Consumidor. Grupo de } \\
\text { Usuários ou Usuário especificado. }\end{array}$ \\
\hline RigAvailability(): & $\begin{array}{l}\text { Para RigSets dados com possibilidade de agendamento, esta mensagem proporciona } \\
\text { consulta dos intervalos dentro de um } \\
\text { cronograma determinado atualmente disponível para agendamento. }\end{array}$ \\
\hline RigBooking(): & $\begin{array}{l}\text { Solicita um agendamento para a Definição de Experimento determinada. Note que um } \\
\text { endereço de e-mail pode ser associado com o agendamento para fornecimento da } \\
\text { confirmação do agendamento inicial e alterações posteriores. }\end{array}$ \\
\hline RigBookingCancel(): & Cancela um agendamento existente. \\
\hline
\end{tabular}




\begin{tabular}{|l|l|}
\hline RigBookingStatus(): & $\begin{array}{l}\text { Consulta o status de um agendamento existente - em particular, se o agendamento está } \\
\text { atualmente disponível para resgate. }\end{array}$ \\
\hline RigBookingsQuery(): & $\begin{array}{l}\text { Fornece uma lista de todos os agendamentos existentes realizados para o } \\
\text { Consumidor, Grupo de Usuários ou Usuário específico. }\end{array}$ \\
\hline RigQueue(): & Adiciona a Definição de Experimento fornecida à fila. \\
\hline RigQueueCancel(): & Remove a Definição de Experimento fornecida de uma fila. \\
\hline RigQueueStatus(): & Solicita informações do status atual de uma Definição de Experimento com fila. \\
\hline
\end{tabular}
Fonte: (GOLC, 2011)

Os métodos sugeridos e testados por GOLC são aderentes ao desenvolvimento de aplicações mais maduras para objetivos forenses.

\subsubsection{Iniciativa "gateway4labs"}

Os pesquisadores de (ORDUNA et al., 2015) propuseram uma arquitetura extensível para a integração de laboratórios remotos e virtuais, com finalidades educacionais. Incluíram uma função denominada "gateway4labs" que integra múltiplos laboratórios e múltiplas ferramentas de aprendizagem em um ambiente educacional público onde os usuários não precisam se registrar. De especial interesse para a presente proposta de solução é que no estudo dos referidos autores os diversos sistemas podem ser integrados a uma federação sem a necessidade de terem sido previamente projetados para isso. Tal pesquisa foca os sistemas aplicativos já referidos neste trabalho, como o iLabs (MIT), o WebLab Deusto (Universidade Deusto) e o Sahara (Labshare). Nesse ambiente, os pesquisadores desenvolveram o middleware "gateway4labs" para suportar múltiplos laboratórios na forma de um plug-in inserido na arquitetura mostrada na Figura 14. 
Figura 14 - Arquitetura do "gateway4labs"

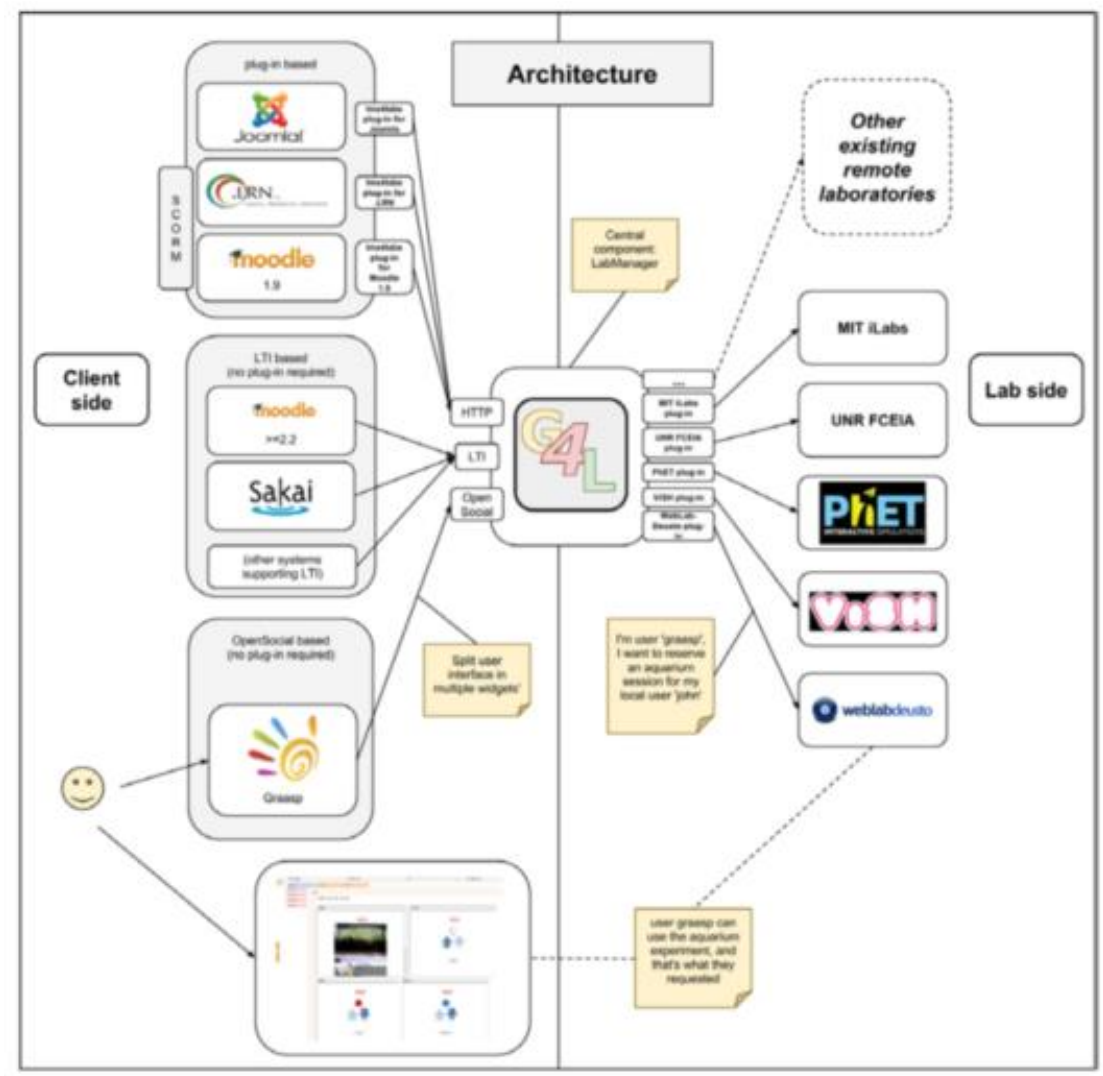

Fonte: (ORDUNA et al., 2015)

Nesse modelo relevante para compor a solução proposta, o referido middleware conecta o lado cliente (à esquerda), correspondente ao sistema educacional (LMS, CMS, etc.), com o lado do laboratório (à direita), onde há um sistema do tipo Remote LaboratoryManagement Systems (RLMS) como o WebLab Deusto ou iLab Shared Architecture. Ao centro há um componente denominado LabManager que opera na forma de plug-in para realizar o acoplamento entre os diversos ambientes.

\subsubsection{Laboratórios como Serviços (LaaS)}

Com base na recente evolução de aplicações em cloud, os autores (CAMINERO et al., 2014) propuseram o desenvolvimento de laboratórios remotos entregáveis na forma de serviços que podem ser livremente consumidos pelos clientes, denominando a solução como Laboratory as a Service (LaaS). Para isso, projetaram um experimento educacional baseado em Apache Shindig como recipiente para os dispositivos acessados remotamente, mecanismo considerando no presente trabalho para o compartilhamento de laboratórios forense como um serviço, propondo-se a adoção da denominação Laboratory as a Forensic Service (LaaFS). 


\subsubsection{WebLab-Deusto}

A Universidade de Deusto desenvolveu ampla tecnologia cuja derivação se mostra de interesse para a integração de laboratório forenses, especialmente quanto aos projetos:

a) Go-Lab - Global Online Science Labs for Inquiry Learning at School: um projeto educacional em conjunto com a Comissão Europeia para atender 19 organizações em 12 países;

b) ICo-op - projeto destinado ao treinamento de estudantes de engenharia, em parceria entre a universidade e a indústria;

c) NeReLa - projeto para inovar os métodos de ensino de engenharia

Os métodos desenvolvidos e os experimentos realizados (ORDUÑA, 2013) constituem base a ser derivada para a construção dos WebLabs Forenses e sua integração em Federação de WebLabs Forenses.

\subsubsection{Modelo Proposto}

Considerando os problemas identificados e os estudos realizados propõe-se que os WebLabs Forenses descritos nos capítulos anteriores sejam integrados entre si com o objetivo de formar Federações de WebLabs Forenses.

Uma Federação de WebLabs Forenses proporciona aos seus usuários finais utilizar remotamente e colaborativamente múltiplos laboratórios físicos como se eles fossem um mesmo laboratório lógico acessível localmente. Cabe ilustrar essa proposta tomando como exemplo um hipotético processo judicial onde tenha sido determinada perícia técnica para averiguar se houve alegado procedimento indevido, sendo para isso necessário examinar peças apreendidas como um telefone celular protegido por senha, um notebook criptografado, lançamentos contábeis em um sistema ERP, um documento manuscrito e imagens de um sistema CFTV. Nesse exemplo hipotético, mas com características cada vez mais usuais, a crescente complexidade dos sistemas impõe encaminhar cada peça a peritos distintos e até mesmo laboratórios diferentes, cada um com sua especialidade, prejudicando seu acompanhamento pelos interessados e a visão integrada de inteligência sobre os eventos registrados em cada dispositivo, prejudicando a eficácia da investigação integrada e praticamente 
impedindo o acompanhamento pelos operadores do Direito. Com a Federação de WebLabs Forense, o exame de cada peça seria realizado no laboratório com profissionais e ferramentas mais especializados e mais disponíveis naquele momento, ao mesmo tempo seria proporcionada uma visão integrada, colaborativa e simultânea entre todos os peritos, assistentes técnicos e demais operadores do Direito, com ganhos importantes de qualidade e produtividade para o Poder Judiciário e para a sociedade como um todo. Outro exemplo hipotético estaria em um caso com apreensão de grande quantidade de HDs cujo exame demoraria tempo demais em um único laboratório, já com a Federação de WebLabs Forenses seria possível encontrar laboratórios com maior disponibilidade e segmentar o trabalho entre diversos laboratórios sem perder a visão de conjunto. Muitos outros ganhos de qualidade e desempenho decorrem da criação de federações.

Em apertada síntese, é necessário primeiramente estabelecer relações contratuais entre os diversos laboratórios integrantes de cada federação e adotar interfaces operacionais comuns. Esses objetivos se tornam mais complexos na medida em que é maior a heterogeneidade administrativa e técnica entre os diversos laboratórios físicos forenses, impondo a utilização de modelos igualmente variados para a sua transformação em WebLabs Forenses e subsequente integração de laboratórios em federações.

Para fazer frente a essas dificuldades, propõe-se que a integração de WebLabs Forenses em ambientes heterogêneos seja realizada mediante o desenvolvimento de um framework para cada caso de uso existente em cada laboratório, sendo que o mesmo framework poderia ser utilizado em todos os laboratórios que tiverem o mesmo caso de uso tratado com métodos e ferramentas similares.

Por exemplo, há no mundo muitos laboratórios físicos que realizam exames forenses em discos rígidos de computador (HD), sendo natural que os melhores utilizem métodos (melhores práticas) e ferramentas iguais ou similares. Assim, não se mostra essencial que cada laboratório forense desenvolva um módulo particular para tornar esse serviço disponível via Web, ao contrário, se mostra mais racional a utilização de um framework comum que venha a ser adotado pela maioria dos laboratórios, trazendo benefícios como implementação mais rápida, menor custo, garantia quanto à sua qualidade, certificação por organismos independentes e disseminação das melhores práticas, entre outras vantagens. No contexto da federação, o uso de um 
mesmo framework pelos diversos laboratórios simplifica ou até mesmo já contempla a integração dos diversos laboratórios, inclusive por proporcionar sintaxe e semântica comuns e integração das diversas rotinas e processos laboratoriais, inclusive em procedimentos como autenticação, autorização, cadeia de custódia, controle de processos, comandos operacionais comuns e outras rotinas.

A Figura 15 mostra diagrama simplificado do modelo proposto para a criação de uma federação de WebLabs mediante o uso de frameworks nos diferentes laboratórios.

Figura 15 - Federação de WebLabs Forenses com framework

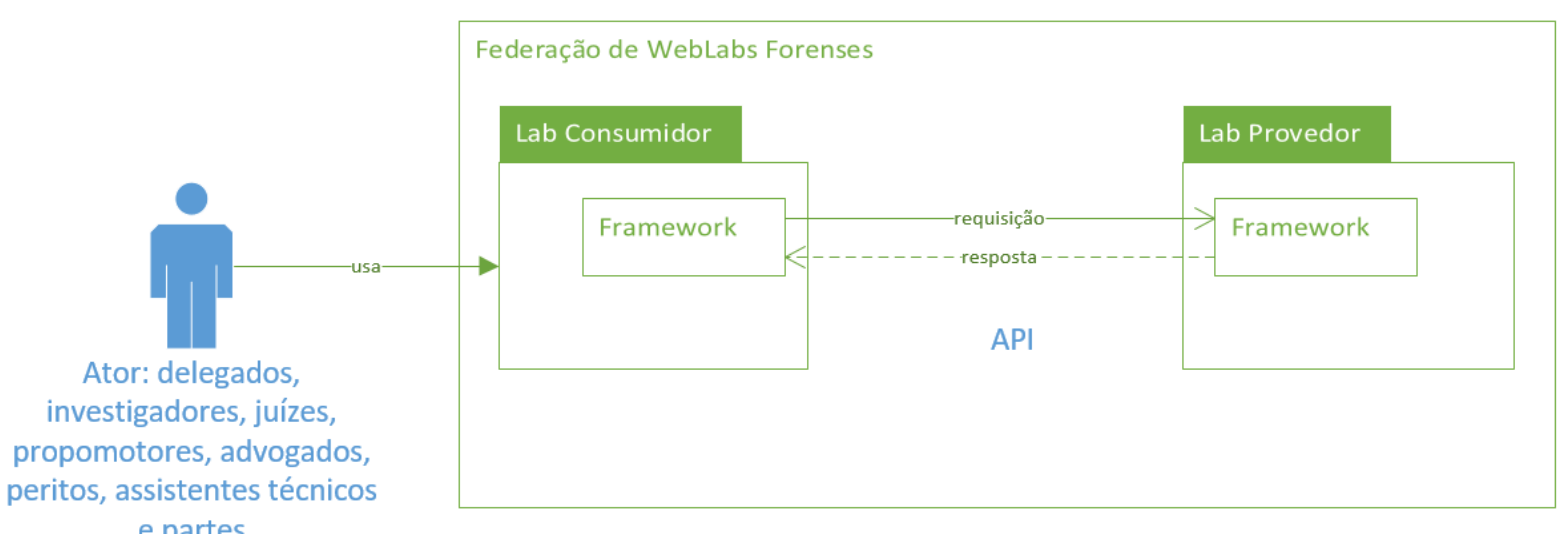

Fonte: Autor, derivado de (ORDUÑA, 2013) e (GOLC, 2011)

Quando não for possível utilizar frameworks comuns para os casos de uso nos laboratórios forenses, se torna necessário adotar middlewares que providenciem conversões de comandos e dados entre ambientes heterogêneos, como ilustra a Figura 16.

Figura 16 - Federação de WebLabs Forenses com middleware

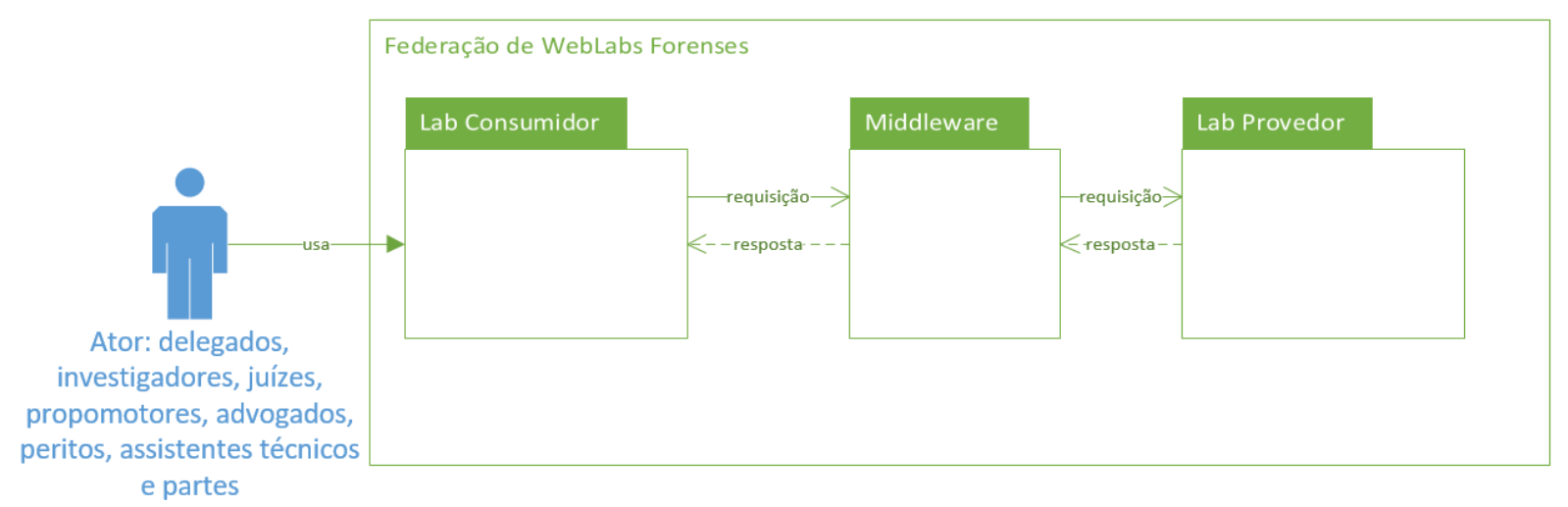


Dessa maneira, o modelo proposto para a Federação de WebLabs Forenses considera basicamente:

a) O usuário final como controlador e demandante dos exames (ator);

b) O laboratório consumidor no qual o usuário está registrado como responsável pela sua identificação, autenticação e intermediação no provimento de recursos, nesse modelo o laboratório consumidor negocia em nome dos seus usuários os recursos proporcionados pelos laboratórios provedores;

c) Interfaces entre laboratórios consumidores e os laboratórios provedores, usualmente baseadas em frameworks ou middlewares;

d) Os laboratórios provedores colocam laboratórios físicos à disposição dos laboratórios consumidores. A autenticação principal nos laboratórios provedores é realizada com a credencial de laboratório consumidor, não como um usuário pois nessa camada o foco é apenas em seus atributos;

e) Serviços de exames forenses, consubstanciados como instâncias de equipamentos laboratoriais físicos que o laboratório provedor coloca à disposição do usuário via laboratório consumidor.

Uma visão simplificada de um diagrama de eventos para esse cenário está ilustrado na Figura 17

Figura 17 - Diagrama de sequência de eventos para federações

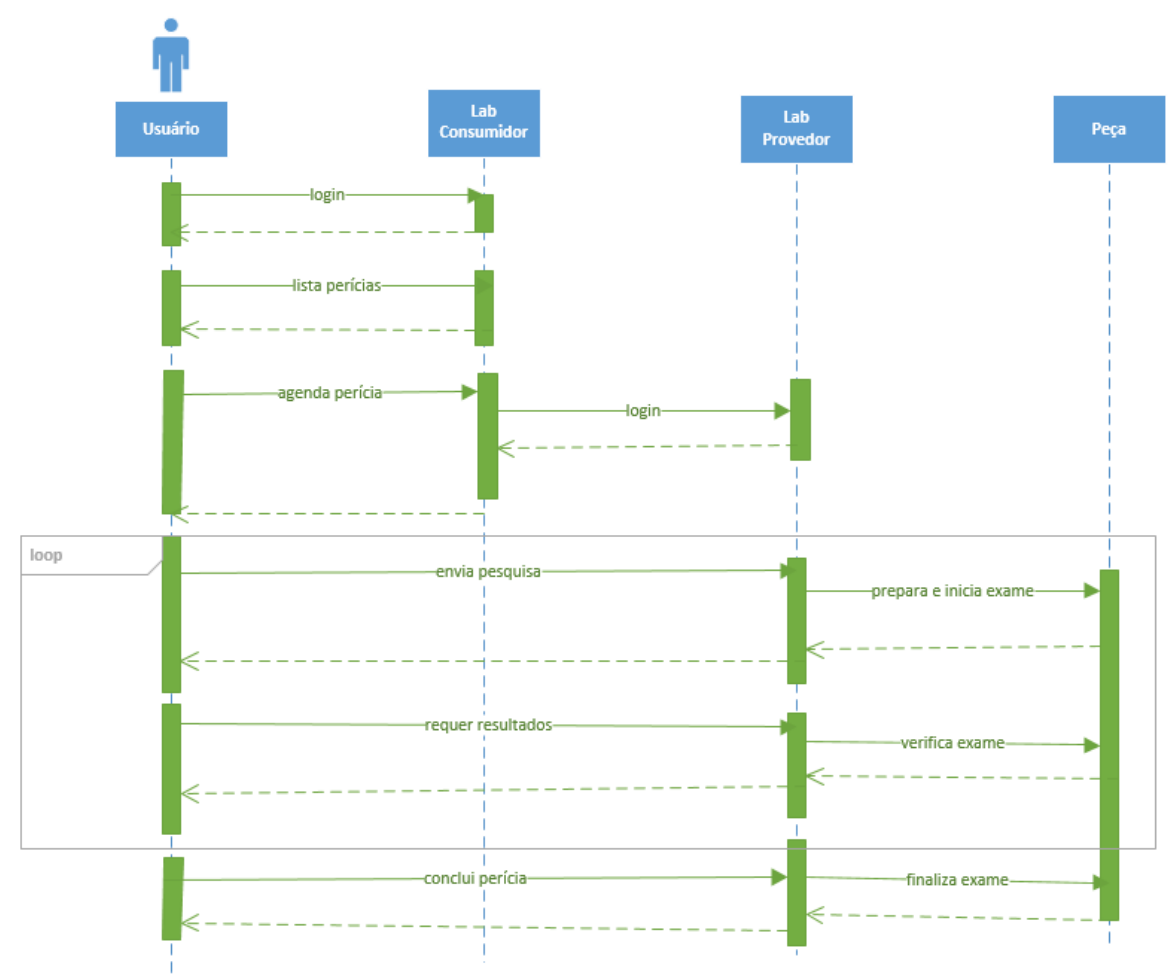


Fonte: Autor, derivado de (ORDUÑA, 2013) e (GOLC, 2011)

Visando tornar a rede de laboratórios forenses ainda mais transitiva e escalável, propõe-se a formação de Confederações de WebLabs Forenses. Diferentemente do que ocorre entre usuários e as federações, as confederações podem se aglutinar e se associar livremente, possivelmente considerando a existência de políticas e padrões operacionais comuns, com isso se aumenta a flexibilidade na alocação de recursos e serviços e se possibilita a intermediação e revenda de recursos e serviços.

Figura 18 - Confederação de WebLabs Forenses

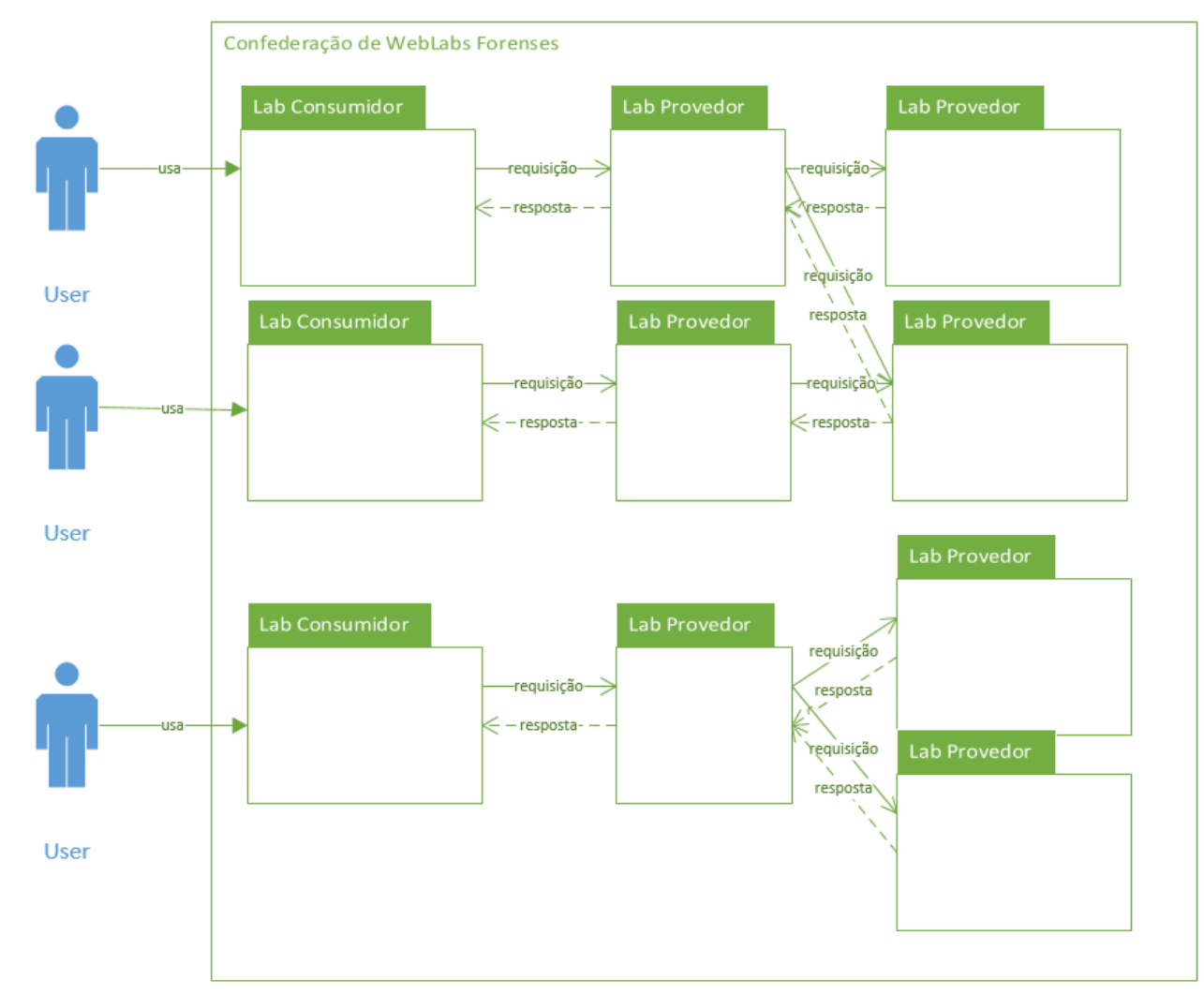

Fonte: Autor, derivado de (ORDUÑA, 2013) e (GOLC, 2011)

Dessa maneira, a Confederação de WebLabs Forenses se caracteriza pela livre associação entre provedores, intermediação e revenda, tornando a rede muito mais transitiva e escalável.

\subsubsection{Integrar Federações de WebLabs aos Sistemas de Processo Judicial Eletrônico}

A criação de federações e confederações de WebLabs Forenses possibilita aos operadores do Direito participar remotamente e colaborativamente dos processos 
realizados no interior dos laboratórios forenses. Com tal aperfeiçoamento, os operadores passam a poder atuar remotamente tanto no trâmite dos processos judiciais pelos tribunais quanto na realização dos exames na intimidade dos laboratórios forenses.

Ocorre que atualmente não existe uma integração efetiva entre os sistemas de gestão dos processos judiciais e os sistemas de gestão dos laboratórios, a despeito dos primeiros serem origem e destino das perícias técnicas e os últimos administrarem os exames periciais. Na prática, a comunicação entre esses processos se dá apenas pelo registro manual independente em ambos os sistemas de documentos formais, como ofícios, petições, manifestações ou laudos, portanto, via de regra, os processos não estão sistemicamente integrados mesmo se o mesmo grupo de operadores do Direito tem interesses e responsabilidades comuns, ou deveria ter, tanto no que ocorre no processo judicial quanto na intimidade do laboratório forense, especialmente com relação à colaboração e fiscalização mútuas. Para suprir essa deficiência, o presente estudo propõe a integração entre os sistemas de suporte das federações de WebLabs Forenses e os sistemas de gestão dos processos judiciais.

A automação dos processos judiciais teve um avanço significativo a partir de 2004 com a implantação do Sistema Creta para os Juizados Especiais Federais da $5^{\text {a }}$ Região, do Ceará a Sergipe, e com o sistema Processo Judicial Eletrônico, conhecido como Projudi ou simplesmente Sistema CNJ porque a partir de 2006 esse órgão passou a distribuí-lo aos tribunais. Marco relevante foi a promulgação da Lei número 11.419, de 19 de dezembro de 2006, dispondo sobre a informatização do processo judicial e regulando em especial o uso de meio eletrônico na tramitação de processos judiciais, na comunicação de atos e na transmissão de peças processuais nos processos civil, penal e trabalhista, bem como nos juizados especiais, em qualquer grau de jurisdição.

Durante a década seguinte os trabalhos evoluíram intensamente, havendo atualmente mais de 40 sistemas de gestão que atendem quase uma centena de tribunais em atividades tão diversas como atualização de cadastros básicos, autuação, numeração, validação e cadastro de processo, distribuição, audiência, pedidos de perícias, intimação, mandados, precatórios, cálculos, segredo de justiça, sigilo e certidões.

Como esses sistemas tiveram origens distintas, ao longo do tempo têm sido empreendidos diversos esforços para a uniformização e integração. Em 2009 foi 
estabelecido um acordo de cooperação técnica ${ }^{17}$ entre o Conselho Nacional de Justiça (CNJ) e os tribunais federais visando 0 desenvolvimento harmônico das funcionalidades básicas relacionadas à tramitação dos processos, o que evoluiu para a tendência de se adotar uma nova solução denominada Processo Judicial eletrônico $(\mathrm{PJe})^{18}$ que visa ser plataforma única para atender às necessidades dos diversos segmentos do Poder Judiciário brasileiro, abrangendo a Justiça Militar da União e dos Estados, a Justiça do Trabalho e a Justiça Comum, Federal e Estadual (CRISTOVÃO, 2011). Por outro lado, existe também a tendência de se fortalecer a interoperabilidade de plataformas heterogêneas já existentes via recursos como o Modelo Nacional de Interoperabilidade (MNI), que está em desenvolvimento ${ }^{19}$ em parceria estabelecida entre dezenas de tribunais de justiça, ministérios públicos e procuradorias estaduais e municipais ${ }^{20}$. Por exemplo, em 2016 esse modelo proporcionou a integração entre o SAj, do Tribunal de Justiça de São Paulo, e o e-STF para a tramitação automática dos processos nessas instâncias ${ }^{21}$. Outros aperfeiçoamentos de interesse pericial ocorreram nesse período, destacando-se o novo Código de Processo Civil e a criação do cadastro único de peritos no âmbito do Poder Judiciário.

Diante desse cenário, o presente estudo propõe a integração entre os sistemas de gestão dos processos judiciais e as federações de WebLabs Forenses, contemplando em síntese as seguintes funções principais:

Quadro 8 - Integração entre Processo Judicial Eletrônico e federações de WebLabs Forenses

\begin{tabular}{|l|l|}
\hline Usuários & $\begin{array}{l}\text { Acesso via Web aos Processos Eletrônicos e às Federações de WebLabs } \\
\text { por meio das mesmas credenciais, usualmente fornecidas pelas serventias } \\
\text { dos tribunais ou via assinatura digital de maneira a garantir a identificação } \\
\text { inequívoca. O modelo deve prever tratamento completo na identificação de } \\
\text { peritos e assistentes técnicos, de maneira integrada ao Cadastro de Peritos. }\end{array}$ \\
\hline
\end{tabular}

17 Termo de Cooperação Técnica número 073/2009, estabelecido entre o CNJ e os Tribunais Federais, disponível em http://www.pje.jus.br/

18 O Processo Judicial Eletrônico (PJe) é um sistema de informática criado para dar fim à tramitação de autos em papel no Poder Judiciário. O desenvolvimento da ferramenta tecnológica é coordenado pelo Conselho Nacional de Justiça, em parceria com diversos tribunais brasileiros. Trata-se de aplicação que substituiu dezenas de sistemas de informática no Poder Judiciário, que atualmente não se comunicam. Trata-se de uma solução única, gratuita, em linguagem moderna e que proporciona interoperabilidade entre os Tribunais e outros órgãos da Administração Pública (Correios, Caixa Econômica Federal, Banco do Brasil, Receita Federal, etc.). Lei 11.419/06. Vide http://www.pje.jus.br

19 Desenvolvimento técnico realizado pela empresa Softplan.

20 Veja em http://www.conjur.com.br/2016-abr-24/entrevista-ilson-stabile-socio-softplan-criousaj?utm_source=dlvr.it\&utm_medium=facebook.

${ }^{21}$ Disponível em http://www.sajdigital.com.br/saj-na-midia/modelo-nacional-de-interoperabilidade-tjspstf/ 


\begin{tabular}{|c|c|}
\hline Perfis & $\begin{array}{l}\text { Utilização de perfis comuns aos ambientes de Processos Eletrônicos e de } \\
\text { Federações de WebLabs, por exemplo, identificando advogado, procurador, } \\
\text { promotor, defensor, perito, assistente, preposto, leiloeiro, técnico, serventia } \\
\text { auxiliar parte etc. O modelo deve prever tratamento completo do perfil } \\
\text { associado aos peritos e assistentes técnicos, de maneira integrada ao } \\
\text { Cadastro de Peritos. }\end{array}$ \\
\hline Órgãos vinculados & $\begin{array}{l}\text { Controle dos órgãos integrantes dos sistemas de Processos Judiciais } \\
\text { Eletrônicos e das Federações de WebLabs Forenses. Controle de } \\
\text { vinculação entre órgãos e usuários. O modelo deve prever tratamento } \\
\text { completo na identificação laboratórios e sua vinculação aos peritos e } \\
\text { assistentes técnicos }\end{array}$ \\
\hline $\begin{array}{l}\text { Escritórios virtuais/laboratórios } \\
\text { virtuais }\end{array}$ & $\begin{array}{l}\text { Sistemas de Processos Judiciais Eletrônicos e Federações de WebLabs } \\
\text { Forenses devem proporcionar visão integrada e participação colaborativa e } \\
\text { fiscalizadora junto aos processos através de escritórios e laboratórios } \\
\text { virtuais. }\end{array}$ \\
\hline Fluxos de trabalho & $\begin{array}{l}\text { Tanto os sistemas de gestão de Processos Eletrônicos quanto as } \\
\text { Federações de WebLabs devem possibilitar a criação e manutenção de } \\
\text { fluxos integrados de trabalho }\end{array}$ \\
\hline Consultas processuais & $\begin{array}{l}\text { Consultas tanto nos sistemas de Processos Judiciais Eletrônicos quanto nas } \\
\text { Federações de WebLabs Forenses. O modelo deve prever integração com o } \\
\text { controle de procedimentos no interior dos laboratórios forenses. }\end{array}$ \\
\hline Distribuição eletrônica & $\begin{array}{l}\text { Os sistemas de Processos Judiciais Eletrônicos tratam da distribuição } \\
\text { eletrônica dos processos judiciais. Deve prever a integração com modelo } \\
\text { para distribuição racional de serviços forense aos laboratórios e peritos, } \\
\text { considerando dados do processo, especialidades, tecnologias, } \\
\text { disponibilidade e proximidade. }\end{array}$ \\
\hline Peticionamento/Atividades & $\begin{array}{l}\text { Os sistemas de Processos Judiciais Eletrônicos tratam do peticionamento } \\
\text { eletrônico. Além da integração entre os sistemas, no âmbito das Federações } \\
\text { de WebLabs abrange a atividade colaborativa e fiscalizadora. }\end{array}$ \\
\hline Intimações, notificações etc. & $\begin{array}{l}\text { Os sistemas de Processos Judiciais Eletrônicos tratam intimações feitas por } \\
\text { meio eletrônico inclusive quanto às consultas realizadas nos sistemas. A } \\
\text { questão se torna pertinente com a integração com as Federações de } \\
\text { WebLabs Forenses utilizadas primeiramente pelos peritos e assistentes } \\
\text { técnicos, mas que também pode ser utilizadas pelos demais operadores do } \\
\text { Direito. }\end{array}$ \\
\hline $\begin{array}{l}\text { Precatórias, rogatórias e } \\
\text { demais ordens }\end{array}$ & $\begin{array}{l}\text { Sistemas de gestão de Processos Eletrônicos, inclusive o Hermes, tratam as } \\
\text { comunicações de atos entre órgãos do Poder Judiciário. Nesse âmbito, as } \\
\text { Federações de WebLabs Forenses possibilitam sob o aspecto técnico ampla } \\
\text { atuação local, estadual, nacional e internacional de laboratórios, usuários e } \\
\text { órgãos vinculados }\end{array}$ \\
\hline Terceiros & $\begin{array}{l}\text { Os Processos Judiciais Eletrônicos proveem integração com terceiros no } \\
\text { âmbito processual (Receita, Bacen, INSS etc.), as Federações de WebLabs } \\
\text { no âmbito técnico (ferramentas, serviços etc.) }\end{array}$ \\
\hline Documentos/Peças & $\begin{array}{l}\text { Os sistemas de Processos Judiciais Eletrônicos custodiam e tratam } \\
\text { documentos, além das condições de acesso aos Autos por exemplo em } \\
\text { situações de segredo de justiça. As Federações de WebLabs Forenses } \\
\text { tratam documentos e também a custódia das evidências em si. Em ambos } \\
\text { há modelos de documentos e procedimentos (frameworks) }\end{array}$ \\
\hline Histórico & $\begin{array}{l}\text { Os sistemas de Processos Judiciais Eletrônicos tratam do histórico de } \\
\text { atividades realizadas. As federações de WebLabs se integram, mantendo } \\
\text { registros mais detalhados sobre as determinações recebidas, os } \\
\text { procedimentos realizados, as atividades de natureza técnica e o exercício do } \\
\text { contraditório técnico entre as partes. Mantém também o registro da cadeia } \\
\text { de custódia das evidências. }\end{array}$ \\
\hline Estatísticas & $\begin{array}{l}\text { Ambos os tipos de sistemas geram estatísticas e apoiam a gestão dos } \\
\text { processos. }\end{array}$ \\
\hline
\end{tabular}

Fonte: autor 
Considerando que os sistemas de gestão de processos judiciais tanto podem tender para o uso de um único modelo quanto para a integração de sistemas diferentes e considerando ainda que o presente estudo propõe essas mesmas duas alternativas para as Federações de WebLabs Forenses, então pode-se considerar que esse mesmo cenário com duas alternativas se impõem para a integração entre os sistemas de gestão de processos e os sistemas de gestão de laboratórios, como ilustra a Figura 19

Figura 19 - Processos judiciais eletrônicos e federações de WebLabs

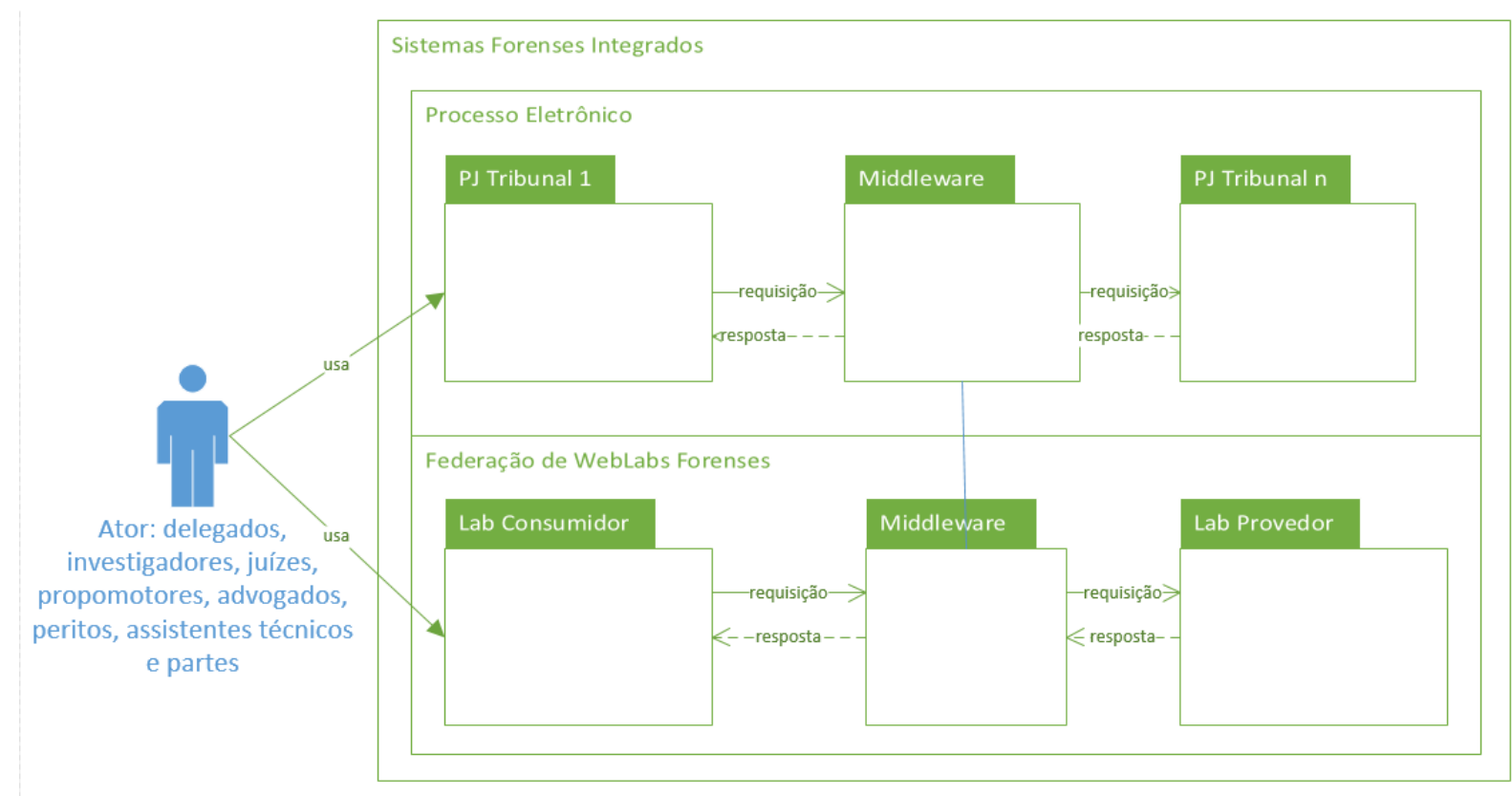

Fonte: autor

Dessa forma, o modelo ora proposto contempla a integração entre os sistemas de gestão do Processo Judicial Eletrônico e os sistemas das Federações de WebLabs Forenses, sendo que essa providência enfatiza o entendimento de que o processo eletrônico não é mais a mera substituição de substituição de documentos e controles em papel por seus equivalentes digitais, bem além disso, a integração ora proposta ultrapassa a tramitação do processo judicial por meio eletrônico ao transportar os operadores do Direito diretamente para o cenário onde estão os vestígios e os imergir na produção e valoração de provas de alta tecnologia. Para essa tarefa devem ser respeitados os padrões de intercâmbio de informações de processos judiciais entre órgãos da administração da justiça, considerando em especial o Modelo Nacional de 
Interoperabilidade de Dados do Poder Judiciário e Órgãos da Administração da Justiça (CONSELHO NACIONAL DE JUSTIÇA, 2014).

\subsubsection{Integração de Provedores de Serviços às Federações de WebLabs}

Nos capítulos anteriores o presente estudo propôs a criação de WebLabs Forenses contendo caixas de areia (sandbox) protegidas, isoladas e fiscalizadas que poderiam ser utilizadas pelos operadores do Direito para realizar remotamente e de maneira colaborativa os exames periciais forenses. Também propôs que esses ambientes fossem integrados aos sistemas de gestão dos processos eletrônicos de modo a assegurar que os procedimentos realizados fossem aderentes às normas vigentes, às determinações do magistrado para cada processo judicial, assegurando amplo contraditório técnico e a profunda fiscalização mútua. Essas caixas de areia têm ainda a incumbência de assegurar a correta custódia das evidências judiciais e a perfeita geração da cadeia de custódia que assegure o pleno controle sobre as atividades realizadas por cada agente e sobre cada vestígio.

A solução proposta pode ser aplicada também nos crescentes conflitos entre autoridades e provedores de serviços ${ }^{22}$ provocados por divergências entre a necessidade de se quebrar o sigilo das comunicações para fins de investigações e o direcionamento dos provedores de serviços em assegurar a proteção da privacidade e a segurança dos seus clientes. Sob o ponto de vista técnico usualmente o ponto central da divergência reside no uso da criptografia fim-a-fim sem uma "porta dos fundos" que possibilite o cumprimento das determinações judiciais. Nesse contexto, o presente estudo propõe a adoção de uma rede de WebLabs Forenses como ambiente neutro e controlado remotamente tanto pelo Poder Judiciário quanto pelo próprio provedor do serviço para a realização de procedimentos ad hoc de exceção que visem tanto o cumprimento das determinações judicias quanto assegurar o sigilo aos usuários que atuam licitamente. (GIOVA, 2011a)

O modelo proposto contempla uma efetiva Caixa de Areia Forense ${ }^{23}$, local onde os procedimentos investigativos de exceção seriam realizados sob controle da Justiça de

\footnotetext{
22 Provedores de serviços como WhatsApp, Telegram, Threema, Viber, Google, entre muitos outros

${ }^{23}$ Forensic Sandbox
} 
um ou mais países, operacionalizados por especialistas neutros em uma caixa de areia isolada e controlada pelo provedor dos serviços questionados. Em síntese, o modelo ora proposto prevê a existência prévia de "portas dos fundos" 24 que somente poderiam ser abertas com dupla chave (Justiça e Provedor). Propõe-se ainda nesse mesmo sentido que, na ausência de backdoor previamente existente, o ambiente de WebLab Forense seja utilizado, igualmente com a dupla chave e mediante trabalho colaborativo e mutuamente fiscalizado, para a criação ad hoc de acessos mediante, por exemplo, a realização em conjunto de procedimentos mais invasivos como chipoff, quebra de chaves ou inserção de programas maliciosos, entre outros, conforme ilustrado na Figura 20 .

Figura 20 - WebLabs Forenses para encontro entre autoridades e provedores

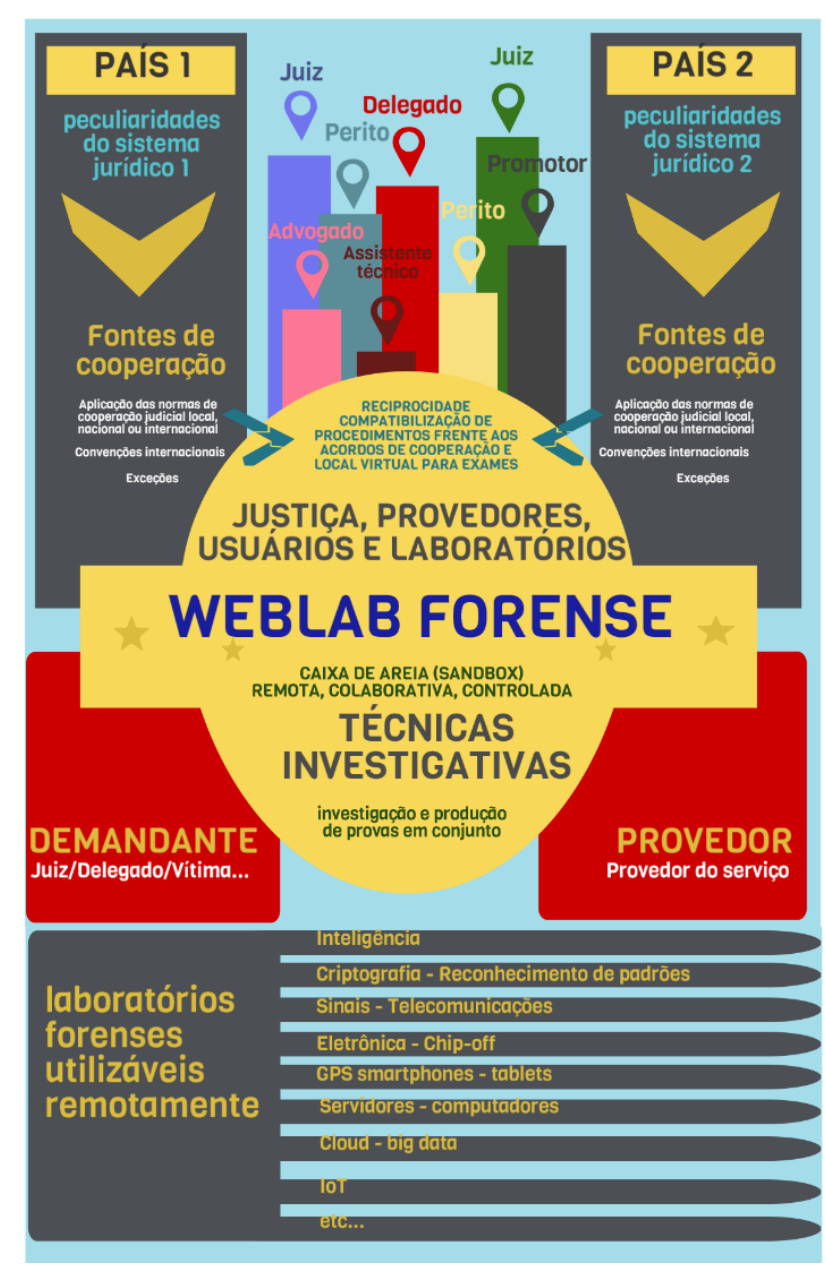

Fonte: autor

${ }^{24}$ Backdoors 
Com o modelo de WebLabs Forenses integrados aos sistemas de gestão de Processos Judiciais minimiza-se o confronto e se cria um "canal do meio" e um "ponto de encontro" técnico entre a necessidade do Poder Judiciário de conhecer as verdades dos fatos e a necessidade dos provedores de serviços quanto a assegurar a privacidade dos usuários, uma vez que o WebLab Forense provê um ambiente judicialmente supervisionado e tecnicamente confiável para procedimentos de exceção junto aos provedores de serviços e tecnologias, sendo controlável remotamente, em nível nacional ou internacional, por magistrados, promotores, advogados, peritos, assistentes técnicos e pelas próprias partes, reduzindo-se o confronto as determinações de quebra do sigilo de algum usuário e a garantia de sigilo dos usuários em geral na medida em que se proporciona um ambiente amplamente controlado para a aplicação das medidas.

\subsubsection{Aprimorar Processos}

O presente estudo apontou que um dos problemas de qualidade da perícia forense é baixa confiabilidade da cadeia de custódia sobre evidências digitais. Ocorre que a criação de redes de WebLabs Forenses requer controles mais efetivo da cadeia de custódia, motivo pelo qual são propostos a seguir aperfeiçoamentos nos mecanismos de cadeia de custódia utilizados atualmente nas perícias em sistemas eletrônicos.

Como já demonstrado, os investigadores forenses precisam coletar e analisar grandes volumes de evidências digitais e submetê-las à corte com a garantia de que elas são confiáveis. Uma vez que as evidências digitais são complexas, difusas e voláteis e podem inadvertidamente ou indevidamente ser modificadas após sua aquisição, a cadeia de custódia precisa assegurar que o material submetido à corte pode ser aceito como verdadeiro. Nesse cenário, se mostra ineficiente a tradicional cadeia de custódia baseada em registros feitos em papel, ela não pode garantir que os procedimentos forenses seguiram os princípios técnicos e legais necessários em uma sociedade eletrônica.

Com a evolução desse modelo, os peritos passaram a utilizar software forense que, além de produzir clones ou imagens de dispositivos eletrônicos, também coleta metadados associados a esse procedimento como o nome do perito e os números de série tanto do disco rígido original copiado quanto daquele onde a cópia foi 
armazenada. Mesmo com esse avanço, esse controle é insuficiente para garantir ao juiz a qualidade do disco original, assegurar que somente pessoas autorizadas tiveram acesso à evidência, certificar que as cópias e análises resultaram apenas de procedimentos autorizados e atestar que todos os procedimentos foram realizados apenas em locais autorizados e não em locais que configurariam violação do sigilo ou privilégio indevido a algumas das partes no processo judicial.

Em um processo, as evidências são utilizadas para demonstrar a verdade e por isso afetam o resultado do processo. Práticas atuais concedem ao juiz um grau importante de liberdade para decidir sobre a admissão de evidências, desde que elas atendam aos requisitos legais básicos, como equidade, racionalidade, razoabilidade e eficiência, considerando-se de qualquer modo que as disputas quanto às evidências é sempre um procedimento contraditório entre as partes (BRIDGE, 1982).

Essas questões seguem regras específicas em cada país. Nos Estados Unidos a questão é regular pela Rule 901, das Federal Rules of Evidences. Em síntese define que a admissibilidade da evidência depende da qualidade percebida pelo juiz ou pelos jurados. Como consequência, a admissibilidade da evidência está associada à existência de uma sólida cadeia de custódia que contribua com a equidade, eficiência e confiabilidade do processo.

Nesse sentido, considera-se que uma evidência digital não poderia ser admitida sem sua cadeia de custódia porque sua avaliação está além da mera percepção sensorial.

O U.S. National Institute of Justice (NIJ) define cadeia de custódia como "um processo utilizado para manter e documentar a história cronológica da evidência”, o que significa ter controle sobre o nome das pessoas que coletam a evidência e de cada pessoa ou entidade que subsequentemente tem a sua custódia, assim como as datas de coleta e transferência, o órgão, o número do processo, os nomes da vítima e do suspeito e uma breve descrição de cada peça (JUSTICE, 2016).

A produção de provas no moderno mundo digital tornou-se uma tarefa complexa, motivo pelo qual (ĆOSIĆ; BAČA, 2010a) e este autor (GIOVA, 2011b) consideram essencial que evidências digitais somente possam ser aceitas em juízo se a cadeia de custódia puder assegurar exatamente o que é a evidência, por que foi selecionada e como foi coletada, analisada e apresentada na corte. Esses autores consideram 
ainda que a cadeia de custódia deve demonstrar exatamente onde, quando e quem entrou em contato com evidências eletrônicas em cada estágio da investigação.

A crescente complexidade da ciência forense na área digital empurra a computação forense tradicional para "a beira de um precipício", especialmente devido à grande diversidade de dispositivos eletrônicos a apreender e ao intenso crescimento da quantidade de dados a coletar e examinar em um investigação digital forense (TURNER, 2005).

Esse cenário torna mais difícil criar e manter cadeias de custódia confiáveis e expõe uma grande lacuna entre os critérios usuais em procedimentos forenses e o ponto de vista da comunidade científica sobre os riscos e condições necessários para considera confiável alguma evidência digital.

A legislação em muitos países estabelece a obrigação para todas as empresas de preservar dados que podem ser relevantes para efeitos legais. Nos Estados Unidos, o Sarbanes-Oxley Act impõe penalidades severa e as regras da Securities Exchange Commission determinam a guarda de dados por seis anos. Log, dados devem ser preservados de maneira que seja possível verificar sua autenticidade e integridade, questões críticas para a cadeia de custódia (PATZAKIS, 2003).

Alguns softwares modernos descrevem diversas propriedades dos arquivos, como localização e datas de criação, acesso, modificação e exclusão, além disso reforçam a verificação de autenticidade pelo controle de redundância cíclica ( $C R C$ ) e pela geração de código hash, um valor numérico único calculado a partir do conteúdo do material original ou da sua cópia.

Softwares mais modernos adotam o conceito de servidores centrais de autenticação que operam pela concessão de chaves de sessão para usuários autorizados, monitorando todas as tarefas realizadas durante os exames e com isso mantendo automaticamente a cadeia de custódia. Muitos desses controles são realizados em modo online e em tempo reduzido por meio de redes locais ou WAN (PATZAKIS, 2003).

Alguns desses softwares utilizam padrões abertos, outros utilizam formatos proprietários para a automação da cadeia de custódia, mas em geral os recipientes para evidências digitais não são interoperáveis e intercambiáveis (GARFINKEL et al., 2006b), gerando dificuldades para a concepção de um modelo de cadeia de custódia 
adequado para a necessária para a Rede de WebLabs Forenses, motivo pelo qual o presente trabalho de pesquisa deve buscar soluções.

Pollit (POLLITT, 2007) estudou os principais processos de perícia digital e identificou pontos que são relevantes também para a construção de uma proposta no presente projeto:

- (NOBLETT; POLLITT; PRESLEY, 2000) estudaram a relação entre os motivos da investigação e as exigências da ciência forense;

- O Digital Forensic Research Workshop DFRWS (PALMER, 2001) consolidou o consenso de que a perícia digital é um processo com "alguma razoabilidade";

- (CLINT et al., 2002) apresentaram um modelo de processo com 9 etapas: identificação, preparação, estratégia de abordagem, preservação, coleta, exame, análise, apresentação e devolução da evidência;

- (CARRIER; SPAFFORD, 2003) apresentaram o Integrated Digital Investigation Process com 17 fases em 5 grupos: prontidão, desenvolvimento, investigação física da cena do crime, investigação digital da cena de crime e revisão;

- (STEPHENSON, 2003) partiu da estrutura DFRWS para desenvolver um modelo de processo para análise de causa-raiz em incidentes com 9 etapas: coleta de evidências, análise dos eventos individuais, correlação preliminar, normalização de eventos, tratamento de conflitos em eventos, correlação de segundo nível, análise da linha de tempo, construção da cadeia de custódia e corroboração;

- (CARRIER, 2003) formulou que nenhum software forense é perfeito por isso deve haver um registro histórico dos erros, útil para avaliar sua confiabilidade;

- (MOCAS, 2004) confirmou que há múltiplos contextos para a perícia digital, como o policial, militar e de segurança das empresas, a partir disso estabeleceu as propriedades desejáveis em cada contexto;

- (BARYAMUREEBA; FLORENCE, 2004) propuseram modificar o modelo de Carrier e Spafford inserindo duas fases adicionais para evitar inconsistências na investigação, obtendo o isolamento entre a cena primária do crime (o computador) e a cena secundária dos crimes (a cena física do crime);

- (BEEBE; CLARK, 2005) afirmaram que os modelos anteriores eram de camada única, mas os processos reais são multi-camada, então introduziram uma 
estrutura baseada em objetivos que visa a neutralidade e aplicável uma ampla comunidade de usuários;

- (CARRIER; SPAFFORD, 2004) adiconaram novos elementos sobre eventos e reconstrução de eventos à estrutura de forense digital;

- (POLLITT, 2004) afirmou que perícia forense não é um processo único, é um conjunto de tarefas agrupadas em funções relacionadas aos papeis e vinculadas a restrições;

- (RUIBIN; YUN; GAERTNER, 2005) propuseram um método para medir a importância de cada informação de determinado caso;

- (ERBACHER; CHRISTENSEN; SUNDBERG, 2006) afirmaram que a perícia em rede não é um processo linear porque há múltiplos ciclos de realimentação;

- O National Institute of Standards and Technology (NIST) publicou o Guide to Integrating Forensic Techniques into Incident Response (KENT et al., 2006) definido que o processo forense básico tem quatro fases: coleta, exame, análse e apresentação.

Pode-se ver uma crescente quantidade de pesquisas sobre os procedimentos da perícia digital forense, contudo a consolidação desses estudos mostra que ainda não havia uma estrutura madura e operacional de cadeia de custódia.

Em 2010, (ĆOSIĆ; BAČA, 2010a) e (CARRIER; SPAFFORD, 2004) propuseram uma estrutura conceitual para administração de cadeia de custódias (DEMF) em todas as fases de uma investigação. Recomendaram a utilização de código hash como impressão digital da evidência (o que), comparação de hash para controlas mudanças (como), identificação biométrica e assinatura eletrônica (quem), carimbos automáticos e certificados de tempo (quando) e localização por GPS e RFID (onde). Pretendiam que esses controles fossem implementados por meio de registros em banco de dados produzidos por delegados, policiais, investigadores forenses e peritos. Este autor considera que essas sugestões (ĆOSIĆ; BAČA, 2010a) e (CARRIER; SPAFFORD, 2004) foram decisivas para aproximar a cadeia de custódia ao mundo real, devendo servir de base para a formulação de um modelo para a Rede de WebLabs Forenses.

Em nova evolução, (KOCH; ELOFF; OLIVIER, 2008) propuseram um paradigma para modelar processos forenses através da Unified Modeling Language (UML), definiram um modelo de processo (DFPM) derivado do modelo de Krause combinado com o 
guia de referência do U.S. DOJ para crimes relacionados a computadores. Em essência o novo modelo mostra 5 atividades:

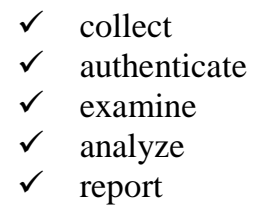

Definiram também 5 participantes principais:

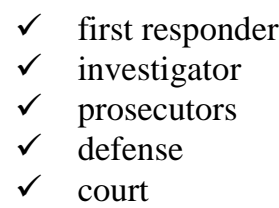

Para efeito da presente pesquisa se considera que, certamente, pode haver diversas variações nesses modelos em função do país, legislação, administração do tribunal, natureza da competência e diversos outros fatores, mas em todos os casos a modelagem fornece esquemas conceituais para melhor entendimento dos participantes e atividades envolvidos com o exame de evidências digitais e para comparações com as diversas ferramentas de software utilizadas para manter cadeias de custódia.

Como se viu, evidências digitais podem ser armazenadas em formatos abertos ou proprietários. O grupo de trabalho CDESF (GARFINKEL et al., 2006a) verificou que à época principais formatos para armazenar evidências digitais eram Raw, AFF, DEB (Qinetiq), EnCase, Expert Witness, GFzip, ProDiscover e SMART, sendo que o formato Raw não armazena metadados, alguns os armazenam no mesmo arquivo das evidência e outros em arquivos separados .

Muitos formatos podem armazenar uma quantidade limitada de metadados, como nome do caso, nome da evidência, nome do perito, data, local, e código hash para assegurar integridade. Outros formatos possibilitam armazenar metadados arbitrários, destacando-se o Advanced Forensic Format (AFF) e o formato GFzip (GARFINKEL et al., 2006a). Uma vez que o formato AFF é aberto, configurável e expansível, para o efeito do presente projeto de pesquisa considera-se que ele é adequado para servir como base para a evolução dos estudos visando o aperfeiçoamento da cadeia de custódia a ser adotada na proposta da Rede de WebLabs Forenses, conforme proposta detalhada a seguir. 


\subsubsection{Proposta de Cadeia de Custódia aderente à Web Semântica}

Em 2006, (GARFINKEL et al., 2006b) definiram o Advancer Forensic Format (AFF) como um recipiente para armazenar evidências digitais em um único arquivo contendo tanto a cópia setor a setor dos dados originais como uma imagem e metadados arbitrários relacionados à imagem e seu conteúdo. Tais metadados podem ser referentes ao sistema, como tamanho do setor ou número de série do dispositivo, aos usuários do software forenses, à configuração do software ou ao nome do departamento, por exemplo.

(COHEN; GARFINKEL; SCHATZ, 2009) constaram problemas a corrigir na primeira versão (AFF1) e perceberam uma intensa evolução nos processos de perícia digital, inclusive o fato de que os peritos começaram a atuar em ambientes distribuídos, com a análises sendo feitas em múltiplos locais e por diferentes pessoas. Com isso em 2009 apresentaram uma nova versão denominada Advanced Forensic Format 4 (AFF4), ela estende a versão anterior passando a suportar múltiplas fontes de dados, evidências lógicas, metadados arbitrários e passa a controlar o fluxo de trabalho forense. Tal evolução se aproxima ainda mais das necessidades próprias para uma estrutura de WebLabs Forenses.

A próxima evolução necessária dentro dos objetivos da presente pesquisa está relacionada à manipulação desses recipientes e seus metadados. Como já demonstrado, uma cadeia de custódia estará mais próxima da realidade se o formato utilizado possibilitar a criação e manutenção de metadados arbitrários com a assinatura hash da evidência (o que), registro dos procedimentos (como), assinatura digital do perito (quem), carimbo de tempo (quando) e geolocalização (onde).

Este projeto considera que o recurso adequado para essa função é o Resource Description Framework (RDF), um padrão e linguagem baseado no XML e criado pelo World Wide Web Consortium (W3C) para facilitar a execução de processos entre diferentes dispositivos. Possibilita codificação, intercâmbio e utilização de metadados de dispositivo com vocabulários que sejam simultaneamente legíveis por humanos e processáveis por máquinas. O RDF utiliza Universal Resource Identifier (RDI) para identificar objetos, assim como metadados, conforme definido em The Internet Society RFC3986, RFC4395 e outros. Cada objeto identificado por um URI pode também ser 
descrito por um Universal Resource Name (URN), seu nome, e um Uniform Resource Locator (URL), seu nome e localização.

Com essa abordagem obtêm-se o intercâmbio de metadados criados por recursos diferentes e em qualquer localização, um conceito básico da Web Semântica e linha de evolução para aperfeiçoamento da cadeia de custódia para WebLabs Forense.

Nos últimos anos pesquisadores propuseram soluções para utilização de recursos AFF4 e RDF para aperfeiçoar modelos e softwares de processos de perícia digital, aperfeiçoando por consequência também as funcionalidades de cadeia de custódia. O presente projeto complementa tais estudos propondo a utilização de AFF4 e RDF para melhorar a confiabilidade da cadeia de custódia em investigações digitais. Nesse sentido, propõe-se para a Rede de WebLabs Forenses a utilização do AFF4 ou outro esquema flexível de metadados em conjunto com descritores RDF com o objetivo de fornecer estruturas que possibilitem automatizar interações entre o mundo real e grande parte dos softwares forenses para cadeia de custódia.

AFF4 armazena metadados arbitrários que podem representar um grande conjunto de objeto do mundo real, nesse sentido a tecnologia chamada Universal Resolver (UR) está preparada para resolver referências externas direcionadas. O acesso e manipulação de evidências AFF4 através da rede podem ser feitos por protocolo HTTP, tonando simples o compartilhamento de arquivos completos de evidências, ou mesmo partes deles, até mesmo um segmento. Essas características são especialmente importantes nas investigações remotas e para implantar sistemas de gestão de evidências efetivamente distribuídos, o que é adequado no caso de processos nos processos digitais grandes e diversificados (ERBACHER; CHRISTENSEN; SUNDBERG, 2006).

Demostra-se como essa abordagem pode aprimorar a segurança de uma cadeia de custódia utilizando uma estrutura tipo DEMF definida por (ĆOSIĆ; BAČA, 2010a), por meio da visão simplificada de estrutura de autor apresentada a seguir:

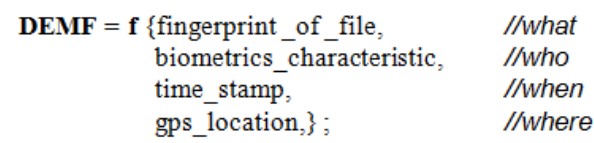


É claro que essa estrutura está focada na interação de dispositivos do mundo rela, como GPS, geradores de carimbos de tempo e calculadores automáticos de código hash, trazendo cadeias de custódia para mais perto do mundo físico e com isso ajudando a que as evidências digitais sejam melhor aceitas e compreendidas pelos tribunais.

Esses critérios são centrais no presente estudo, porque a moderna cadeia de custódia será confiável somente se os fatos do mundo físico real forem acuradamente representados nas cadeias de custódia. Isso significa que os sistemas forenses devem capturar dados ambientais diretamente de transdutores apropriados.

Em nosso exemplo, tal solução será viável se o esquema DEMF ou similar puder implementar um formato aberto expansível como o AFF4 e se no mesmo ambiente puder ser utilizado o RDF para gerenciar diversos metadados arbitrários que interagem diretamente com o mundo físico real por meio de transdutores remotos.

Diferentemente do que (possivelmente) ocorre com o Expert Witness Format (EWF) e outros formatos proprietários (COHEN; GARFINKEL; SCHATZ, 2009), o formato AFF pode armazenar grande quantidade de propriedades (metadados) relacionadas à imagem forense e seu ambiente. As funcionalidades de usuário para metadados proporcionadas pela versão AFF4 podem ser utilizadas para descrever propriedades do objeto uma vez que qualquer metadados por ser reduzida a uma notação de tupla com o formato geral a seguir (ĆOSIĆ; BAČA, 2010b):

SUBJECT ATTRIBUTE VALUE

(2)

Objetos do mundo físico rela podem então ser descritos por meio do seu Universal Resource Name (URN), como (COHEN; GARFINKEL; SCHATZ, 2009):

$\checkmark \quad$ ISBN-10 and ISBN-13 of Federal Rules of Evidence Manual:

urn:isbn10: 0327159219

urn:isbn10: 978-0327159216

$\checkmark$ IETF's RFCs: 
Utilizando o URN em ambiente AFF4, se obtém o seguinte exemplo (COHEN; GARFINKEL; SCHATZ, 2009):

urn:aff4:83a3d6db-85d

Esses autores usam o AFF4 mostrando empresa fictícia com dois escritórios em duas distintas cidades, cada uma tendo seu próprio laboratório de forense computacional conectado via WAN. Neste trabalho se explora exemplo similar, mas não somente em empresa fictícia. Expandindo o uso do RDF e adaptando estruturas como o DEMF definido por Ćosić e Bača é possível estender tais funcionalidade para o ambiente dos tribunais.

Essa abordagem permite agora propor a interação direta entre sistemas forenses e peritos, policiais, investigadores, promotores e Advogados como mostra o diagrama a seguir. 


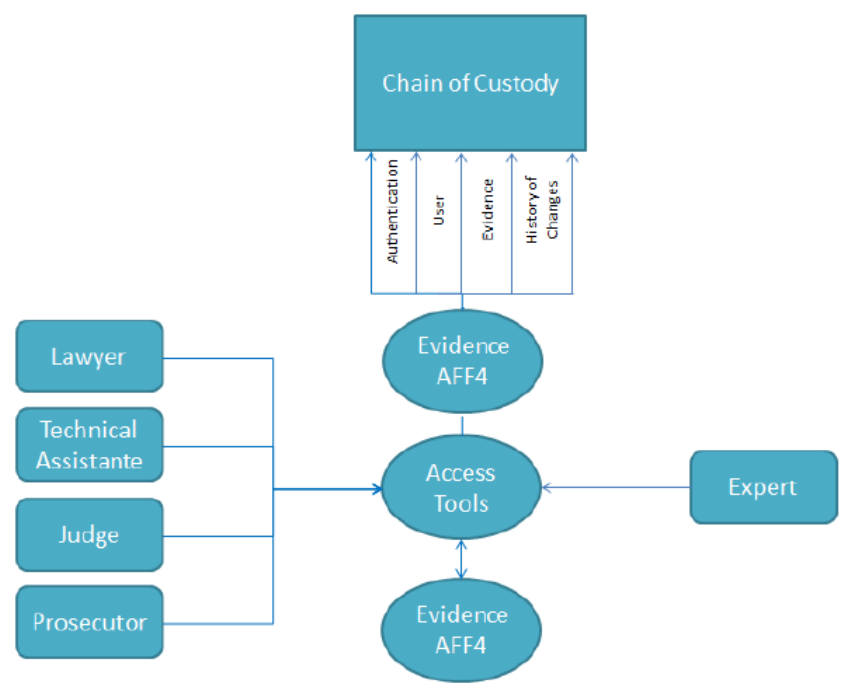

Figura 21 - Diagrama de bloco simplificado

Podemos representar esse diagrama também conforme segue.

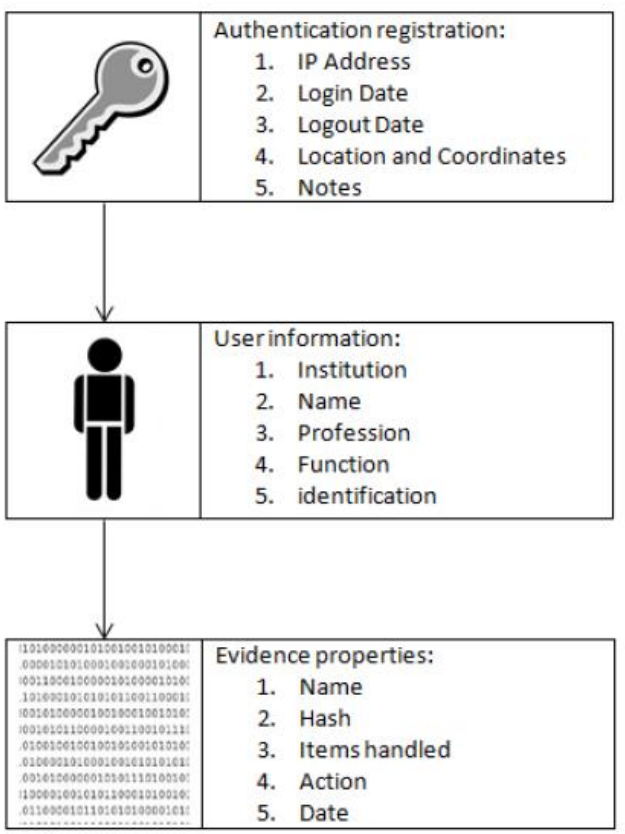

Figura 22 - Visão geral da autenticação para a cadeia de custódia

Partindo desse modelo, a implementação RDF pode ser representada de maneira livre como exposto a seguir:

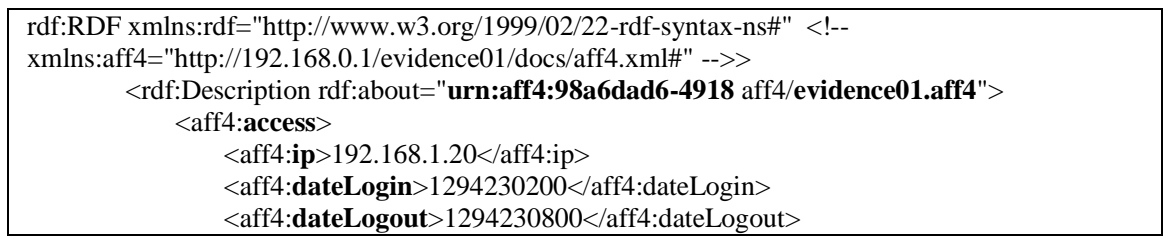




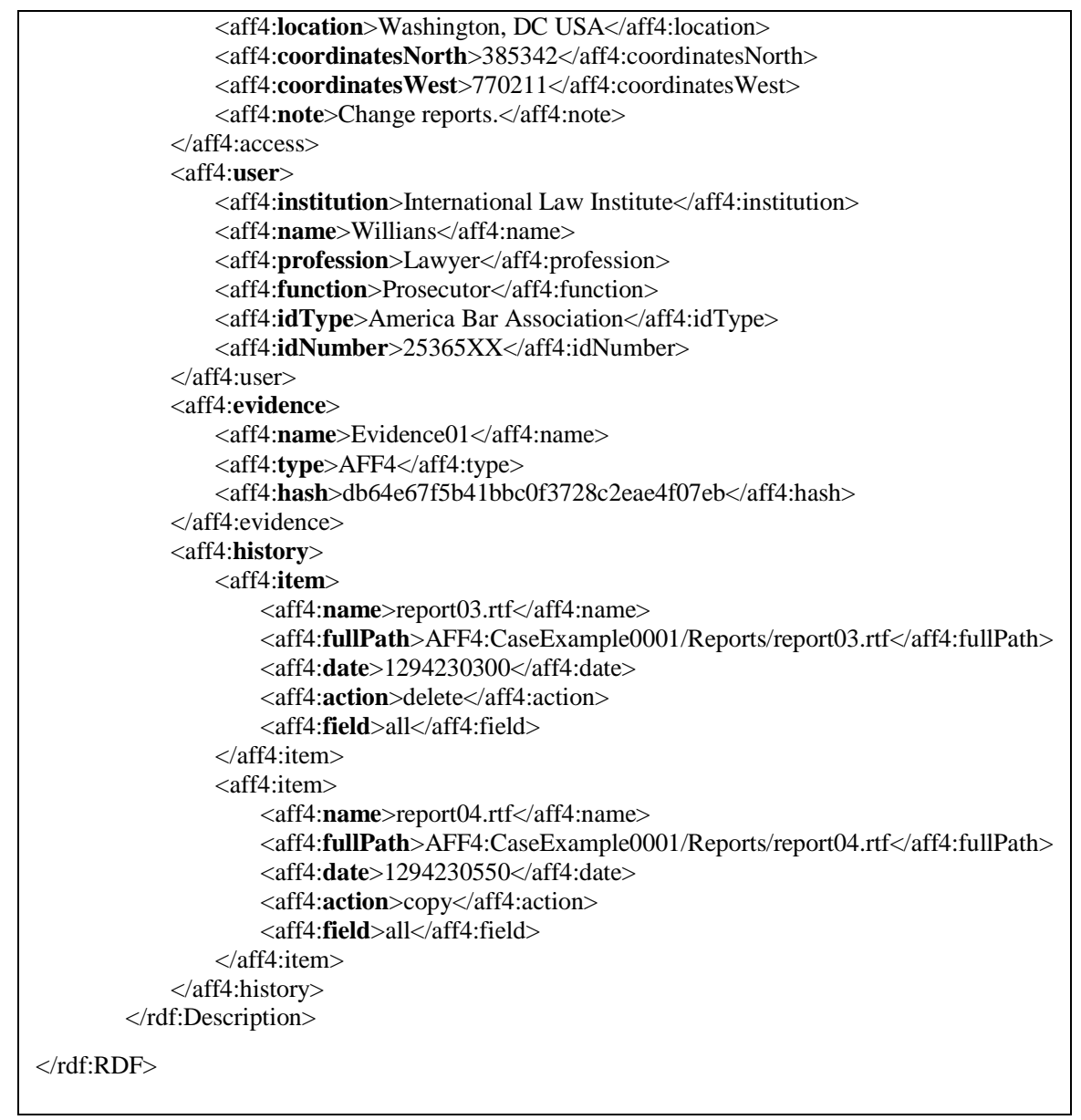

O método apresentado revela que a utilização das facilidades do RDF junto aos metadados flexíveis do AFF4 e seu ambiente para gestão distribuída de evidências configuram uma importante ferramenta para aprimorar a confiabilidade da cadeia de custódia, especialmente se esse sistema proposto de basear em transdutores do mundo físico real, como GPS, gerados de carimbo de tempo e assinatura digital.

O método proposto é essencial no projeto e desenvolvimento de sistemas para gestão distribuída de evidências e para o controle da cadeia de custódia (GIOVA, 2011b), sendo aderente à arquitetura da Web Semântica. Adicionalmente, o método proposto foi comentado por diversos pesquisadores (DOSIS; HOMEM; POPOV, 2013) consideraram a proposta deste autor a respeito da utilização de RDF em conjunto com AFF4 para ampliar o controle por metadados adicionais, (JASMIN; COSIC, 2015) concordaram com a posição deste autor sobre a necessidade dos tribunais conhecer não somente a localização das evidências, mas toda a movimentação das evidências, além considerações de (BULBUL; YAVUZCAN; OZEL, 2013), (PRAYUDI; ASHARI; PRIYAMBODO, 2014) e (PRAYUDI; AZHARI, 2015) 


\subsubsection{Modelando a Cadeia de Custódia}

Outro problema a ser resolvido refere-se à maneira pela qual os peritos planejam os recursos de cadeia de custódia que pretendem utiliza em uma busca e apreensão. Este autor considera que a Rede de WebLabs Forenses deve oferecer suporte para que os seus usuários interajam com o sistema no sentido de aprimorar a utilização dos controles.

O estudo da literatura indica que os métodos para avaliação da cadeia de custódia encontram-se em estágio bastante avançado em outras áreas de conhecimento. Destacam-se as normas nacionais e internacionais, os métodos e as ferramentas adotadas nos exames de DNA e no manuseio de produtos como materiais nucleares, madeiras nobres, pedras preciosas e diversos outros. Verifica-se que grande parte desses controles utilizam entre suas técnicas o mapeamento de processos.

$\mathrm{Na}$ computação forense verifica-se também a utilização de técnicas de mapeamento, herdada do seu uso na ciência da computação e na engenharia eletrônica. Encontramse estudos que utilizam a técnica para avaliar cenas de crimes (BULBUL; YAVUZCAN; OZEL, 2013), processos de investigação digital (SELAMAT; YUSOF; SAHIB, 2008) e avaliar a qualidade dos softwares forenses (GUO; SLAY; BECKETT, 2009), contudo mesmo se essa técnica é adequada para avaliações rápidas de processos, funções, recursos, não se encontra sua aplicação efetiva para a escolha dos melhores meios para registrar a cadeia de custódia em uma investigação forense (ROBERT E. HORN, 1974).

Nesse contexto, o presente trabalho propõe a adoção dessa técnica de mapeamento como inovação prática para apoiar os especialistas usuários da Rede de WebLabs Forenses a planejar e realizar a vistoria, a vistoria, os exames e o encaminhamento das evidências ao tribunal para que o julgador $e$ as partes no processo judicial possam posteriormente avaliar se podem, ou não, confiar nos registros da cadeia de custódia e, como consequência, nas próprias evidências

Com esse escopo se propõe a adoção da técnica de mapeamento para:

(i) Mapear o ambiente alvo onde se pretende buscar e preservar potenciais evidências ("Target Map");

(ii) Mapear os possíveis sistemas de cadeia de custódia que se pretende adotar em determinado trabalho forense (“Custody Map"); 
(iii) Confrontar ambos os mapas para averiguar gaps e sobreposições ("Overlap Map"), passando a utilizar o resultado para confirmar ou reformular as escolhas dos métodos que serão utilizados na cadeia de custódia;

(iv) Se para a investigação em curso houver um mapa de possíveis evidências ("Trace Map"), conforme sugerido por (SELAMAT SITI RAHAYU et al., 2013), confrontá-lo com o "Overlap Map" para certificar-se da aderência das escolha realizadas.

Dessa maneira, o processo proposto abrange, em síntese, as atividades da Figura 23.

Figura 23 - Cadeia de custódia: processo simplificado

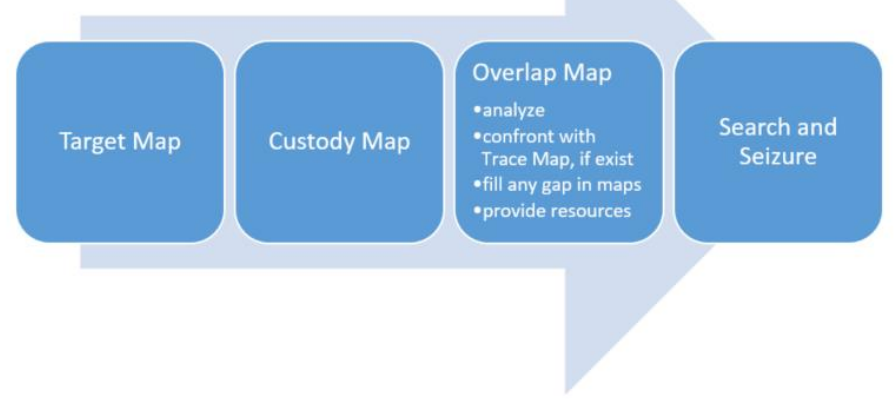

Fonte: autor

Cada mapa deve ser construído partindo do seu nível mais alto (top level map) e ser melhor detalhado apenas na medida em que for necessário. Idem para o confronto dos mapas, que deve ser realizado no nível mais alto possível dentro dos objetivos desta proposta, visando averiguar:

a) Se o modelo de cadeia de custódia a ser adotado assegura a possibilidade de registro de todos os eventos periciais de interesse da investigação técnica;

b) Se a tecnologia adotada no modelo de cadeia de custódia é compatível com a tecnologia e dimensão do ambiente a ser vistoriado é consistente com a tecnologia e a dimensão do ambiente a ser vistoriado;

c) Se esse modelo é adequado sob o ponto de vista do esforço necessário para a construção da cadeia de custódia.

Dessa forma, propõe-se um método que primeiramente auxilia a escolha do melhor modelo para a cadeia de custódia e em segundo lugar proporciona critérios e documentos adicionais para que a corte e as partes possam melhor avaliar a qualidade probante das evidências. 


\subsection{O Método: Mapeamento Comparativo}

Os mapas nasceram com a representação gráfica da esfera celeste e da superfície do globo terrestre, mas logo esse método passou a ser utilizado em outras áreas de conhecimento pela facilidade de criar representações claras. Mais recentemente a técnica passou a ser utilizada para mapear informações com o objetivo de comunicar rapidamente suas categorias e estruturas por meio de textos curtos, claros, inteligíveis e autoexplicativos. Para a construção de um mapa são realizadas as atividades de identificação, categorização, relacionamento e sequenciamento e apresentação gráfica da informação, provendo ferramenta simples e modular para apresentar conceitos, estruturas, funções e processos (ROBERT E. HORN, 1974).

O método proposto adota o mapeamento para identificar as funções de mais alto nível que o investigador observa no ambiente alvo da investigação. Em seguida, utiliza técnicas de decomposição, isto é, a divisão de um sistema complexo em partes mais facilmente visíveis e entendíveis, mas essa decomposição deve ser feita apenas até que se tenha visibilidade dos principais tipos de sistemas ou componentes que podem ser de interesse pericial durante a vistoria do ambiente. A estratégia de decomposição funcional já é largamente utilizada nas ciências da computação (decomposition paradigm), sendo utilizada neste momento para mostrar as funções de mais alto nível, os principais processos, as áreas envolvidas e os principais objetos tratados pelo sistema alvo.

\subsection{Mapa do Ambiente Alvo (Target Map)}

A humanidade gera e armazena quantidade sem precedentes de dados, fator que torna mais complexa e trabalhosa qualquer investigação em meio digital. Por esse motivo é essencial que o investigador procure se informar previamente a respeito do ambiente alvo e que utilize as informações obtidas para planejar melhor as suas ações de investigação, especialmente quando for necessário realizar uma vistoria judicial sem aviso prévio, com a coleta e preservação de evidências de interesse para o processo judicial que forem encontradas no local (SCHULER et al., 2015).

Dessa maneira, com base nas informações que o investigador obtiver a respeito dos principais processos de interesse e dos recursos de infraestrutura que eles utilizam, 
deverá montar o mapa do ambiente alvo, adotando um modelo similar ao sugerido na Figura 24. A escolha dos processos alvo depende dos objetivos estabelecidos pela autoridade que determinou a investigação e a escolha da infraestrutura resulta dos levantamentos preliminares realizados pelo investigador, por exemplo nos documentos que são parte do processo digital ou em levantamentos na Internet em busca de informações públicas como currículos de empregados, informações de fornecedores, informações divulgadas pelo alvo ou mesmo com base nas práticas de mercado. Nos casos reais, o mapa poderá ser mais ou menos detalhado em função das características particulares de cada caso.

Figura 24 - Mapa do ambiente alvo (Target Map)

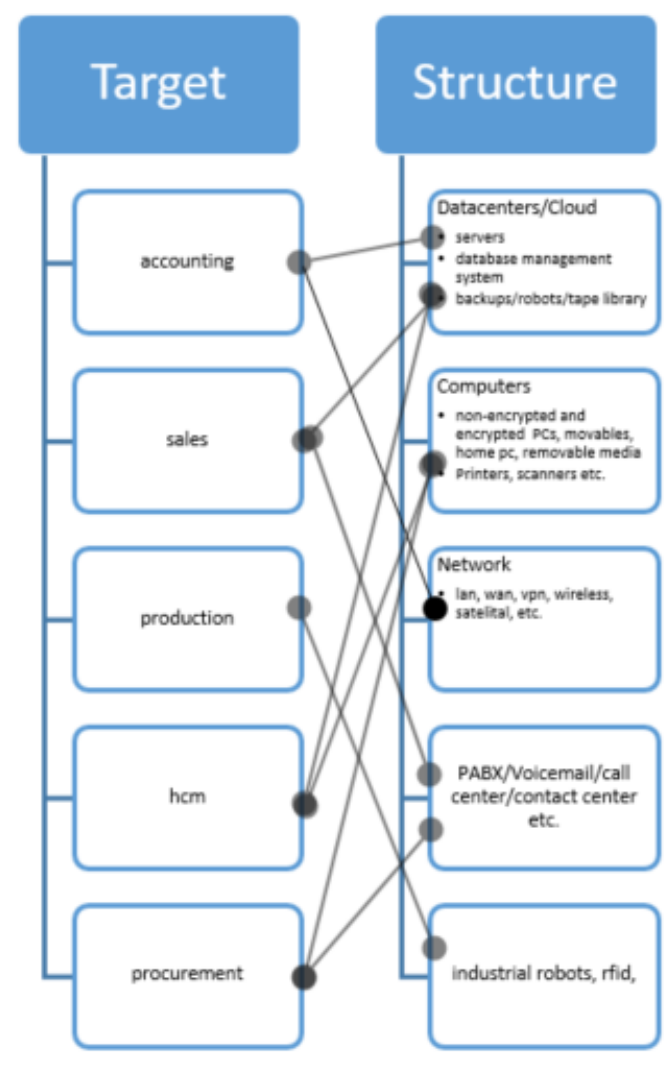

Fonte: autor

Ainda com relação ao mapa da Figura 24 , uma vez estabelecidos os principais processos e componentes de estrutura, o investigador estabelece as relações de dependência entre esses elementos sob a óptica dos procedimentos que deverão ser realizados durante a vistoria do local alvo. Por exemplo, o investigador pode prever que para averiguar uma fraude relacionadas a vendas precisará vistoriar tanto os dados atuais armazenados no banco de dados da empresa, assim como os dados antigos armazenados em uma biblioteca de fitas backup. Nesse exemplo, assinalará no mapa os respectivos relacionamentos. 


\subsection{Mapa da Cadeia de Custódia (Custody Map)}

O próximo passo é mapear a cadeia de custodia pretendida. Para isso, primeiramente indica no mapa as principais ferramentas e métodos forenses que pretende utilizar na vistoria e nas demais fases do trabalho forense, conforme apresentado no lado esquerdo do exemplo mostrado na Figura 25. Em seguida, o investigador deve mapear as principais funções de cadeia de custódia em cada uma das ferramentas forenses que pretende utilizar, assinalando no diagrama o relacionamento entre a ferramenta e a função de custódia. O investigador deve também indicar nesse mapa a possível existência de evidências cujos registros de cadeia de custódia não serão assegurados pelas ferramentas forenses previstas. Portanto, para esses casos 0 investigador deverá indicar também qual o método alternativo que pretende adotar para esses casos.

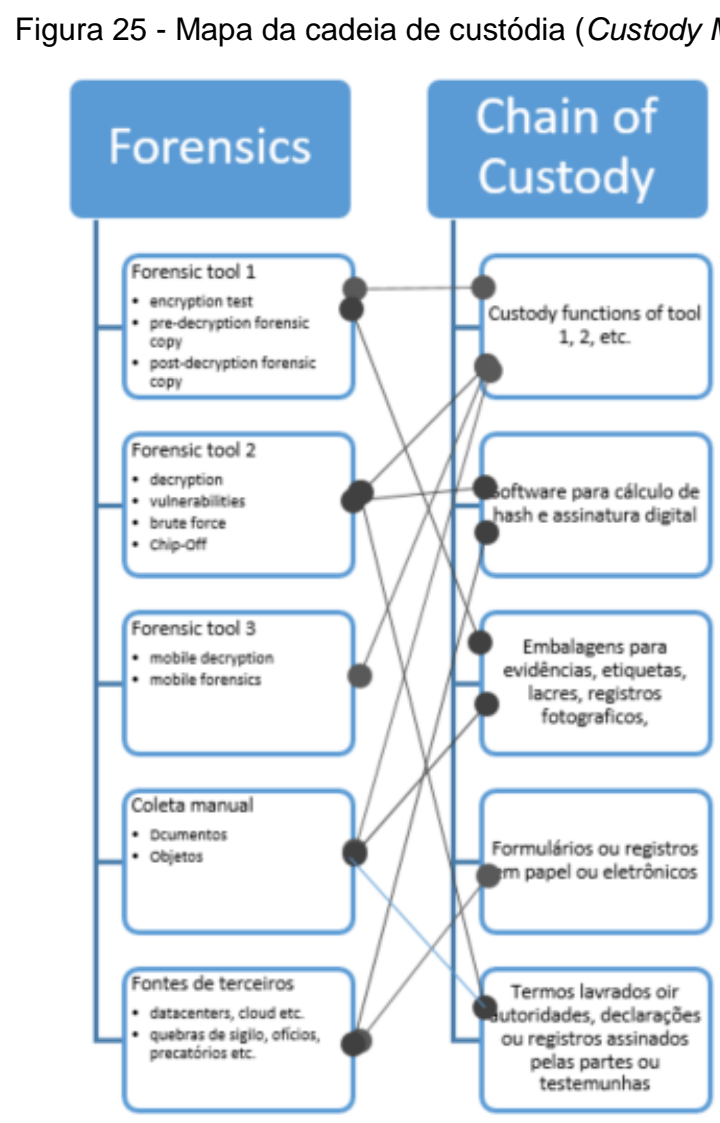

Fonte: autor

Assim, o mapa de custódia deve indicar as ferramentas e métodos de coleta forense que se pretende adotar e quais são os correspondentes registros de cadeia de 
custódia que assegurarão seu valor probante das potenciais evidências quando elas forem submetidas ao tribunal.

\subsection{Mapeamento Comparativo (Overlap Map)}

A etapa seguinte do método proposto comparar o mapa do ambiente alvo com o mapa de custódia. Para isso os dois mapas devem ser postos lado a lado, com isso o investigador poderá indicar no mapa os relacionamentos entre os componentes da estrutura e as ferramentas ou métodos forenses que serão empregados na identificação, coleta e preservação de potenciais evidências, como mostra o exemplo da Figura 26. Como resultado final, o mapa indicará o relacionamento entre as funções que são alvo do procedimento judicial e o componente da cadeia de custódia responsável por assegurar o valor probante das evidências coletadas e examinadas.

Figura 26 - Mapeamento comparativo (Overlap Map)

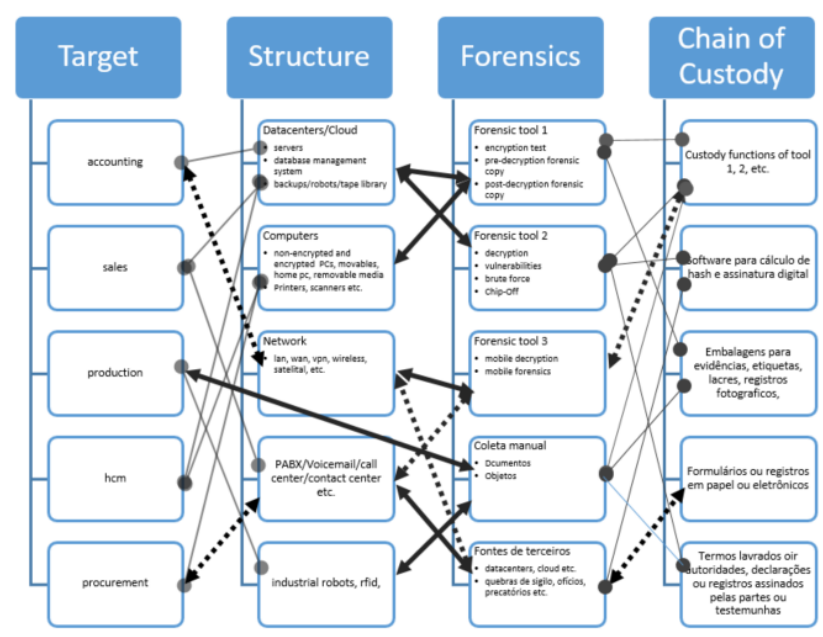

Fonte: autor

Tendo o mapa final montado, o investigador deve então averiguar visualmente se há consistência entre as evidências potenciais que pretende coletar para cada função alvo e a documentação de cadeia de custódia que será gerada, nesse momento deve buscar eventuais gaps, que indicam evidências não adequadamente protegidas por registro de cadeia de custodia como indicam as linhas tracejadas na Figura 26, e eventuais sobreposições de registros que podem significar perda de tempo durante a vistoria pelos recursos dispendidos na geração redundante de registros de cadeia de custódia. 
Neste trabalho propõe-se também a adoção de tecnologias Web Ontology Language (OWL) e Resource Description Framework (RDF) para criar e utilizar os mapas aqui sugeridos e integrá-los com as ferramentas propostas por outros pesquisadores para automatizar procedimentos forenses um ambiente de Web Semântica. Essa proposta adicional complementa estudos vêm de outros pesquisadores no sentido de automatizar tarefas de coleta e análise de evidências. Dentre eles é necessário destacar a estrutura do Advanced Forensic Format (AFF) proposta por Garfinkel et al. (GARFINKEL et al., 2006b) em 2006, ampliada em 2009 para a versão AFF4 que passou a suportar múltiplas fontes de dados e evidências lógicas. Em 2010, os autores (ĆOSIĆ; BAČA, 2010a) propuseram a Digital Evidence Management Framework (DEMF) que aplica à cadeia de custódia a visão Five W's and one $\mathrm{H}$ (who, what, when, where, why, and how) de maneira associada às assinaturas digitais e dados reais como de geolocalização para registrar a manipulação de evidências. Em 2012, os autores (GAYED; LOUNIS; BARI, 2012) partem do conceito de cadeia de custódia (CoC) para apresentar a electronic chain of custody (e-CoC) que visa substituir o formulário em papel por um framework baseado em tecnologias de Web Semântica a partir de OWL e RDF. Os autores (DOSIS; HOMEM; POPOV, 2013) propuseram um método para representar e integrar evidências digitais provenientes de fontes diversas. Em síntese sugerem uma ontologia pragmática e simples para modelar evidências de origens distintas como imagens de discos rígidos ou captura de pacotes em redes. Assim, um parser processa a evidência capturada e gera asserções dinâmicas que representa os objetos e os associa às respectivas classes e, em uma visão agregada compõem uma base de conhecimento Web Ontology Language (OWL). Com isso, o investigador poderá utilizar uma linguagem de consulta padrão Resource Description Framework (RDF) para realizar consultas e transações com as evidências heterogêneas modeladas, possibilitando a descoberta de complexos padrões e relações. Esse modelo contempla também a modelagem dos metadados e registro de interesse da cadeia de custódia.

Nessa mesma linha, em (JASMIN; COSIC, 2015) é apresentada a proposta de um Evidence Management Framework modelado em OWL, com destaque para procedimentos que visem avaliar se determinada evidência é aceitável ou não, contexto no qual o modelo aponta pode exemplo uma divergência de código hash na cadeia de custódia. 
Com a utilização do método ora proposto obtêm-se maior rapidez e uma visão mais ampla e objetiva na tarefa de escolher os mecanismos de cadeia de custódia, através de:

a) Formato ágil para mapear alvos e recursos a empregar em investigações judicias

b) Formato visual eficaz na comunicação tanto com técnicos quanto com operadores do Direito

c) Abrangência maior do que aquelas proporcionadas isoladamente por cada ferramenta forense

d) Visualização mais ampla e rápida dos gaps que podem pôr em risco o valor probante de evidências

e) Visualização das sobreposições que podem significar desperdícios de recursos por geração redundante de registros

f) Apoio ao planejamento das atividades de forense computacional

g) Apoio à escolha racional de ferramentas forenses e mecanismo de cadeias de custódia

h) Apoio à melhor execução dos procedimentos periciais

i) Apoio à proteção da cadeia de custódia

j) Fortalecimento do valor probante de evidências

Verifica-se que o modelo aqui proposto traz uma solução simples para o problema apontado na introdução deste artigo e supre uma lacuna pois porque não se encontram na literatura soluções que sugiram uma abordagem ágil e visual para confrontar as evidências pretendidas no alvo da investigação com os componentes de cadeia de custódia que serão necessários para dar segurança probante frente aos objetivos estabelecidos pelo juiz.

O exame da literatura indica que outro autores como em (BULBUL; YAVUZCAN; OZEL, 2013) propõem a utilização de mapas em rede para representar em detalhes os processos, fases, procedimentos, tarefas e sub-tarefas que o investigador pretende realizar no local do crime, porém diferenciam-se do modelo ora proposto porque contemplam abordagens muito mais detalhadas, tendo portanto objetivos diferentes, e não contemplam com prioridade a qualidade da cadeia de custodia e a comunicação com os operadores do Direito.

O método aqui proposto atende a necessidade de auxiliar os investigadores em sua responsabilidade de assegurar 0 valor probante das evidências que coletam, 
preservam, analisam e apresentam nos tribunais, além de apresentar de forma visual e de fácil entendimento os elementos técnicos principais para que os operadores do Direito possam avaliar o valor probante das evidências que acolhem nos processos.

Como evolução, propõe-se a incorporação desse modelo nos formatos adotados pelas principais ferramentas forenses, como AFF4, EWF e outros, além de criar modelo de estrutura RDF visando sua integração mais ampla e automática no ambiente de softwares forenses.

\subsection{Confronto entre as Propostas e o Mundo Real}

\subsubsection{Qualidade dos Processos}

A sociedade moderna demanda produtos e serviços cada vez mais sofisticados e eficazes, um desejo que tem sido atendido graças ao desenvolvimento de sistemas eletrônicos mais possantes, confiáveis e economicamente viáveis. A onipresença desses sistemas faz com que os dados neles armazenados frequentemente sejam utilizados como evidências para demonstrar a verdade dos fatos discutidos em processos judiciais, porém, para que isso ocorra, é indispensável que os registros da cadeia de custódia consigam comprovar que os dados originais, altamente voláteis, foram adequadamente identificados, coletados e preservados para fins judiciais. $\mathrm{O}$ presente trabalho aponta discrepâncias de qualidade existente entre os complexos sistemas vistoriados e os procedimentos geralmente limitados utilizados para documentar as vistorias forenses. Em seguida propõe que se passe a considerar como item relevante ou até mesmo obrigatório para a aceitação judicial de evidências a presença de avaliação comparativa entre a complexidade do sistema de onde os dados foram coletados a qualidade do método empregado na geração da cadeia de custódia.

Cabe aos juízes dos tribunais solucionar conflitos julgando as causas com base na legislação e na jurisprudência vigentes e no seu convencimento a respeito da verdade dos fatos que the são submetidos, porém a identificação dessas verdades nunca foi uma tarefa simples. As regras e os métodos utilizados pelos juízes e pelas partes em processos judicias para comprovar alegações variaram bastante ao longo da história, mas modernamente tem crescido o papel da prova técnica no convencimento do 
julgador ou dos jurados, sendo sua eficácia tanto maior, quanto mais firmes e claras forem as certezas física e lógica a respeito das evidências que são submetidas à corte. O termo evidência indica qualquer item que seja admitido pelo juiz em um processo, para isso a evidência precisa ser considerada relevante e confiável, inclusive por se basear em fatos ou dados suficientes, resultar de métodos adequados e poder ser bem avaliada sob a óptica das ciências forenses (CARRIER, 2002). Progressivamente aumenta a proporção de evidências apresentadas em formato digital, em decorrência da revolução provocada no mundo pelas tecnologias da informação e das comunicações: já há mais 3 bilhões de usuários da Internet e mais de 7 bilhões de assinantes de telefonia celular, configurando a crescente adoção de sistemas eletrônicos no dia-a-dia pelos governos, empresas e pessoas, conforme (SANOU, 2015), (FBI, 2015) e (SYMANTEC, 2013).

A tendência de virtualização das evidências traz consequências marcantes, como um maior distanciamento entre o mundo físico do julgador e as evidências que habitam mundos virtuais, inclusive pela dificuldade de encontrá-las entre uma grande massa de dados além de uma maior complexidade para a sua valoração em função da sua grande volatilidade, portanto da facilidade com que podem ser criadas, modificadas ou destruídas.

Em uma visão simplificada, pode-se caracterizar o mundo virtual como um ambiente muito amplo, praticamente sem limites físicos, onde interagem dinamicamente usuários e complexos sistemas eletrônicos que estão em constantes transformações. Quando há a perspectiva de alguma disputa digital, torna-se necessário identificar minúsculas parcelas dispersas nesse mundo e em seguida coletá-las e preservá-las de modo a que possam ser submetidas ao julgador no seu exato estado original, para que possam então ser avaliadas para estabelecer sua relevância e confiabilidade como evidência para a produção de provas.

Tendo em vista ubiquidade e volatilidade desses dados, é imprescindível que as amostras coletadas e os procedimentos realizadas sejam perfeitamente controlados, uma vez qualquer modificação de dados ou procedimento indevido pode pôr a evidência a perder ou até mesmo levar o julgador a engano, controle que cabe à cadeia de custódia. 
O U.S. National Institute of Justice (NIJ) define que no local de crime as autoridades policiais ou agentes de segurança que fazem o atendimento inicial devem fazer cuidadosa verificação inicial para avaliar a situação, reconhecer potenciais evidências e identificar os recursos necessários, passando então a atuar outros profissionais tais como investigadores e examinadores forenses encarregados de detectar, documentar e reter as potenciais evidências e amostras para comparações e organizá-las após devidamente identificadas com etiquetas, recipientes e afins. Após as devidas providências, deve realizar um exame final para assegurar que o local foi efetivamente e completamente processado. Todas essas atividades devem ser registradas na cadeia de custódia como "a process used to maintain and document the chronological history of the evidence", prosseguindo esse registro ao longo do ciclo de vida das evidências, como exames posteriores e sua submissão ao juiz (JUSTICE, [s.d.]).

Muitos países mantêm leis, normas técnicas e orientações, com maior ou menor nível de detalhe, com o objetivo de proporcionar serviços forenses adequados. O mundo acadêmico e a indústria realizam esses objetivos proporcionando pesquisas, métodos e ferramentas utilizadas pelas autoridades policiais e pelos especialistas em computação forense para identificar, preservar, examinar e apresentar evidências à corte. Em aderência a esse cenário, o presente trabalho estudou as questões relacionadas ao método utilizado pelos peritos para escolher o modelo a ser adotado para registrar a cadeia de custódia em cada caso, aspecto relevante porque ela é elemento central na atribuição de valor probante às evidências. Propôs um método que visa aumentar a qualidade dos registros em cadeias de custódia de evidências digitais.

Como vimos, a cadeia de custódia é um processo utilizado para manter e documentar a história cronológica de uma evidência. Há muitos métodos possíveis, aquele mais simples consiste em um livro ou até mesmo uma simples folha de papel onde são descritas em ordem cronológica e no momento em que são realizadas quaisquer atividades relacionadas à evidência. Dessa forma, em síntese, se trata de um procedimento muito similar ao diário de bordo de um navio onde são sequencialmente registrados o porto de origem, as medições de posição tomadas ao longo do caminho e os eventos que ocorrem até a chegada ao porto de destino. É o registro do ciclo de vida do navio ou da evidência. A segurança desse processo reside: (i) na obrigação de registrar as atividades relacionadas à evidência; (ii) que os registros sejam 
realizados ordem cronológica e (iii) que eles sejam feitos no momento em que as atividades ocorrem.

Com essas providências se dá transparência aos fatos ocorridos no manuseio de evidências e se dificultam eventuais tentativas de adulterar a documentação sobre os fatos através da posterior inserção, alteração ou exclusão de registros. Outra medida de segurança para prevenir eventuais adulterações é produzir cópias fieis do livro ou documentos de cadeia de custódia logo após o lançamento das anotações e entregálas aos interessados ou a terceiros que possam ser considerados seus fiéis depositários.

Esses cuidados são essenciais quanto à sintaxe da cadeia de custódia, mas além disso é necessário avaliar a sua semântica no sentido de se assegurar que cada descrição se refere a determinada evidência e a determinado evento, não a outros. Essa questão usualmente é resolvida atribuindo-se números únicos aos objetos envolvidos nos procedimentos. Governos mantém serviços de identificação que registram e atribuem, diretamente ou por concessão ao setor privado, identificadores únicos a pessoas, empresas, órgãos, locais, imóveis, produtos, veículos, atividades, sistemas, assinaturas eletrônicas, transações bancárias e assim por diante. $\mathrm{Na}$ ausência de identificação única, ou mesmo como um seu complemento, as autoridades policiais, investigadores, oficiais de justiça e peritos forenses devem gerar identificadores ad hoc para identificar determinado disco rígido, arquivo ou qualquer outro componente digital.

Cabe notar que o identificador único muitas vezes não é suficiente diante das finalidades forenses, pois a atividade documentada na cadeia de custódia precisa estar relacionada não apenas a determinado objeto, mas especialmente ao estado daquele objeto no momento em que foi realizada a atividade forense, por esse motivo mesmo quando existe um identificar único oficial é necessário que o evento registrado na cadeia de custódia tenha controles adicionais que possam assegurar aos tribunais o estado daquela evidência antes, durante e depois de qualquer atividade técnica forense. Por exemplo, se é realizado um exame forense destrutivo em uma evidência física, é necessário que a cadeia de custódia aponte para controles como filmagens e preservação de amostras que comprovem o estado da evidência pelo menos antes e depois dos procedimentos forenses. Em se tratando de uma evidência digital é necessário que a cadeia de custódia demonstre que o código hash da evidência é 
idêntico antes e depois da atividade forense, havendo também a guarda do conteúdo total original da evidência correspondente a esse hash. Caso o procedimento forense seja obrigado a alterar a evidência, por exemplo ao remover a criptografia de um disco rígido, é necessário que a cadeia de custódia registre os códigos hash antes e depois e que além disso haja clones ou imagens forenses correspondentes a esses códigos que comprovem o estado completo da evidência antes e depois do procedimento forense (PRAYUDI; AZHARI, 2015). Alguns procedimentos forenses são ainda mais destrutivos, como a remoção da memória flash (Chip-Off) de um telefone celular para que possa ser inserida em uma máquina que clonará diretamente o seu conteúdo (SWGDE, 2006), nesse procedimento muitos vezes não é possível calcular o código hash do material efetivamente original, motivo pelo qual a cadeia de custódia deve conter buscar outros controles auxiliares que mostrem o estado da evidência antes e durante o procedimento forense, inclusive mediante gravação em vídeo dos procedimentos realizados e dos instrumentos laboratoriais que foram utilizados. Nesses casos, é necessário que a documentação da cadeia de custódia mostre, por exemplo, medições tomadas por meio de equipamentos como osciloscópios para posteriormente seja possível confirmar o valor probante da evidência e dos resultados obtidos durante o seu exame. Deve-se ainda considerar se procedimentos como o de Chip-Off e a posterior verificação do seu conteúdo são realizados no mesmo laboratório e sempre com acompanhamento por representantes técnicos de todas as partes envolvidas ou se, ao contrário, os trabalhos são realizados em locais distintos e sem acompanhamento por representantes das partes.

Os governos, pesquisadores e a indústria fornecem normas, estudos, melhores práticas e uma gama variada de ferramentas para identificar, preservar e analisar evidências. Contudo, apenas uma pequena parte desse material se refere às evidências digitais e, menos ainda, à crítica dos métodos escolhidos para a geração da cadeia de custódia.

As recomendações tradicionais sobre como construir uma cadeia de custódia começam com simples formulários em papel ou eletrônicos, passam por ferramentas embutidas em softwares forenses e chegam até sofisticados sistemas nacionais ou mesmo internacionais de cadeia de custódia. Além deles, há ainda variadas ferramentas que atuam continuamente na geração de cadeias de custódia, embutidas em ambientes como de descoberta eletrônica (e-discovery) nas empresas, em 
sistemas de segurança ambiental, em syslogs de data-centers, nas gravações de conversas em call-centers, nos sistemas de interceptação das operadoras de telecomunicações ou no centros de monitoramento da Internet, entre outras muitas aplicações.

As principais atividades realizadas pelos peritos em forense computacional usualmente consistem em identificar, preservar, analisar e apresentar evidências digitais, atividades essas que precisam ser realizadas até certo ponto de maneira padronizada para atender aos princípios legais e científicos, às normas técnicas e às melhores práticas. Por outro lado, as características da moderna sociedade digital e a complexidade dos inovadores sistemas digitais fazem com que as pesquisas acadêmicas e as especificações das ferramentas forenses disponíveis atualmente indiquem a existência de uma grande variedade de métodos para realizar até mesmo atividades periciais básicas.

A revisão dos procedimentos e a própria certificação da evidência resultante dependem da confiabilidade do mecanismo de cadeia de custódia. Em outras palavras, se o sistema de registro de custódia for confiável, então considera-se que ele pode ser utilizado como meio para se aferir os procedimentos realizados e a evidência resultantes. Entretanto, se o sistema de cadeia de custódia não puder ser considerado confiável, ele será imprestável para o fim a que se destina, logo não será possível atribuir valor probante à evidência produzida. Assim sendo, a qualidade do software de cadeia de custódia é essencial para a aceitabilidade de uma potencial evidência pelo juízo.

O modelo proposto neste trabalho não se refere à avaliação comparativa simples e objetiva entre as qualidades da cadeia de custódia e do sistema vistoriado. Por exemplo, pode não ser necessária a utilização de uma complexo e completo software online de cadeia de custódia para registrar a apreensão e o transporte ao laboratório de um ingresso de teatro encontrado sobre uma mesa, em casos como esses podem ser suficientes os formulários de cadeia de custódia sugeridos por diversos órgãos governamentais. Por outro lado, parece ser temerária a utilização de um formulário como esse para registrar em cadeia de custódia a vistoria e coleta de dados em um grande sistema de gestão empresarial ou em serviços em cloud. Não se trata apenas de calcular o hash de um container de dados que armazena os resultados, pois demonstrar que o container permanece preservado não assegura que os 
procedimentos anteriores realizados no sistema de gestão ou no cloud tenham sido corretos e que não existiu manipulação dos dados antes ou durante a sua colocação no container. Em casos como esses certamente é requerido um processo de registro de custódia bem mais amplo e potente. Contexto similar pode ocorrer quando os dados são gerados continuamente e automaticamente com possível futura finalidade forense, por exemplo no monitoramento sobre suposta lavagem de dinheiro via transações processadas pelo sistema de conta corrente de um banco, na infraestrutura de uma operadora de telecomunicações que cumpre ordens judicias de interceptação ou no registro detalhado da navegação dos usuários websites suspeitos de comércio ilícito que estejam sendo monitorado pelas autoridades policiais com autorização judicial. Nesses exemplos não será suficiente que o registro de cadeia de custódia seja um mero formulário, será necessário um efetivo e possivelmente complexo sistema de cadeia de custódia. Nesse contexto, as pesquisas demonstram que o método a ser utilizado para documentar a cadeia de custódia deve ser compatível com as características técnicas e complexidade do sistema a ser examinado e dos procedimentos de coleta a realizar. (GIOVA, 2011b)

Estudos realizados a respeito das práticas mais adotadas no mundo pericial indicam a existência de quatro ou cinco fases comuns aos trabalhos técnicos forenses: (i) preparação; (ii) coleta e preservação; (iii) exame e análise; (iv) apresentação e laudo; e (v) disseminação dos resultado, havendo pequenas diferenças na quantidade de fases e tipos de atividades em cada fase (SELAMAT; YUSOF; SAHIB, 2008). Diversos estudos levantaram cada atividade e avaliaram quais seriam as melhores em função da complexidade e volatilidade do mundo digital e das características dos diversos locais de crime (BULBUL; YAVUZCAN; OZEL, 2013). Em função da dimensão e complexidade crescente do mundo cibernético, tais tarefas passam a depender cada vez mais do auxílio de softwares forenses que automatizam processos e apoiam o trabalho de investigadores e especialistas em computação forense, contudo não se constata a existência de um software universal que se aplique a todos ou quase todos os casos de investigação digital, ao contrário, a intensa evolução tecnológica gera dispositivos e aplicativos cada vez mais diversificados e, portanto, seu exame requer ferramentas forenses cada vez mais específicas e especializadas. A velocidade com que evoluem e se modificam os dispositivos submetidos aos exames impõe que as antigas ferramentas forenses tenham que ser reavaliadas, para evitar que 
incompatibilidades com dispositivos mais recentes provoquem erros nos resultados. Essas reavaliações são realizadas periodicamente à pedido dos fabricantes em laboratórios especializados que emitem certificados de conformidade, mas diante da rapidez e da variedade das mudanças, torna-se necessário que o próprio especialista em forense computacional saiba avaliar na prática do dia-a-dia a adequação de cada método aos objetos a examinar. A literatura traz diversos estudos sobre a verificação e validação dos softwares forenses, detalhando e testando suas principais funções, como a coleta de evidências, a realização de pesquisas por palavras-chave e a apresentação de resultados aos tribunais. Porém, nesses estudos raramente se encontram avaliações mais profundas a respeito da qualidade do registro de cadeias de custódia. A maior parte das avaliações são feitas pelo próprio fabricante de cada ferramenta e, portanto, se limita a enfatizar os procedimentos por ela atendida. Para ilustrar, uma ferramenta originalmente projetada para o exame de discos rígidos usualmente não possui funções adequadas para gerar uma cadeia de custódia segura durante um exame de dados em cloud.

Dessa maneira, resulta que as funções destinadas a assegurar a qualidade da cadeia de custódia estão segmentadas em diversos controles manuais ou automáticos e ainda não estão integrados entre si (GIOVA, 2011b), impondo ao investigador realizar escolhas ad hoc para selecionar e compor um leque de ferramentas de cadeia de custódia que cubram todas as possibilidades de cada cenário a ser investigado, para evitar que eventuais gaps na cadeia de custódia impeçam assegurar o correto valor probante para as evidências submetidas aos tribunais.

\subsubsection{Inflexão Tecnológica}

Dentro da etapa de confronto dos modelos ora propostos com os problemas do mundo real, não se pode deixar de considerar os mais recentes acontecimentos envolvendo disputas entre autoridades policiais, representantes do poder judiciário e provedores de produtos ou serviços como serviços criptografados de mensagens ou buscadores de Internet, entre outros.

Segundo o método de pesquisa SSM, nesta etapa do trabalho os modelos são qualitativamente e sob o ponto de vista observacional confrontados com o mundo real, assim, com esse objetivo compara-se primeiramente recente episódio ocorrido nos 
Estados Unidos, ocasião na qual a polícia federal daquele país requereu judicialmente que o fabricante de um equipamento smartphone providenciasse uma quebra de segurança ou uma porta dos fundos (backdoor), para que com isso pudesse ter acesso ao conteúdo protegido por senha. A autoridade policial alegou questões de segurança nacional para justificar a medida, enquanto que 0 fabricante do equipamento se negou a tomar as providências requeridas alegando, em síntese, que se elas fossem tomadas então seriam postas em risco a segurança e a privacidade de todos os usuários do equipamento. A questão estava ainda pendente quando a autoridade policial informou ao juiz encarregado do caso que já havia conseguido por outros meios acessar o conteúdo do equipamento. Os principais métodos técnicos para acessar tais dispositivos são, em apertada síntese, a identificação e aproveitamento via software de vulnerabilidade existentes no sistema ou então a dessoldagem do chip de memória com cópia do seu conteúdo criptografado para possibilitar reiteradas tentativas de quebra. De especial interesse para o presente estudo é a possibilidade proporcionada pelo modelo ora proposto no sentido de que se compartilhe o ambiente em que essa peça está sendo examinada de maneira que os operadores do Direito, a autoridade policial, o fabricante do equipamento e os peritos incumbidos da tarefa possam realizar as tarefas de modo colaborativo e mutuamente supervisionado. Além dos ganhos de escala, o ambiente colaborativo proporciona condições para que os próprios participantes decidam, de maneira ad hoc e hands on, os procedimentos técnicos específicos a realizar em cada caso e quais são os limites, buscando o equilíbrio, caso a caso, entre a eficácia investigativa e a necessidade de preservar o sigilo de dados dos usuários e as características do produto.

Dessa maneira, o modelo proposto traz ao ambiente jurídico-pericial ferramentas e métodos que são usuais em outras áreas, pois não apenas compartilha o ambiente virtual composto por software e dados, mas também o ambiente físico onde estão dispositivos, chips, mídias e demais componentes, mantendo-se inclusive com relação a eles os requisitos de cadeia de custódia e atuação compartilhada. Cabe complementar considerando que o modelo contempla questões como a guarda de chaves ou informações secretas e se mostra compatível com a próxima onda tecnológica de dispositivos conectados (IOT). O compartilhamento de laboratórios 
possibilita endereçar também crescentes necessidades de técnicas e recurso para lidar com a crescente necessidade de quebra de criptografias.

\subsubsection{Prova de Conceito}

O presente trabalho propõe o acesso remoto a laboratórios forenses a partir de interfaces Web e a integração dos diversos laboratórios em federações pela construção de middlewares ou frameworks definidos a partir dos casos de uso de cada laboratório. São exemplos típicos de casos de uso o exame de um HD ou de um modelo específico de telefone celular, assim a criação dos respectivos frameworks começa com a identificação dos requisitos de cada um desses exames em um ambiente de acesso remoto. Com base nesse entendimento, se propôs no âmbito do presente trabalho a realização de protótipos simplificados de provas de conceito exatamente a respeito desses dois casos.

Um protótipo de prova de conceito é um modelo construído segundo métodos similares àqueles de um protótipo convencional, porém apenas para demonstrar que uma nova técnica é factível, não se trata de construir uma versão inicial ou precoce de um projeto. Na prova de conceito foram montadas simulações desses laboratórios em locais diferentes entre si e distantes de usuários que simulavam o papel de juiz, patronos das partes, delegado, perito, assistentes técnicos e a próprias partes no processo judicial.

O protótipo para exame do HD foi montado com as principais ferramentas forenses próprias desse ambiente, em síntese: equipamento para clonagem de discos ImageMASSter Solo 4 (Intelligent Computers), o software forense Autopsy, o aplicativo VNC para acesso remoto e um sistema de vigilância de áudio e vídeo para supervisão do ambiente. No experimento, o perito comanda remotamente as operações enquanto é supervisionado também remotamente a partir de outros locais pelos usuários juiz, delegado, advogados e assistentes técnicos. Todos monitoram o ambiente do laboratório via tela de comandos e sistema de vigilância em áudio e vídeo. Para a prova de conceito o VNC foi instalado experimentalmente no equipamento Solo 4 e através dele o perito comandou a geração de uma imagem forense do HD, com criação da respectiva cadeia de custódia, e em seguida procedeu ao exame do conteúdo dessa imagem via software Autopsy, registrando o resultado 
em um laudo. Nesse experimento os usuários puderam acompanhar e executar remotamente os procedimentos realizados, demonstrando a viabilidade do modelo sugerido no presente trabalho.

SOLO 4 - Intelligent Computer

Solutions

Equipamento para coleta forense de dados mais utilizado por autoridades policiais e peritos no Brasil, USA e no mundo.
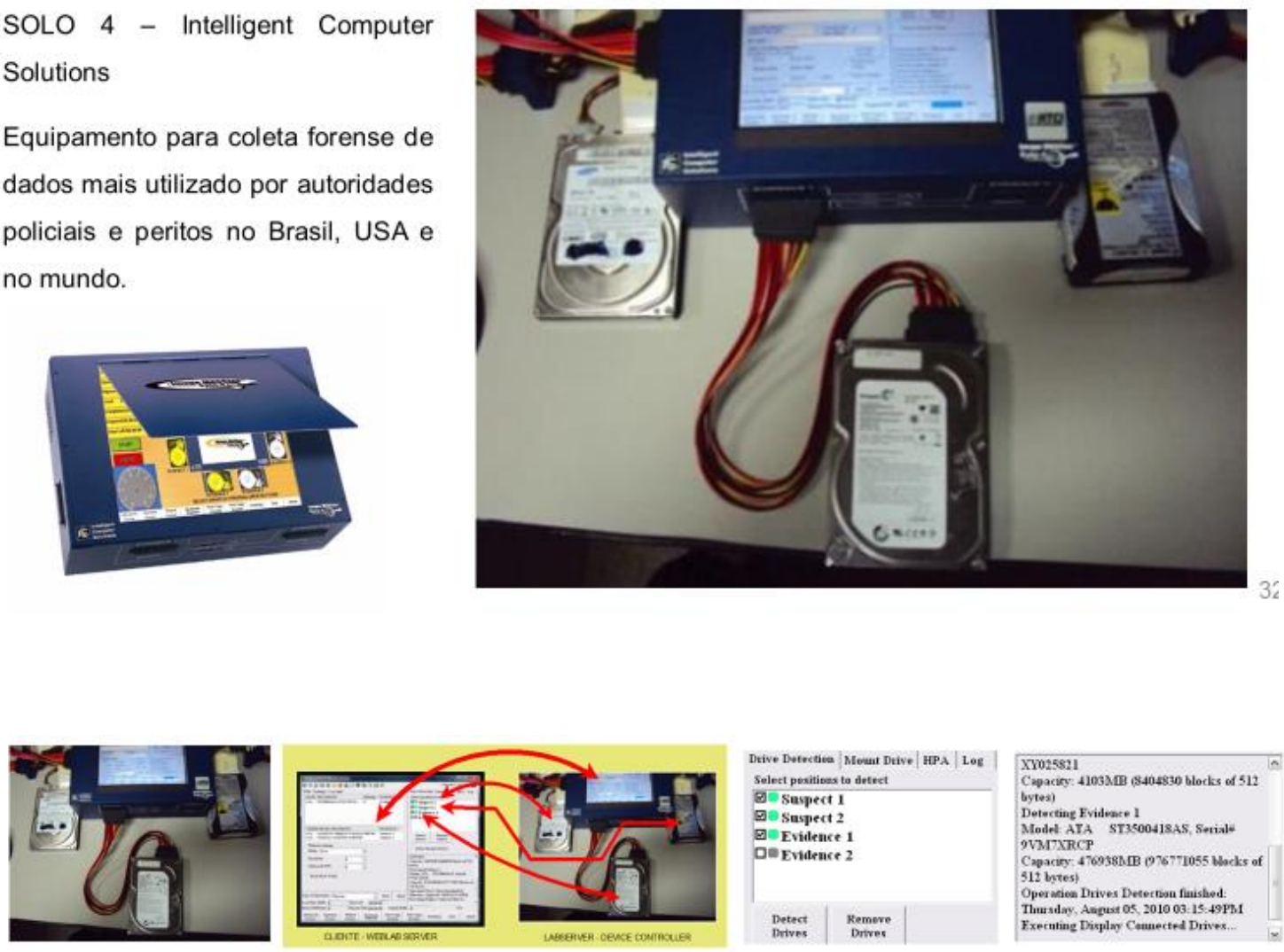

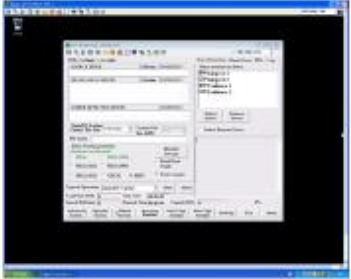

Perito controla remotamente a coleta de dados

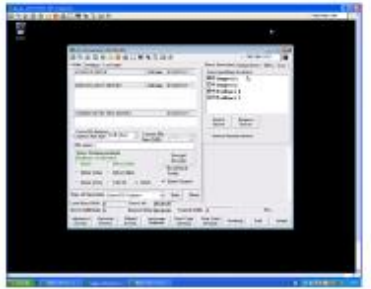

Delegado fiscaliza remotamente perito e a coleta da evidência

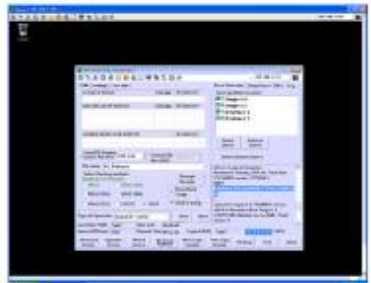

Juiz e partes no processo igualmente fiscalizam e até mesmo colaboram remotamente na coleta

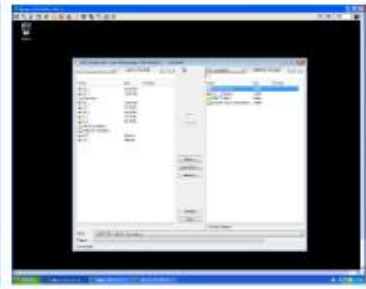

Perito comanda e partes verificam transferência para a custódia de evidências 


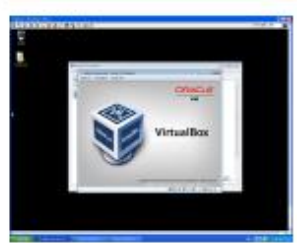

Perito gera maquina virtual para exames do material coletado

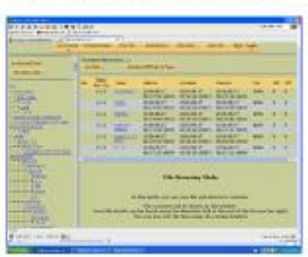

Perito encontra evidências

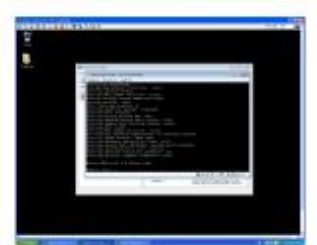

Partes controlam procedimentos remotamente

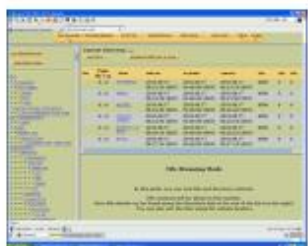

Partes atuam no exame sob controle do perito, Juiz fiscaliza

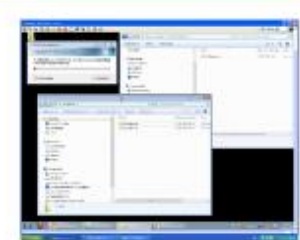

Perito organiza remotamente o material custodiado

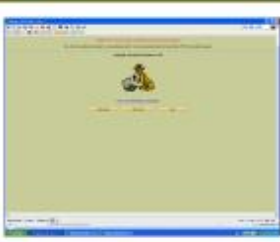

Perito examina remotamente a imagem do HD

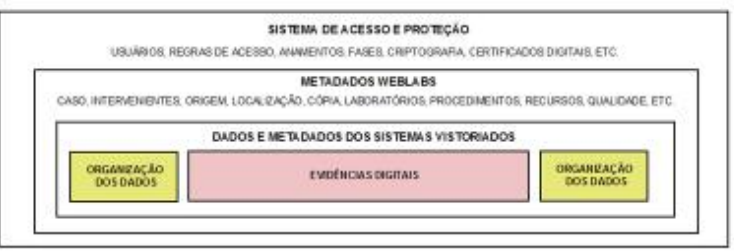

Imagem forense com cadeia de custódia do HD coletado e examinado

O segundo protótipo construído teve como objetivo realizar exame remoto em um telefone celular, tendo-se para isso adotado o software forense Cellebrite UFED 4PC instalado em um computador igualmente acessível remotamente por VNC, sendo o celular submetido a perícia conectado ao software via cabos personalizados da Cellebrite, obtendo-se assim a coleta e análise do seu conteúdo pelo perito judicial em um ambiente supervisionado remotamente pelo juiz, delegado, promotor, advogado e assistente técnico.

Cellebrite - UFED 4PC

Equipamento para coleta forense de dados de dispositivos móveis utilizado por autoridades policiais e peritos no Brasil, USA e no mundo.

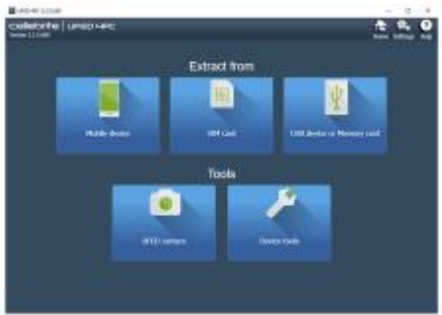

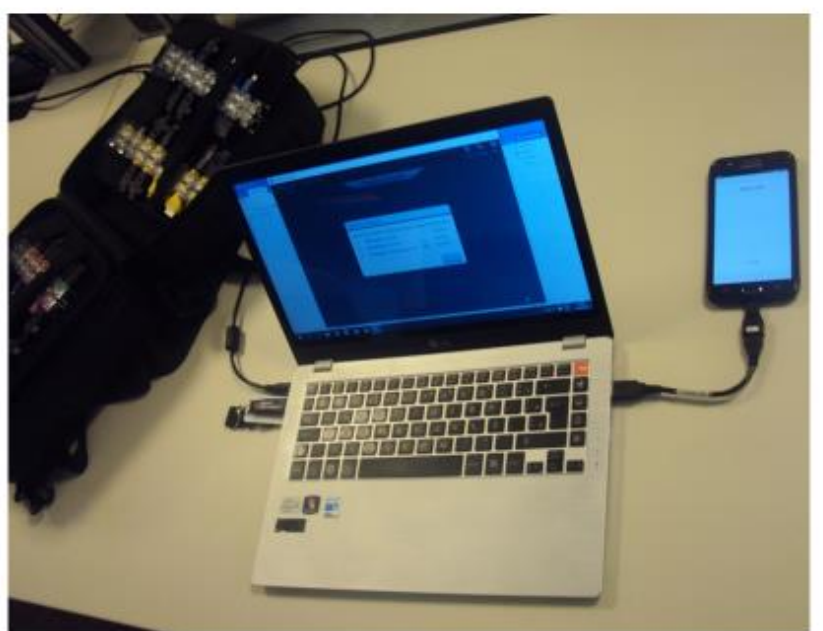




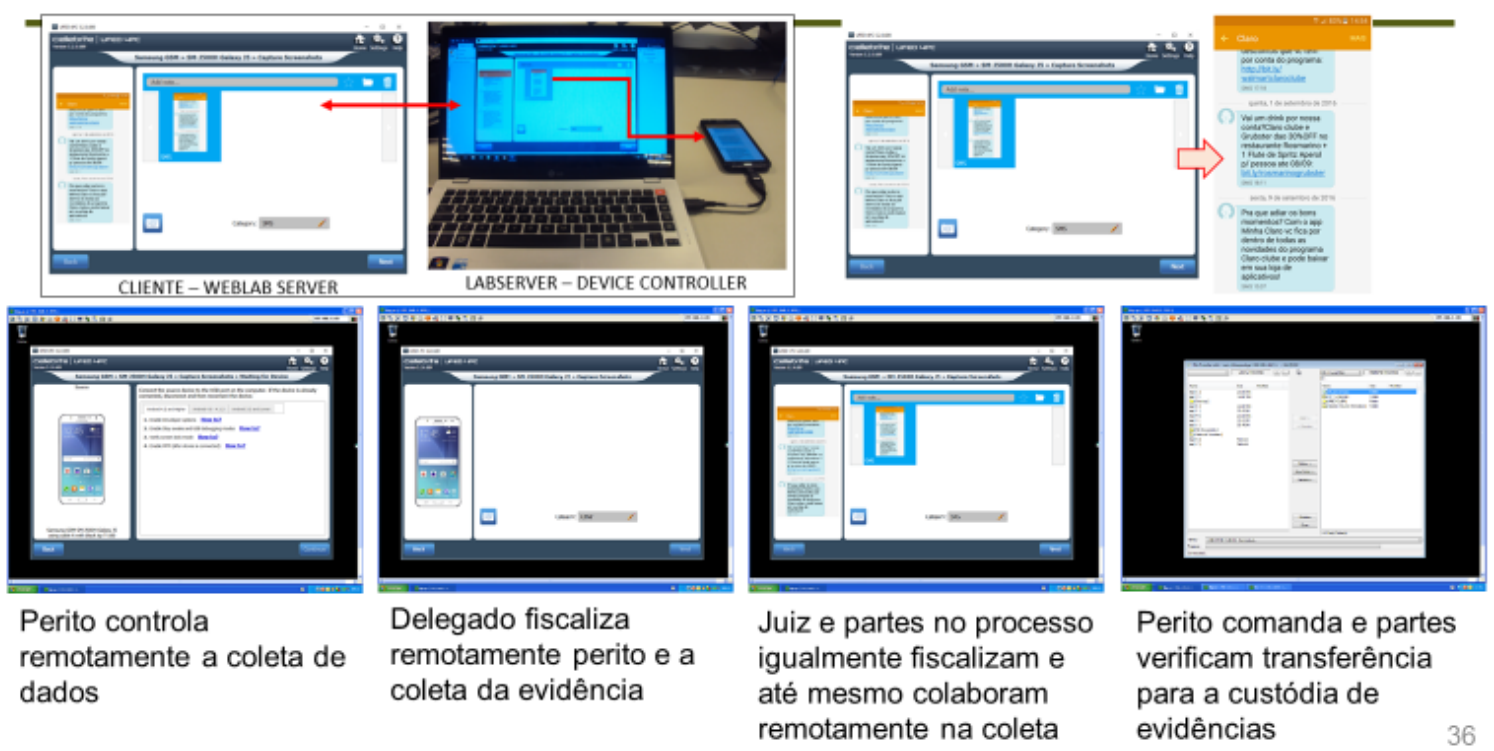

Os protótipos simplificados apresentados ilustram a realização de perícias técnicas em um HD e em um telefone celular realizadas remotamente via Web.

\subsection{Mudanças Desejáveis e Viáveis}

Até este ponto, foram cumpridas quase toda as etapas da Soft System Methodology, faltando apenas obter referências organizacionais relacionadas a quem estará envolvido na sua implementação ou afetado pelas mudanças propostas, em síntese:

a) Tecnologia WebLabs: Adotar a tecnologia WebLabs para compartilhar remotamente os laboratórios forenses;

b) Integrar Laboratórios: Integrar nacional e internacionalmente tais laboratórios, alavancando qualidade e escala de produção;

c) Aprimorar Processos: Aumentar a segurança dos processos prioritariamente sob o ponto de vista das evidências, portanto da sua cadeia de custódia.

Os pontos de atenção que surgiram a partir do método empregado e as informações disponíveis podem ser resumidos como segue.

1) Há marcantes diferenças de normas, políticas, estruturas e procedimentos entre laboratórios que operam na esfera criminal e aqueles da esfera cível, ambiente de interesse para a adoção de tecnologias WebLabs devido à sua capacidade de integrar ambiente heterogêneos. Contudo, não se registram tendências efetivas de aproximação horizontal entre esses domínios distintos, 
possivelmente em função das normas e políticas, contexto que impacta negativamente as propostas em estudo;

2) Os maiores e melhores laboratórios forenses atuam na esfera criminal e estão em células praticamente estanques e sujeitos a modelos muito rígidos. A atuação do Instituto Nacional de Criminalística e dos órgãos dessa natureza em nível estadual segue as regras próprias de cada domínio, inclusive quanto às diretrizes técnico-administrativas. Por outro lado, há linhas intensas de desenvolvimento e padronização de procedimentos como aquelas empreendidas pela Secretaria Nacional de Segurança Pública e outras iniciativas para aperfeiçoamento dos sistemas de gestão e operacional;

3) A atuação pericial na esfera cível adota modelo aberto e flexível, essencialmente formado por especialistas que prestam serviços ad hoc segundo determinações de cada tribunal e decisões de cada juiz. Neste domínio são raros os laboratórios melhor equipados, a maior parte dos peritos atua em pequenos escritórios ou mesmo em suas residências. No outro extremo há grandes universidades ou mesmo fornecedores de ferramentas forenses que também prestam serviços ao poder judiciário, inclusive seguindo motivação do Novo Código de Processo Civil. A grande heterogeneidade de estrutura e a possibilidade de ganhos importantes em qualidade e produtividade faz prever boa aderência às propostas apresentadas;

4) As diferenças entre os domínios alvo tornam mais complexa a tarefa de identificar modelos de investimento para desenvolvimento e implantação das propostas apresentadas. As indagações realizadas sugerem a implantação de redes distintas, mas que poderiam ser integradas ao longo do tempo por adotarem padrões comuns de interoperabilidade;

5) Os estudos realizados indicam elevado descontentamento dos clientes de serviços periciais com a qualidade, prazo e custo, sugerindo que a sociedade enquanto cliente teria um grau elevado de interesse em que os modelos sugeridos fossem implantados;

6) A inflexão tecnológica traz graves consequências para as atividades de investigação e produção de provas, chegam a ser inviabilizadas em determinados contextos quando há, por exemplo, criptografia forte que protege a privacidade de usuários de computadores, celulares e serviços de mensagens, pondo em confronto inclusive governos e fabricantes sobre quais 
são as normas, tecnologias e limites a respeitar, nacionalmente e internacionalmente. Esse contexto torna as propostas ora apresentadas candidatas a inspirar fóruns técnico-jurídicos, algo similar a um sandbox ou câmara de arbitragem técnico-operacional, virtual e remota, para resolver os casos de maneira hands-on;

7) Os modelos sugeridos se mostram desejáveis e viáveis sob o ponto de vista técnico, contudo sua implementação pode ser considerada complexa devido a esperáveis restrições legais e administrativas.

8) Sob o ponto de vista técnico, o modelo aberto sugerido tende a facilitar progressivamente as implantações, inclusive prevendo diferenças de critérios e procedimentos entre laboratórios. Os problemas técnicos mais severos a enfrentar estão no âmbito da segurança física e lógica do sistema e da custódia das peças submetidas a perícia.

Esses são os principais pontos surgidos, considerando-se que a lista não é exaustiva. 


\section{RESULTADOS E DISCUSSÃO}

Os estudos realizados focalizaram de forma prática os problemas visualizados na prestação dos serviços periciais, utilizando método exploratório que proporcionou maior familiaridade com esses problemas e possibilitou a interpretação de situações e a consequente construção de novas proposições. A escolha da Soft System Methodology (SSM) se mostrou adequada primeiramente para a análise com sucesso das situações complexas que envolvem o Poder Judiciário e as questões científicas e técnicas da Engenharia e Administração. Com isso, preteriu-se uma exaustiva listagem histórica e mensurações detalhadas, preferindo-se uma visão mais objetiva das dificuldades segundo a visão direta e livre dos agentes que atuam nesses cenários. Em seguida, ainda conforme o método SSM, se passou à construção de modelos baseados no entendimento das atividades humanas e na comparação desses modelos com o mundo real. Essa linha de ação se mostrou adequada, porque proporcionou a construção de modelos inéditos na literatura e que também podem ser aplicados imediatamente.

Em síntese, o método aplicado trouxe como resultados a constatação prática de que os recursos mais sofisticados e produtivos estão disponíveis nos grandes centros econômicos e nas principais universidades e tais recursos poderiam ser utilizados remotamente pelos peritos e operadores do Direito que atuam nos milhares de comarcas localizadas no interior dos estados, trazendo com isso benefícios diretos e em curto prazo à sociedade, justificando a sua necessidade.

Quanto ao que é necessário, o método adotado indicou, de forma inovadora, a adoção da tecnologia WebLab pelos laboratórios forenses fisicamente instalados e sua subsequente integração e compartilhamento remoto via Internet, trazendo alavancagem, ganhos de escala e melhor distribuição dos recursos aplicados nesses laboratórios e o atendimento em nível nacional.

A questão sobre quem fará isso, o trabalho realizado mostrou que a tarefa cabe primeiramente à academia, não apenas por ser geradora dos conhecimentos científicos e tecnológicos que são a essência dos laboratórios forenses, mas objetivamente para definir os princípios e modelos detalhados para a concepção e implementação da rede de laboratórios forenses que integre não apenas aqueles dedicados ao exame de sistemas eletrônicos digitais, mas também aqueles de outras 
áreas de conhecimento. Consta também como subproduto deste trabalho a importância da rede de WebLabs a disseminação de conhecimento e o treinamento multidisciplinar pertinentes às Ciências Forenses como um todo.

Com relação ao método, é altamente recomendável o estabelecimento de parcerias com as universidades que tem projetos avançados na área da educação, já citadas, e com a indústria provedora de componentes de interesse ao projeto.

Dessa maneira, os modelos propostos beneficiam a sociedade como um todo. Quanto aos eventuais prejuízos e aos possíveis fatores externos que restrinjam as atividades, cumpre considerar que o presente estudo teve foco prático e formato livre, sendo necessário complementar em trabalhos futuros o detalhamento de requisitos e a construção de protótipos operacionais para subsidiar a especificação detalhada dos sistemas e integrações necessárias. 


\section{CONCLUSÕES E CONTRIBUIÇÕES}

Considerando o escopo e o método de trabalho adotados, considera-se que foram encontrados e propostos novos modelos que contribuem para a solução dos problemas identificados.

Em síntese, os resultados obtidos e as discussões apresentadas, trouxeram as contribuições indicadas a seguir.

a) A deficiência dos serviços periciais relacionados a sistemas eletrônicos pode ser reduzida pela adoção de tecnologia WebLabs nos laboratórios fisicamente instalados. Tais laboratórios podem ser integrados e postos à disposição dos peritos e operadores do Direito, melhorando disponibilidade, qualidade e confiabilidade do serviço pericial que embasa os julgamentos realizados pelos juízes;

b) A proposta sobre WebLabs Forenses se mostra inédita, não era retratada na literatura técnica antes da pesquisa e trabalhos do autor, representado, portanto, uma novidade no campo forense, e contribui efetivamente para com a sociedade;

c) Milhares de comarcas distantes dos grandes centros passam a ter acesso a serviços forenses de melhor qualidade ou até mesmo a suprir sua inexistência;

d) Os gastos com a criação da Rede de WebLabs Forenses podem ser compensados pela redução dos gastos com transporte físico e estadia de peritos, assistentes técnicos e demais operadores do Direito para acompanhar pessoalmente exames periciais;

e) Reduz ociosidade e ineficiência de laboratórios forenses, por facilitar e racionalizar o acesso aos serviços;

f) Proporciona acesso a laboratórios mais potentes, em condições de fazer frente ao crescimento do poder computacional utilizado nos dispositivos utilizados pela sociedade para proteger a privacidade, tendo como consequência indesejada a necessidade de quebra da segurança para se poder produzir provas;

g) Melhoria da qualidade média dos exames periciais realizados no país;

h) Proporciona condições para manter a qualidade e produtividade da perícia forense em função do impacto negativo provocado pelo aumento do volume de 
dados a examinar e maior complexidade técnica das peças submetidas a exame;

i) A possibilidade de utilização internacional, desde que regulamentada, pode ser uma alternativa para reduzir as atuais dificuldades enfrentadas por quem precisa utilizar acordos internacionais de colaboração mútua, como o MLAT;

j) Pode se constituir em uma alternativa técnica para situações de confronto entre o Poder Judiciário e os provedores de serviços e produtos, em casos cada vez mais frequentes como se tem visto na imprensa nacional e internacional, nas quais determinada tecnologia de proteção de privacidade que bloqueiam o acesso a aparelhos celulares ou a mensagens interceptadas, por exemplo, tiverem que ser objeto de procedimentos excepcionais de quebra ou busca de alternativas, sendo que o modelo proposto proporciona o foro a ser utilizado em comum e com validade técnica e jurídica para realizar os procedimentos de exceção sob vigilância mútua e à distância;

k) Mesmo se não demonstrado explicitamente, se considera que o modelo ora sugerido para laboratórios periciais em sistemas eletrônicos pode igualmente se aplicar a laboratórios de outras áreas do conhecimento.

I) Considera-se essencial que o projeto seja desenvolvido em parceria com as universidades já citadas, cujos protótipos educacionais já se encontram em estágio avançado, além de parceria com a indústria fornecedora de componentes.

Com relação a trabalhos futuros, recomenda-se:

a) Especificar e executar projeto detalhado para implantação de tecnologia WebLab em dois laboratórios forenses pioneiros;

b) Avaliar esses projetos pioneiros e desenvolver frameworks e middlewares genéricos para os casos de uso identificados;

c) Prover a integração dos WebLabs Forenses em rede de modo a formar uma Federação de WebLabs Forenses;

d) Ampliar a quantidade de WebLabs Forenses, configurar laboratórios consumidores e laboratórios provedores e montar uma Confederação de WebLabs Forenses;

e) Reavaliar os componentes implantado e planejar e executar a expansão nacional e internacional das federações e confederações forenses. 
Essas são as principais conclusões e contribuições do trabalho realizado. Nesse contexto, cumpre recordar tratar de um ambiente humano e tecnologicamente complexo, multidisciplinar e com dimensão não apenas nacional, mas também internacional, assim os exames realizados e os modelos propostos devem ser vistos como uma busca prática e objetiva de possíveis soluções cuja validação detalhada extrapola os objetivos deste trabalho, sob pena de inviabilizá-lo. Tampouco fazem parte deste trabalho os detalhes técnicos construtivos ou operacionais das ferramentas forenses, o detalhamento de políticas ou normas e as questões jurídicas. 


\section{REFERÊNCIAS}

ABNT. Requisitos Ergonômicos para Trabalho de Escritórios com ComputadoresNBR 9241-11. [s.I: s.n.].

AKTAN, B. et al. Distance learning applied to control engineering laboratories. IEEE TRANSACTIONS ON EDUCATION, v. 39, n. 3, p. 320-326, 1996.

BALDAN, G. R. Meio eletrônico: uma das formas de diminuição do tempo de duração do processo no $4^{\circ}$ juizado especial cível de Porto Velho- RO. [s.l.] Fundação Getulio Vargas, 2011.

BARYAMUREEBA, V.; FLORENCE, T. The Enhanced Digital Investigation Process Model. Asian Journal of Information Technology, v. 5, p. 790-794, 2004.

BEEBE, N. L.; CLARK, J. G. A hierarchical, objectives-based framework for the digital investigations process. Digital Investigation, v. 2, n. 2, p. 147-167, 2005.

BRIDGE, W. J. Burdens Within Burdens at a Trial Within a Trial. Boston College Law Review, v. 23, n. 4, 1982.

BRYNJOLFSSON, E. The Productivity Paradox of Information Technology. Computing, v. 36, n. 12, p. 77, 1993.

BULBUL, H. I.; YAVUZCAN, H. G.; OZEL, M. Digital forensics: An analytical crime scene procedure model (ACSPM). Forensic Science International, v. 233, n. 1-3, p. 244-256, 2013.

CAMINERO, A. C. et al. On the creation of customizable laboratory experiments: Deconstruction of remote laboratories to create laboratories as a service (LaaS). International Journal of Online Engineering, v. 10, n. 6, p. 35-42, 2014.

CARR, N. G. IT Doesn't MatterHarvard Business Review, 2003.

CARRIER, B. Open Source Digital Forensics Tools: The Legal ArgumentOctober. [s.l: s.n.].

CARRIER, B. Defining digital forensic examination and analysis tools using abstraction layers. International Journal of digital evidence, v. 1, n. 4, p. 1-12, 2003.

CARRIER, B.; SPAFFORD, E. Getting physical with the digital investigation process. International Journal of Digital Evidence, v. 2, n. 2, p. 1-20, 2003. 
CARRIER, B.; SPAFFORD, E. An event-based digital forensic investigation framework. Digital forensic research workshop, p. 1-12, 2004.

CASINI, M.; PRATTICHIZZO, D.; VICINO, A. The automatic control telelab: A userfriendly interface for distance learning. IEEE Transactions on Education, v. 46, n. 2, p. 252-257, 2003.

CINTRA, A. C. DE A.; GRINOVER, A. P.; DINAMARCO, C. R. Teoria Geral do Processo. São Paulo: São Paulo: Malheiros Editores, 2009.

CLINT, M. R. et al. An Examination of Digital Forensic Models. International Journal of Digital Evidence, v. 1, n. 3, p. 1-12, 2002.

COHEN, M.; GARFINKEL, S.; SCHATZ, B. Extending the advanced forensic format to accommodate multiple data sources, logical evidence, arbitrary information and forensic workflow. Digital Investigation, v. 6, n. SUPPL., p. 57-68, 2009.

CONSELHO NACIONAL DE JUSTIÇA. Modelo de Interoperabilidade de Dados do Poder Judiciário e Órgãos de Administração da Justiça e Órgãos da Administraçaõ da JustiçaPoder Judiciário. Brasília DF: [s.n.]. Disponível em: <http://www.cnj.jus.br/\%0Ahttp://www.cnj.jus.br/programas-e-acoes/pj-justica-emnumeros $>$.

CORTES, S. Information Assurance Program College of Computer and Information Science. [s.I.] Northeastern University, 2015.

ĆOSIĆ, J.; BAČA, M. A framework to (Im)Prove "Chain of Custody" in Digital Investigation Process. Proceedings of the 21st Central European Conference on Information and Intelligent Systems, p. 435-438, 2010a.

ĆOSIĆ, J.; BAČA, M. Do we have full control over integrity in digital evidence life cycle? Information Technology Interfaces (ITI), 2010 32nd International Conference on, p. 429-434, 2010b.

CRISTOVÃO, P. Apresentação sobre o Processo Judicial Eletrônico. Brasília: [s.n.]. Disponível em: <http://www.cnj.jus.br/tecnologia-da-informacao/processojudicial-eletronico-pjes.

DOSIS, S.; HOMEM, I.; POPOV, O. Semantic representation and integration of digital evidence. Procedia Computer Science, v. 22, n. April 2016, p. 1266-1275, 2013. 
EFIMCHICK, E.; LYAMIN, A. Remote Laboratory Control Protocol. Fremont: Internet Engineering Task Force, 2013.

ERBACHER, R. F.; CHRISTENSEN, K.; SUNDBERG, A. Visual Network Forensic Techniques and Processes. 9th Annual NYS Cyber Security Conferece Symposium on Information Assurance, p. 72-80, 2006.

FACCHINI, N. M. Função social do juizEscola Superior da Magistratura, , 2006.

FBI. 2014 Internet Crime Report. [s.l: s.n.].

FELDER, R. A. et al. Development of a robotic near patient testing laboratory. Archives of Pathology and Laboratory Medicine. Anais...1995

FRANCIA, G. A.; CLINTON, K. Computer forensics laboratory and tools. Journal of Computing Sciences in Colleges, v. 20, n. 6, p. 143-150, 2005.

GARFINKEL, S. et al. Disk Imaging with the Advanced Forensics Format, Library and Tools. Proc. IFIP WG 11.9 International Conference on Digital Forensics (IFIP), p. 1-19, $2006 a$.

GARFINKEL, S. L. et al. Advanced Forensic Format: An Open, Extensible Format for Disk Imaging. In Advances in Digital Forensics II: FIP International Conference on Digital Forensics, v. 222, p. 17-31, 2006b.

GARFINKEL, S. L. Digital forensics research: The next 10 years. Digital Investigation, v. 7, n. SUPPL., 2010.

GARTNER. Top 10 Strategic Predictions for 2016 and Beyond: The Future Is a Digital Thing. [s.l: s.n.].

GAYED, T. F.; LOUNIS, H.; BARI, M. Cyber Forensics: Representing and ( Im ) Proving the Chain of Custody Using the Semantic web. COGNITIVE 2012: The Fourth International Conference on Advanced Cognitive Technologies and Applications, n. Im, p. 19-23, 2012.

GIOVA, G. Weblabs na Investigação Forense de Sistemas Eletrônicos Digitais. São Paulo: [s.n.]. Disponível em: <http://www.teses.usp.br/teses/disponiveis/3/3142/tde-02052011123348/publico/DISSERTACAO_GIULIANO_GIOVA_WEBLABS_FORENSES.pdf>. Acesso em: 1 jan. $2016 a$. 
GIOVA, G. Improving Chain of Custody in Forensic Investigation of Electronic Digital Systems. International Journal of Computer Science and Network Security, v. 11, n. 1, p. 1-9, 2011b.

GO-LAB. Learning by Experience | Go-Lab. Disponível em: <http://www.go-labproject.eu/>. Acesso em: 9 abr. 2016.

GOLC. Remote Laboratory Systems Interoperability Standard? Interface Definitions. 2011.

GUIMARÃES, M. O Juiz e a Função Jurisdicional. [s.I.] Forense, 1958.

GUO, Y.; SLAY, J.; BECKETT, J. Validation and verification of computer forensic software tools-Searching Function. Digital Investigation, v. 6, n. SUPPL., p. S12S22, 2009.

HARFIELD, C. G. Process and practicalities: mutual legal assistance and the investigation of transnational crime within the EU from a UK perspective, 1990-2004. p. 268, 2004.

JASMIN, Ć.; COSIC, J. Leveraging DEMF to Ensure and Represent 5ws \& $1 \mathrm{~h}$ in Digital Forensic Domain. International Journal of Computer Science and Information Security, v. 13, n. 2, p. 5-9, 2015.

JUSTIÇA, M. DA. Diagnóstico da Perícia Criminal no Brasil. Brasília DF: Secretaria Nacional de Segurança Pública, 2013.

JUSTICE, N. I. OF. Crime Scene Investigation: Guides for Law Enforcement I National Institute of Justice. Disponível em: <http:/www.nij.gov/topics/lawenforcement/investigations/crime-scene/guides/pages/glossary.aspx>. Acesso em: 16 abr. 2016.

JUSTICE, N. I. OF. Crime Scene Investigation: Guides for Law Enforcement. Disponível em: <http://www.ojp.usdoj.gov/nij/topics/law-enforcement/inve>. Acesso em: 16 abr. 2016.

KENT, K. et al. Guide to integrating forensic techniques into incident responseNIST Special Publication. [s.l: s.n.]. Disponível em: <http://csrc.nist.gov/publications/nistpubs/800-86/SP800-86.pdf>.

KOCH, M.; ELOFF, J. H. P.; OLIVIER, M. S. UML modelling of digital forensic process 
models (DFPMs). Proceedings of the ISSA Innovative Minds Conference, Pretoria, South Africa, p. 1-13, 2008.

KOSTULSKI, T.; MURRAY, S. The National Engineering Laboratory Survey: A Review of the Delivery of Practical Laboratory Education in Australian Undergraduate Engineering Programs. n. December, p. 77, 2010.

LOSAVIO, M.; KEELING, D.; ELMAGHRABY, A. Work-in-progress: A distributed triage model for digital forensic services to state and local law enforcement. 4th International Workshop on Systematic Approaches to Digital Forensic Engineering, SADFE 2009, p. 36-37, 2009.

LU, L.; WANG, L. The virtual laboratory system on law education. 2009 International Symposium on Intelligent Ubiquitous Computing and Education, IUCE 2009, p. 258-261, 2009.

LYAMIN, A. V; EFIMCHIK, E. A. RLCP-compatible virtual laboratories. e-Learning and e-Technologies in Education (ICEEE), 2012 International Conference on. Anais...St. Petersburg, Russia: 2012

MALATESTA, N. F. D. A Lógica das Provas em Matéria Criminal. Livraria Clássica

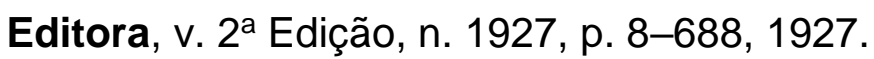

MARTINS, R. O Valor Probatório do Documento Eletrônico: Análise Interdisciplinar entre Arquivologia e o Direito. [s.I.] UNESP Universidade Estadual de Marília, 2015.

MEDINA, J. M. G. Novo Código de Processo Civil Anotado. 4a. Edicão ed. [s.I.] Revista Dos Tribunais, 2015.

MOBACH, M. P. The Art of Modelling in SSM. International Society for the Systems Sciences ISSS 2000. Anais...2000

MOCAS, S. Building theoretical underpinnings for digital forensics research. Digital Investigation, v. 1, n. 1, p. 61-68, 2004.

NALINI, J. R. A Ética e a Profissão Forense. Revista dos Tribunais, p. 1-16, 2001.

NEUFELD, P.; SCHECK, B. Making forensic science more scientific. Nature, v. 464, n. 7287, p. 351, 2010.

NOBLETT, M. G.; POLLITT, M. M.; PRESLEY, L. A. Recovering and Examining 
Computer Forensic Evidence. Forensic Science Communications, v. 2, n. 4, p. 1-8, 2000.

ORDUNA, P. et al. An Extensible Architecture for the Integration of Remote and Virtual Laboratories in Public Learning Tools. Revista Iberoamericana de Tecnologias del Aprendizaje, v. 10, n. 4, p. 223-233, 2015.

ORDUÑA, P. Transitive and scalable federation model for remote laboratories. [s.l.] Universidad de Deusto, 2013.

PACHECO, J. DA S. Direito Processual Civil. [s.I.] Saraiva, 1976.

PALMER, G. A Road Map for Digital Forensic Research. Proceedings of the 2001 Digital Forensics Research Workshop (DFRWS 2004), p. 1-42, 2001.

PATZAKIS, J. Maintaining The Digital Chain of Custody. Password - The ISSA Journal, n. February, p. 14-15, 2003.

PIRES, P. F. et al. Plataformas para a Internet das Coisas. Anais do Simpósio Brasileiro de Redes de Computadores e Sistemas Distribuídos, p. 110-169, 2015. POLLITT, M. A Framework for Digital Forensic Science - Six Blind Men from Indostan. First Digital Forensic Research Workshop (DFRWS). Anais...Digital Evidence Professional Services, Inc., 2004

POLLITT, M. M. An Ad Hoc Review of Digital Forensic Models National Center for Forensic Science Department of Engineering Technology University of Central Florida. 2007.

PRAYUDI, Y.; ASHARI, A.; PRIYAMBODO, T. K. Digital Evidence Cabinets: A Proposed Frameworks for Handling Digital Chain of Custody. International Journal Of Computer Applications (IJCA), v. 109, n. 9, p. 30-36, 2014.

PRAYUDI, Y.; AZHARI. Digital Chain of Custody: State Of The Art. International Journal Of Computer Application (IJCA), v. 114, n. 5, p. 1-9, 2015.

ROBERT E. HORN. Information Mapping. Training in Business and Industry, v. 11, n. 3, p. 1-10, 1974.

ROSEKIND, M. R.; COATES, T. J.; THORESEN, C. E. Telephone transmission of allnight polysomnographic data from subjects' homes. J Nerv Ment Dis, v. 166, n. 6, p. 438-41 ST-Telephone transmission of all-night p, 1978. 
RUIBIN, G.; YUN, C. K.; GAERTNER, M. Case-Relevance Information Investigation : Binding Computer Intelligence to the Current Computer Forensic Framework. International Journal, v. 4, n. 1, p. 1-13, 2005.

SANOU, B. ICT Facts \& Figures. The world in 2015. Disponível em: <http://www.itu.int/en/ITU-D/Statistics/Documents/facts/ICTFactsFigures2015.pdf>.

SARAVANAN, P; JEYASEKAR, J. J. A Scientometric Analysis of Global Forensic. Library Philosophy and Practice (e-journal), 2014.

SCHULER, K. et al. E-discovery: Creating and Managing an Enterprisewide Progragram. [s.l.] Syngress Publishing, Inc. Elsevier, 2015.

SECRETARIA NACIONAL DE SEGURANÇA PÚBLICA. Procedimento operacional padrão: Perícia CriminalMinistério da Justiça. Brasília DF: [s.n.].

SELAMAT, S. R.; YUSOF, R.; SAHIB, S. Mapping Process of Digital Forensic Investigation Framework. Journal of Computer Science, v. 8, n. 10, p. 163-169, 2008.

SELAMAT SITI RAHAYU et al. A Forensic Traceability Index in Digital Forensic Investigation. Journal of Information Security, v. 4, n. 1, p. 19-32, 2013.

SILVA, A. W. D. M. R. B. C. F. D. S. E.; CASTRO, A. L. M. DE. Mapa da defensoria publica no Brasil. Brasília DF: [s.n.].

SIMONETTE, M. J. Engenharia de sistemas em sistemas sociotécnicos. [s.I: s.n.]. STEPHENSON, P. Modeling of Post-Incident Root Cause Analysis. International Journal of Digital Evidence, v. 2, n. 2, p. 1-16, 2003.

SWGDE. SWGDE Best Practices for Collection of Damaged Mobile Devices. [s.l: s.n.].

SYMANTEC. Internet Security Threat Report 2016. v. 19, n. April, 2013.

TURNER, P. Unification of digital evidence from disparate sources (Digital Evidence Bags). Digital Investigation, v. 2, n. 3, p. 223-228, 2005.

TURRIONI, J. B.; MELLO, C. H. P. Metodologia de pesquisa em engenharia de produção. Universidade Federal de Itajubá - UNIFEI, p. 191, 2012.

YEUNG, H.; LOWE, D.; MURRAY, S. Interoperability of Remote Laboratories Systems. International Journal of Online Engineering (iJOE), v. 6, n. SI1, p. 71-80, 
2010.

ZOCHIO, M. F. Qualidade dos laudos periciais emitidos na comarca de São

Paulo. [s.l.] Universidade de São Paulo, 2010. 